\title{
Novel Dual-Functional Membrane for Controlling Carbon Dioxide Emissions from Fossil Fuel Power Plants
}

\author{
Final Scientific/Technical Report \\ Reporting Period: August 23, 2004 to April 30, 2009 \\ Principal Author(s): \\ C. Jeffrey Brinker, George K. Xomeritakis, C.-Y. Andy Tsai, Ying-Bing. Jiang
}

Date Report was Issued (August 2009)

Prepared for the United States Department of Energy under DOE Award Number:

DE-FG26-04NT42120

Name and Address of Submitting Organization:

NSF Center for Micro-engineering Materials, The University of New Mexico, Albuquerque, NM 87106

Subcontractor

T3 Scientific LLC, $163091^{\text {st }}$ Ave NE STE 101, Blaine, MN 55449 


\section{DISCLAIMER}

"This report was prepared as an account of work sponsored by an agency of the United States Government. Neither the United States Government nor any agency thereof, nor any of their employees, makes any warranty, express or implied, or assumes any legal liability or responsibility for the accuracy, completeness, or usefulness of any information, apparatus, product, or process disclosed, or represents that its use would not infringe privately owned rights. Reference herein to any specific commercial product, process, or service by trade name, trademark, manufacturer, or otherwise does not necessarily constitute or imply its endorsement, recommendation, or favoring by the United States Government or any agency thereof. The views and opinions of authors expressed herein do not necessarily state or reflect those of the United States Government or any agency thereof." 


\begin{abstract}
$\mathrm{CO}_{2}$ captured from coal-fired power plants represents three-quarters of the total cost of an entire carbon sequestration process. Conventional amine absorption or cryogenic separation requires high capital investment and is very energy intensive. Our novel membrane process is energy efficient with great potential for economical $\mathrm{CO}_{2}$ capture. Three classes of microporous sol-gel derived silica-based membranes were developed for selective $\mathrm{CO}_{2}$ removal under simulated flue gas conditions (SFG), e.g. feed of $10 \%$ vol. $\mathrm{CO}_{2}$ in $\mathrm{N}_{2}, 1$ atm total pressure, $\mathrm{T}=50-60^{\circ} \mathrm{C}, \mathrm{RH}>50 \%, \mathrm{SO}_{2}>10 \mathrm{ppm}$. A novel class of amine-functional microporous silica membranes was prepared using an amine-derivatized alkoxysilane precursor, exhibiting enhanced ( $>70) \mathrm{CO}_{2}: \mathrm{N}_{2}$ selectivity in the presence of $\mathrm{H}_{2} \mathrm{O}$ vapor, but its $\mathrm{CO}_{2}$ permeance was lagging ( $\left.<1 \mathrm{MPU}\right)$. Pure siliceous membranes showed higher $\mathrm{CO}_{2}$ permeance (1.5-2 MPU) but subsequent densification occurred under prolonged SFG conditions. We incorporated $\mathrm{NiO}$ in the microporous network up to a loading of $\mathrm{Ni}: \mathrm{Si}=0.2$ to retard densification and achieved $\mathrm{CO}_{2}$ permeance of $0.5 \mathrm{MPU}$ and $\mathrm{CO}_{2}: \mathrm{N}_{2}$ selectivity of 50 after $163 \mathrm{~h}$ exposure to SFG conditions. However, $\mathrm{CO}_{2}$ permeance should reach greater than 2.0 MPU in order to achieve the cost of electricity (COE) goal set by DOE. We introduced the atomic layer deposition (ALD), a molecular deposition technique that substantially reduces membrane thickness with intent to improve permeance and selectivity. The deposition technique also allows the incorporation of $\mathrm{Ni}$ or $\mathrm{Ag}$ cations by proper selection of metallorganic precursors. In addition, preliminary economic analysis provides a sensitivity study on the performance and cost of the proposed membranes for $\mathrm{CO}_{2}$ capture. Significant progress has been made toward the practical applications for $\mathrm{CO}_{2}$ capture. $\left(1 \mathrm{MPU}=1.0 \mathrm{~cm}^{3}(\mathrm{STP}) \cdot \mathrm{cm}^{-2} \cdot \mathrm{min}^{-}\right.$ $\left.{ }^{1} \cdot \mathrm{atm}^{-1}\right)$
\end{abstract}

\title{
KEYWORDS
}

Inorganic membranes, ceramic membranes, non metallic membranes, carbon dioxide capture, carbon dioxide sequestration, gas separation, high temperature gas separation, flue gas $\mathrm{CO}_{2}$ capture, sol-gel, global warming 


\section{TABLE OF CONTENTS}

1 - Executive Summary $\quad$................................................. 5

2 - Project Overview $\quad$................................................... 7

3 - New Membrane Material Development $\quad$.................................... 8

3.1 Experimental Methods $\quad$........................................ 8

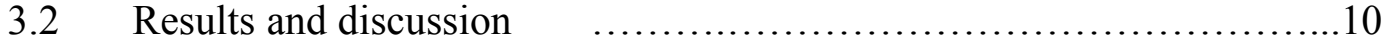

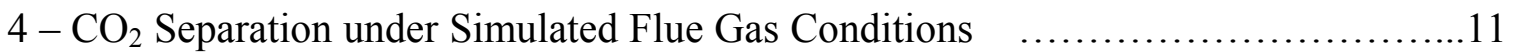

4.1 Experimental Methods $\quad$.......................................11

4.2 Results and discussion $\quad$....................................... 12

5 - Optimization of Thin Membrane Deposition $\quad$................................ 13

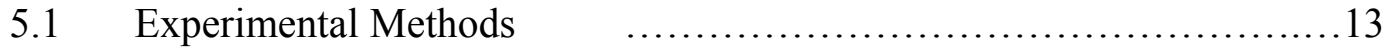

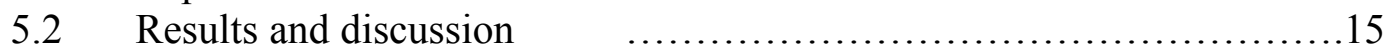

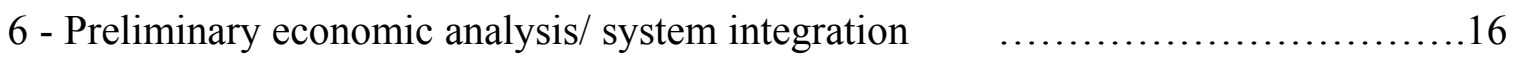

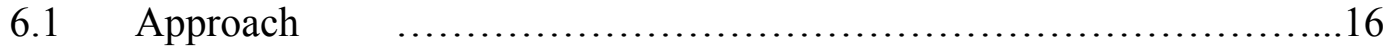

6.2 Results and discussion $\quad$........................................17

7 - Refinement of Membrane Deposition $\quad$......................................... 19

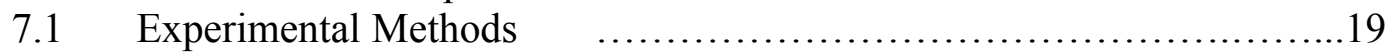

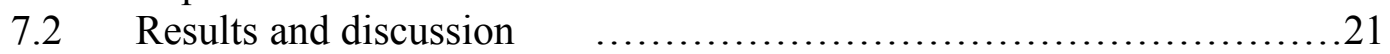

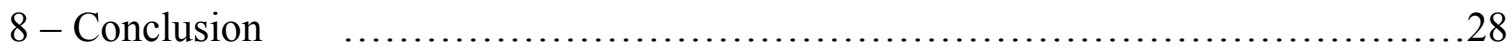

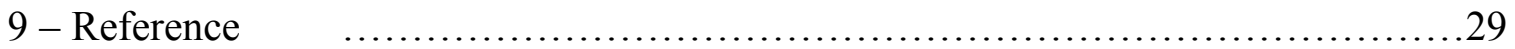

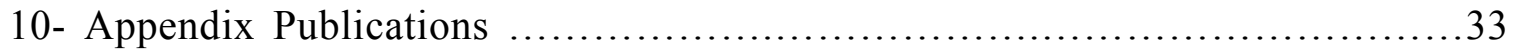

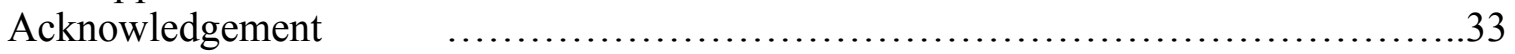

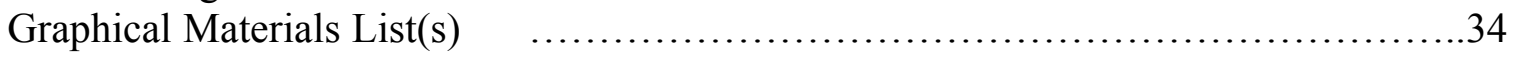

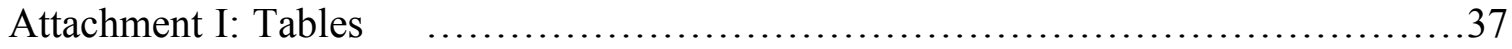

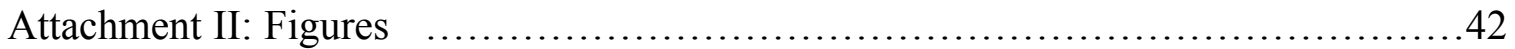

List of Acronyms and Abbreviations $\quad$........................................... 74 


\section{EXECUTIVE SUMMARY}

Providing a reliable, clean and economical energy source is a priority of the US government. Coal is the largest source of fossil fuel for the generation of electricity worldwide and US has the leading recoverable coal reserve among the nations. However, currently coal is also one of the largest sources of carbon dioxide emissions which contribute greatly to global warming. The challenge is to capture $\mathrm{CO}_{2}$ from flue gas and subsequently sequestrated. Success of $\mathrm{CO}_{2}$ capture from flue gas is hinged on the breakthrough of capture processes. The use of a membrane system with high $\mathrm{CO}_{2}$ permeance and selectivity holds promise for reducing costs by avoiding the expensive absorber/stripper equipment required with liquid-amine-based systems.

This work has explored four types of silica based membranes for $\mathrm{CO}_{2}$ separation: pure, amine-derivatized, nickel-doped silica membrane and PA-ALD deposited silica membrane, one characterized by the deposition method.

Pure, amine-derivatized and nickel-doped sol-gel silica membranes have been developed on tubular Membralox-type commercial ceramic supports for the purpose of carbon dioxide separation from nitrogen under coal-fired power plant flue gas conditions. An extensive synthetic and permeation test study was carried out in order to optimize membrane $\mathrm{CO}_{2}$ permeance, $\mathrm{CO}_{2}: \mathrm{N}_{2}$ separation factor and resistance against densification. Amine-derivatized silica membranes could not achieve combined high $(>50)$ selectivity and high ( $>1$ MPU) $\mathrm{CO}_{2}$ permeance, most likely because of the difficulty in independently controlling the pore size and porosity of the aminosilicate framework. Pure silica membranes prepared under optimized conditions exhibited an attractive combination of $\mathrm{CO}_{2}$ permeance of $2.0 \mathrm{MPU}\left(1 \mathrm{MPU}=1 \mathrm{~cm}^{3}(\mathrm{STP}) \cdot \mathrm{cm}^{-2} \cdot \mathrm{min}^{-1} \cdot \mathrm{atm}^{-1}\right)$ and $\mathrm{CO}_{2}: \mathrm{N}_{2}$ separation factor of 80 with a dry 10:90 (v/v) $\mathrm{CO}_{2}: \mathrm{N}_{2}$ feed at $25^{\circ} \mathrm{C}$. However, these membranes exhibited flux decline phenomena under prolonged exposure to humidified feeds, especially in the presence of trace $\mathrm{SO}_{2}$ gas in the feed. Doping the membranes with nickel (II) nitrate salt was effective in retarding densification, as manifested by combined higher permeance and higher separation factor of the doped membrane compared to the pure (undoped) silica membrane after 168 hours exposure to simulated flue gas conditions. Despite the improvement in performance imparted by metal oxide doping, the permeance of the membranes still needs to be improved to be attractive for power plant scale $\mathrm{CO}_{2}$ capture.

PA-ALD membrane deposition technique was introduced to the project to further improve $\mathrm{CO}_{2}$ permeance and possibility $\mathrm{CO}_{2} / \mathrm{N}_{2}$ selectivity by depositing an ultra thin membrane layer. This monolayer-by-monolayer deposition technique was indeed capable of depositing a $2.5-5 \mathrm{~nm}$ defect-free layer on top of a mesoporous/microporous support, more than an order of magnitude reduction from the previous 100-200 nm thickness by spin or dip coating techniques. Various strategies were employed to enhance membrane performance, such as utilizing larger porogens to enlarge pore size for higher permeance, incorporation of titanium to stabilize hydrothermal performance, doping of small metal particles with $\mathrm{CO}_{2}$ affinity to enhance $\mathrm{CO}_{2}$ selectivity. An extensive parametric study was also performed to optimize various process factors. Both Ag-doped and dual-Ni-doped microporous silica membranes deposited by the PA-ALD method had good $\mathrm{CO}_{2} / \mathrm{N}_{2}$ selectivities (40-60) at moderately elevated temperatures $\left(200-250^{\circ} \mathrm{C}\right)$, as well as good thermal stability and humidity resistance. Sulfur-resistance for Ag-doped membrane was 
apparently not sufficient but the dual-Ni-doped membrane had moderate sulfurresistance. With significant reduction in membrane thickness and subsequent performance enhancing strategies, PA-ALD membranes did not show significant permeance improvement as expected. The best reported $\mathrm{CO}_{2}$ permeance was approaching $2 \mathrm{MPU}$ at $250^{\circ} \mathrm{C}$.

The deposition methods employed were versatile enough for various forms of support. In this study both hollow fiber support and anodic alumina (Anodisk ${ }^{\mathrm{TM}}$ ) were included. With the smoother surface of the Anodisk, membrane performance is in general better with Anodisk. For example, in the case of $\mathrm{CO}_{2}: \mathrm{N}_{2}$ separation, the $\mathrm{CO}_{2}$ permeance exceeded 3.0 MPU (1 MPU $\left.=1.0 \mathrm{~cm}^{3}(\mathrm{STP}) \mathrm{cm}^{-2} \mathrm{~min}^{-1} \mathrm{~atm}^{-1}\right)$ coupled with a $\mathrm{CO}_{2}: \mathrm{N}_{2}$ separation factor in excess of 70 at $25^{\circ} \mathrm{C}$.

An economic analysis of the membrane-based $\mathrm{CO}_{2}$ capture for post combustion applications was conducted. The goal of the analysis was to provide a ballpark cost estimate on the concept of using the membrane system for $\mathrm{CO}_{2}$ capture and to provide a sensitivity study on the performance and cost of the proposed membranes. DOE carbon capture and sequestration systems analysis guidelines and information from literature were used as for calculation. Our analysis was based on the removal of $\mathrm{CO}_{2}$ from pulverized coal (PC) power plants using Illinois \#6 bituminous coal as fuel using our inhouse spreadsheet model for $90 \% \mathrm{CO}_{2}$ removal efficiency. In this calculation, the additional $\mathrm{CO}_{2}$ emission from auxiliary load was considered and vacuum instead of compression was used as driving force for membrane-based $\mathrm{CO}_{2}$ separation. Performance of the membrane-based $\mathrm{CO}_{2}$ removal system was compared to MEA-based $\mathrm{CO}_{2}$ removal system. The basic conclusion from these results was that with the combination of high membrane $\mathrm{CO}_{2}$ permeance and low membrane cost, the membrane approach could show lower overall cost for $\mathrm{CO}_{2}$ capture compared to the state-of-the-art MEA sorption technology approach.

In summary, the membranes in this study fell short of the stringent performance goals for $\mathrm{CO}_{2}$ capture from flue gas. However, significant progress has been made toward the practical applications. In addition, these membranes had exceeded the performance of the best published membrane for $\mathrm{N}_{2} / \mathrm{CO}_{2}$ separation. 


\section{Project Overview}

Providing a reliable, clean and economical energy source is a priority of the US government. Coal is the largest source of fossil fuel for the generation of electricity worldwide and US has the leading recoverable coal reserve among the nations. However, currently coal is also one of the largest sources of carbon dioxide emissions which contribute greatly to global warming. The challenge is to capture $\mathrm{CO}_{2}$ from flue gas and subsequently sequestrated. A success ensures reduction in foreign dependency, settling of environmental concerns, availability of energy resource, competitive advantage for the U.S. and chain-benefits to many other fields. Urgency of a solution is driven in part by the imminent legislature pressure, but more so, by an alarming level of greenhouse effect caused by the cumulative and ever increasing carbon dioxide emissions.

If $\mathrm{CO}_{2}$ capture from flue gas is ever to become economically feasible, improved capture processes are needed. The use of a membrane system with high $\mathrm{CO}_{2}$ permeance and selectivity holds promise for reducing costs by avoiding the expensive absorber/stripper equipment required with liquid-amine-based systems. The problem is a seven-way challenge of producing a defect free membrane that has high flux, high selectivity, high resistance to contaminants, be able to handle high pressure and temperature, is durable and at the same time economical.

\section{Membrane-based gas separation}

Membrane-based gas separations gain considerable growth due to the benefits of low capital costs, low energy requirements and ease in operation. Present industrial-scale applications of gas separation membranes include carbon dioxide removal from natural gas and hydrogen purification in refinery operations [1]. Most commercial-scale membranes are polymer-based spiral-wound or hollow-fiber type devices, while ceramic or metallic membranes find applications in smaller duty separations. Polymeric membranes separate gases based on the solution-diffusion mechanism and are typically limited by the well-known tradeoff between permeability and selectivity [2]. Current development efforts in the area focus on new high-performance polymers or the design of mixed-matrix systems comprising of a molecular sieve guest phase dispersed in a continuous polymer host matrix [3].

An emerging opportunity for large-scale membrane gas separations is the capture of greenhouse gases such as carbon dioxide from the emissions of coal-fired power plants [4]. Current commercial process employed in this area is amine absorption which is energy and capital-intensive and environmentally hazardous because of the corrosive nature of the solvents involved in the process [5]. A membrane-based carbon dioxide capture process would mitigate these issues provided that suitable membrane materials are available that can meet the requirements of treating large volumes of gas under low driving force and producing high purity carbon dioxide to inject underground [6, 7].

Currently available commercial polymer membranes such as cellulose acetate do not meet the performance requirements for economical capture of $\mathrm{CO}_{2}$ from flue gas (e.g. $\mathrm{CO}_{2}$ permeance $>2 \mathrm{MPU}$ and $\mathrm{CO}_{2}: \mathrm{N}_{2}$ selectivity $>80$ ) [8]. An alternative class of membrane materials that could be used in $\mathrm{CO}_{2}: \mathrm{N}_{2}$ separation is inorganic microporous molecular sieves such as zeolites, carbons and sol-gel silicas [9]. Certain large-pore zeolites such as FAU have been reported to exhibit sufficient $\mathrm{CO}_{2}: \mathrm{N}_{2}$ selectivity [10] while molecular sieve carbons are also good candidates for this application [11]. The main challenge however is to fabricate these materials as thin membranes on large-area 
modules at reasonable cost, while avoiding formation of cracks that would compromise separation efficiency [12].

Chemical Vapor Deposition (CVD) or sol-gel derived microporous silicas are also good candidates for application in flue-gas $\mathrm{CO}_{2}$ capture, provided their amorphous structure is engineered to optimize $\mathrm{CO}_{2}$ permeance and $\mathrm{CO}_{2}: \mathrm{N}_{2}$ selectivity [4]. So far these membranes are known to efficiently separate $\mathrm{H}_{2}$ from larger gas molecules at elevated temperatures $[13,14]$ or $\mathrm{CO}_{2}$ from $\mathrm{CH}_{4}$ at ambient temperature (T) [15], relevant to purification of natural gas from corrosive acid gas contaminants. Current efforts in the field of sol-gel silica membranes include pore size engineering by molecular templating [16-19] and introduction of chemical functionality to improve $\mathrm{CO}_{2}$ affinity of the membrane $[20,21]$.

The objective of this study is to explore the separation performance and stability of sol-gel silica-based membranes for $\mathrm{CO}_{2}$ removal under flue gas conditions. An extensive synthesis of both pure and amine-derivatized silica membranes was carried out, aiming to achieve combined high $\mathrm{CO}_{2}$ permeance and high $\mathrm{CO}_{2}: \mathrm{N}_{2}$ selectivity, necessary for economical membrane-based flue gas $\mathrm{CO}_{2}$ capture. The effects of operating temperature, feed humidity content and presence of flue gas contaminants such as $\mathrm{SO}_{2}$ on membrane performance were investigated. The possibility of retarding densification phenomena by metal oxide doping was also studied. This study was motivated by the combination of several attractive features such as good processibility, pore size control and low cost of precursor materials [22], which make silica membranes a good candidate for future applications in carbon dioxide capture in power generation.

\section{3 - New Membrane Material Development}

\subsection{Experimental methods}

\section{Membrane Support}

Two types of commercial porous alumina-based supports were employed in this study. The most commonly employed support was a commercial Membralox tube of 10 $\mathrm{mm} \mathrm{OD}, 7 \mathrm{~mm}$ ID and asymmetric pore structure with a final $50-\AA$ pore $\gamma-\mathrm{Al}_{2} \mathrm{O}_{3}$ top layer (Pall Corp., part no. S700-00117). The 250-mm long support was cut in 5-cm long segments with a diamond wafering blade (Buehler) before membrane deposition. Occasionally, we also performed membrane deposition on a low-cost 20-nm Anodisk support [23] (Whatman, UK) as described in detail in section 5.

\section{Mesoporous silica sublayer}

A $25-\AA$ pore surfactant-templated silica sublayer was deposited on the surface of both the Membralox and the Anodisk supports in order to provide a smooth pore size transition between the support and the final microporous silica gas separation membrane. The details of the 2-step surfactant-silica sol preparation can be found in previous publications [15]. The final molar composition of the sol was: $1 \mathrm{Si}-22 \mathrm{EtOH}-5 \mathrm{H}_{2} \mathrm{O}-$ $0.004 \mathrm{HCl}-0.08 \mathrm{Brij56}$. In the case of the Anodisk support, the sol was further diluted with equal volume of ethanol prior to casting.

\section{Aminosilica sol preparation}


For preparation of amine-derivatized silica membranes, 3 main sol recipes were employed, designated as aSi-n in the order of decreasing $\mathrm{H}^{+}:-\mathrm{NH}_{2}$ molar ratio in Table 3.1. In all 3 recipes, the alkoxysilane precursors $($ TEOS=tetraethylorthosilicate, APTES $=$ 3-aminopropyltriethoxysilane, Aldrich) were first added to ethanol and then stirred until homogeneous. Subsequently $\mathrm{H}_{2} \mathrm{O}$ and $\mathrm{HCl}$ were added and the sol was shaken for $15 \mathrm{~min}$ and then aged for 24 hours at $25-50^{\circ} \mathrm{C}$ without agitation. A high $\mathrm{H}^{+}: \mathrm{Si}$ molar ratio was necessary to prevent premature gelation of the sols due to the high reactivity of APTES with $\mathrm{H}_{2} \mathrm{O}$ [20]. For recipe aSi-3 with the lowest $\mathrm{H}^{+}:-\mathrm{NH}_{2}$ molar ratio, the initial EtOH TEOS - APTES mixture was chilled to $-20^{\circ} \mathrm{C}$ before $\mathrm{H}_{2} \mathrm{O}$ and acid were added in order to retard premature gelation reactions. No aging step was used in this case since the sol would turn turbid due to particulate silica precipitation after about $30 \mathrm{~min}$ at room temperature. Evidence of incorporating amine group in the silica framework was identified by Fourier transform inferred spectroscopy (FTIR) and thermal gravimetric analyzer (TGA) characterization techniques [42].

\section{Pure silica sol preparation}

For preparation of pure silica membranes we adopted a modified version of the recipe reported by Verweij and coworkers: $1 \mathrm{Si}: 3.8 \mathrm{EtOH}: 6.4 \mathrm{H}_{2} \mathrm{O}: 8.5 \times 10^{-2} \mathrm{HNO}_{3}$ [24]. However in our study we found that optimal membrane performance was achieved by 10 -fold decrease of the amount of acid. As seen in Table 3.1, for recipe Si-1 the reactants were stirred for 3 hours at $60^{\circ} \mathrm{C}$ and then 1 volume of sol was diluted with 2 volumes of ethanol prior to membrane casting. For recipe $\mathrm{Si}-2$ the reactants were shaken for $15 \mathrm{~min}$ and then aged for 24 hours at $25-50^{\circ} \mathrm{C}$ without agitation.

\section{Nickel doping}

Doping of nickel ions in the silica membrane was achieved by adding nickel (II) nitrate hexahydrate salt $\left(\mathrm{Ni}\left(\mathrm{NO}_{3}\right)_{2} \cdot 6 \mathrm{H}_{2} \mathrm{O}\right.$, Aldrich) to a mixture of $\mathrm{H}_{2} \mathrm{O}$ and $\mathrm{HNO}_{3}$. This mixture was then added to the EtOH:TEOS mixture prior to shaking and aging. The typically employed $\mathrm{Ni}: \mathrm{Si}$ molar ratio was 0.1 although we attempted a few preparations with twice the Ni loading in the doped sol.

\section{Membrane deposition}

Deposition of sublayer and membrane on the tubular Membralox or Anodisk supports was carried out by dip- or spin-coating, as described in details elsewhere [20, 23]. All sols were purified with $0.2 \mu \mathrm{m}$ syringe filters prior to casting. The xerogel membrane films were calcined for $3 \mathrm{~h}$ at $500^{\circ} \mathrm{C}$-air (for the mesoporous sublayer) or at $300-500^{\circ} \mathrm{C}$ in vacuum (for the microporous membranes). All heating and cooling steps were controlled at $1^{\circ} \mathrm{C} \cdot \mathrm{min}^{-1}$.

\section{Membrane permeation}

Pure and mixed-gas permeation studies of the Anodisk and Membralox supported membranes were carried out in our in-house permeation system as described elsewhere $[20,23]$. For permeation at elevated $\mathrm{T}$ (up to $100^{\circ} \mathrm{C}$ ), the tubular permeation cell was wrapped with heating tape and heated with a Variac transformer. A type $\mathrm{K}$ thermocouple (Omega) inserted in the annulus of the tubular membrane was used for temperature readout. The $\%$ humidity level in the feed was controlled by passing a certain flow rate of 
$\mathrm{N}_{2}$ through a water saturator maintained at ambient $\mathrm{T}$. The total feed $\left(\mathrm{CO}_{2}: \mathrm{N}_{2}\right)$ and sweep gas $(\mathrm{He})$ flow rates were $100 \mathrm{~cm}^{3}(\mathrm{STP}) \cdot \mathrm{min}^{-1}$. All mixed gas permeation tests were carried out at ambient feed and sweep gas pressure.

\subsection{Results and Discussion}

\section{Aminosilicate Membranes}

Figures 3.1, 3.2 and 3.3 present the room- $\mathrm{T} \mathrm{CO}_{2}: \mathrm{N}_{2}$ mixed gas separation performance of the aminosilica membranes prepared by recipes aSi-1, aSi-2 and aSi-3 in Table 3.1, respectively. The $\mathrm{CO}_{2}: \mathrm{N}_{2}$ separation factor $\alpha$ of membranes prepared by recipe aSi-1 was initially low $(<10)$, but increased drastically to $\sim 50$ with increasing feed humidity content, indicating the presence of a population of larger micropores of size 4-6 $\AA$. Membranes prepared by recipe aSi- 2 exhibited better separation performance with dry feeds and increasing feed humidity had less pronounced improvement in $\alpha$. This indicates that these membranes comprised primarily of ultramicropores of size $<4 \AA$. However, the $\mathrm{CO}_{2}$ permeance of these membranes was relatively low ( $\left.<1 \mathrm{MPU}\right)$ compared to the aSi-1 membranes.

On the other hand, membranes aSi-3 prepared on Anodisk showed much higher $\mathrm{CO}_{2}$ permeance and moderate $\alpha$ that were less sensitive to the feed humidity content. These membranes possess a wider pore size distribution with significant portion of mesopores since under the particular synthesis conditions the fast condensation reactions in the aminosilicate sol result in nanostructures with fractal dimension closer to 3 , which are not suitable for achieving molecular-sized pores for gas separation [25].

For both the aSi-1 and aSi-2 membranes, the $\mathrm{CO}_{2}$ and $\mathrm{N}_{2}$ permeances decreased rapidly and continuously with increasing feed humidity, while $\alpha$ increased initially and quickly reached a maximum at a feed relative humidity of 20-30\%. The observed permeance and $\alpha$ changes as a result of increasing feed humidity content can be explained by: (a) the pore blocking effect of $\mathrm{H}_{2} \mathrm{O}$ on the transport of $\mathrm{CO}_{2}$ and $\mathrm{N}_{2}$ through the less selective large micropores; (b) the higher pore surface occupancy of $\mathrm{H}_{2} \mathrm{O}$ in the ultramicropores (at $25^{\circ} \mathrm{C} \mathrm{H}_{2} \mathrm{O}$ alone occupies roughly about $70 \%$ of the pore surface at feed $\mathrm{RH}=20 \%$ ); and (c) the enhanced adsorption of $\mathrm{CO}_{2}$ on the pore wall due to the more favorable interactions with the amine groups in the presence of $\mathrm{H}_{2} \mathrm{O}$ and the reduction in surface coverage available for sorption and diffusion of $\mathrm{N}_{2}$ [20].

The results in Figures 3.1, 3.2 and 3.3 suggest that it is difficult to achieve combined high ( $>1.5 \mathrm{MPU}) \mathrm{CO}_{2}$ permeance and high $(>50) \alpha$ with the aminosilicate membranes explored in this study. Incorporation of amine groups in the silica matrix may enhance the membrane affinity for $\mathrm{CO}_{2}$ but on the other hand may increase the effective pore size by preventing efficient interpenetration and packing of dendritic nanoclusters during xerogel drying and condensation [20]. Reducing the $\mathrm{H}_{2} \mathrm{O}: \mathrm{Si}$ molar ratio in the case of the aSi-2 membranes resulted in better cluster packing but the porosity of the membrane was lower and hence the membrane showed lower $\mathrm{CO}_{2}$ permeance $(<1 \mathrm{MPU})$. Finally, reducing the $\mathrm{H}^{+}:-\mathrm{NH}_{2}$ molar ratio resulted in remarkable pore size and porosity increase for the aSi-3 membranes.

It is noted that in our earlier study [20] we could achieve $\alpha>50$ with membranes prepared by recipe aSi-1, but in this case we used a mesoporous sublayer with smaller pore size $(\sim 10-15 \AA)$. However, this type of sublayer may not show good long term 
structural stability under flue gas conditions, so we have adopted a protocol based on the Brij56 surfactant which results in more stable cubic-ordered mesoporous structures [26].

\section{Pure Silica Membranes}

Membranes prepared without amine groups showed better performance for $\mathrm{CO}_{2}: \mathrm{N}_{2}$ separation, as shown by the results summarized in Table 3.2. The critical factor that affected membrane pore structure and hence $\mathrm{CO}_{2}: \mathrm{N}_{2}$ separation performance was the $\mathrm{H}^{+}$:Si molar ratio of the precursor silica sol. In this study, we adjusted this ratio to $1 / 10$ of the value used by previous workers [24] in order to obtain satisfactory separation performance with the present support and preparation protocol. For comparison, sample M8 in Table 3.2 and Figure 3.4 prepared according to [24] showed much higher $\mathrm{CO}_{2}$ permeance and lower $\alpha$ compared to the rest of the samples. This sample exhibited a detectable $\mathrm{SF}_{6}$ permeance of $\sim 0.1 \mathrm{MPU}$, suggesting the presence of a broad distribution of micropores of sizes up to 5-6 $\AA$ that give rise to higher permeance but moderate $\mathrm{CO}_{2}: \mathrm{N}_{2}$ selectivity.

Figure 3.5 shows the $\mathrm{CO}_{2}: \mathrm{N}_{2}$ mixed gas separation performance of sample M4 in the temperature range of $25-100^{\circ} \mathrm{C}$. As seen in the figure, the permeance of $\mathrm{CO}_{2}$ increases moderately while that of $\mathrm{N}_{2}$ increases more drastically as a result of activated diffusion, resulting in a fast $\alpha$ decline. This behavior was reversible with temperature cycling and typical of all membrane samples prepared in this study under similar conditions. In order to reduce the fast decline of $\alpha$ at elevated $\mathrm{T}$, we performed membrane calcination at progressively higher $\mathrm{T}$ (up to $500^{\circ} \mathrm{C}$ ) in order to densify the membrane framework and reduce its pore size [24], but this treatment did not prove effective in our case. However, as seen in Figure 3.6, the presence of humidity in the feed aids in improving $\alpha$ at elevated $\mathrm{T}$ but at the expense of $\mathrm{CO}_{2}$ permeance, as was also observed with the aminosilicate membranes in Figures 3.1, 3.2 and 3.3.

\section{Ni-doped silica membranes}

Ni-doped membranes were also prepared in this study because of their potential to resist densification under the flue gas conditions involving $\mathrm{H}_{2} \mathrm{O}$ vapor and $\mathrm{SO}_{2}$ impurity gas [27-29]. Table 3.3 shows the room- $\mathrm{T} \mathrm{CO}_{2}: \mathrm{N}_{2}$ mixed gas separation performance of $\mathrm{Ni}$-doped silica membranes prepared with a molar ratio $\mathrm{Ni}: \mathrm{Si}=0.1$. These membranes in general exhibit higher $\mathrm{CO}_{2}$ permeance and lower $\alpha$ compared to the pure silica membranes prepared under comparable conditions. We also prepared membranes with molar ratio $\mathrm{Ni}: \mathrm{Si}=0.2$ but the separation performance of these samples was less reproducible. Some samples would exhibit low $\mathrm{CO}_{2}$ permeance $(<1$ MPU) combined with high $\alpha$ (close to 100), whereas other samples showed $\alpha<10$, implying the presence of film defects. For this reason, we focused our attention on the membranes prepared with molar ratio $\mathrm{Ni}: \mathrm{Si}=0.1$, since these membranes have higher initial (fresh) porosity and/or pore size and hence they have better potential to resist densification during prolonged exposure to SFG conditions.

\section{$4-\mathrm{CO}_{2}$ Separation under Simulated Flue Gas Conditions}

\subsection{Experimental Methods}


Simulated flue gas (SFG) treatment

Prolonged exposure of the membrane to SFG conditions was carried out either inside the stainless steel permeation cell or in a separable pyrex holder heated at $60-80^{\circ} \mathrm{C}$ by an external heating tape. The humidified feed (50\% R.H.) of $10 \% \mathrm{CO}_{2}$ in $\mathrm{N}_{2}$ was introduced at a rate of $100 \mathrm{~cm}^{3}(\mathrm{STP}) \cdot \mathrm{min}^{-1}$ and ambient pressure $(1 \mathrm{~atm})$ over the membrane for a period of several days. The content of $\mathrm{SO}_{2}$ in the mixed gas was adjusted to $\sim 10 \mathrm{ppm}$ by controlling the flow rate of a $50 \mathrm{ppm} \mathrm{SO}_{2}-\mathrm{in}-\mathrm{N}_{2}$ calibrated gas mixture (Matheson). After the treatment, the membrane was tested in the stainless steel cell to record any performance changes due to the prolonged exposure to $\mathrm{H}_{2} \mathrm{O}$ vapor and $\mathrm{SO}_{2}$.

\subsection{Results and Discussion}

\section{Membrane stability under SFG conditions}

The $\mathrm{CO}_{2}: \mathrm{N}_{2}$ mixed gas separation performance of pure and Ni-doped silica membranes was studied after several days of exposure to SFG conditions in order to assess the impact of $\mathrm{H}_{2} \mathrm{O}$ vapor and trace $\mathrm{SO}_{2}$ gas on the membrane pore structure. Figure 4.1 shows the overall effect of $\mathrm{SFG}$ exposure time on membrane $\mathrm{CO}_{2}$ permeance and $\mathrm{CO}_{2}: \mathrm{N}_{2}$ separation factor. As seen in the Figure, the $\mathrm{CO}_{2}$ permeance decreases rapidly in the first 24-48 hours of exposure and then stabilizes at about $25 \%$ of its original level after prolonged exposure. The reduction in $\mathrm{CO}_{2}$ permeance is accompanied by different levels of improvement in $\alpha\left(\mathrm{CO}_{2}: \mathrm{N}_{2}\right)$, depending on the initial absolute membrane permeance and the presence of $\mathrm{Ni}$ dopant in the microstructure.

Figures 4.2 and 4.3 show the separation performance of a pure silica membrane after 60 and 120 hours exposure to SFG conditions, respectively. From these Figures we observe that a $50 \%$ reduction in $\mathrm{CO}_{2}$ permeance with only $15 \%$ increase in $\alpha$ occurs when the exposure time to SFG conditions increases from 60 to 120 hours. On the other hand, the Ni-doped silica membrane studied in Figure 4.4 maintains higher $\mathrm{CO}_{2}$ permeance and higher $\alpha$ even after 168 hours exposure to SFG conditions. The stabilizing effect of Ni can be explained by the enhanced porosity of the doped membranes and the reduction in the rate of condensation reactions between neighboring $-\mathrm{Si}-\mathrm{OH}$ units in the silica framework due to the presence of Ni oxide. This stabilizing effect of metal oxide doping on the pore structure of sol-gel derived nanostructured ceramics was established in previous studies with a variety of guest metal atoms such as $\mathrm{La}, \mathrm{Y}, \mathrm{Mg}$, and $\mathrm{Al}$ on both the xerogel and the thin film form of alumina, titania, zirconia and silica membranes [30, 31].

\section{Future directions}

As seen in Figure 4.4, although the Ni-doped silica membrane maintains high $\alpha$ at elevated $\mathrm{T}$, its $\mathrm{CO}_{2}$ permeance is still significantly lower than the level necessary (e.g. $>2$ MPU) for large scale application of the membrane in power plant flue gas $\mathrm{CO}_{2}$ capture. We attempted to improve the $\mathrm{CO}_{2}$ permeance of these membranes by diluting the precursor Ni-doped silica sol with ethanol prior to membrane deposition in order to decrease membrane thickness, but this resulted in reduced $\alpha$, suggesting that a fundamentally different approach is necessary to prepare silica membranes meeting the stringent separation performance and stability requirements for large scale flue gas $\mathrm{CO}_{2}$ capture. 
An alternative technique that can potentially allow the preparation of molecular sieving silica membranes combining high $\mathrm{CO}_{2}$ permeance ( $\left.>2 \mathrm{MPU}\right)$ and high $\alpha(>50)$ is atomic layer deposition (ALD). The advantage of this technique is that it allows monolayer-by-monolayer growth of a metal oxide thin film on a suitable support by cycling contact of the metalorganic and water vapor reactants with the film surface, thus allowing molecular level control of the film thickness and nanostructure [32]. Recently we demonstrated successful introduction of attractive molecular sieving properties on mesoporous silica films supported on anodic alumina disks by a plasma-modified ALD technique [33]. Currently we are working on extending this approach on tubular supports for the purpose of preparing high permeance, high $\alpha$ molecular sieve silica membranes that would be suitable for power plant flue gas capture. Other than reducing membrane thickness, the ALD technique also offers improved flexibility for derivatizing the membrane with amine groups while overcoming the gelation issues associated with the traditional liquid phase sol-gel processing. Detailed discussion on ALD approach is shown in section 7 .

\section{Summary}

We have explored 3 types of silica-based, tubular microporous membranes for $\mathrm{CO}_{2}: \mathrm{N}_{2}$ separation under simulated flue gas conditions. Amine-derivatized silica membranes could not achieve combined high ( $>50) \alpha$ and high ( $>1 \mathrm{MPU}) \mathrm{CO}_{2}$ permeance, most likely because of the difficulty in independently controlling the pore size and porosity of the aminosilicate framework. Pure silica membranes prepared under optimized conditions showed the best combination of high (1.5-2.0 MPU) $\mathrm{CO}_{2}$ permeance and high (50-80) $\mathrm{CO}_{2}: \mathrm{N}_{2}$ separation factor, but $\alpha$ decreased drastically with increasing operating temperature. These membranes showed gradual decline in permeance as a result of prolonged exposure to SFG conditions due to densification and shrinkage of the framework induced by $\mathrm{H}_{2} \mathrm{O}$ vapor and trace $\mathrm{SO}_{2}$ gas. Doping the membrane with nickel oxide mitigated the densification due to enhancement in porosity and reduction in condensation reactions in the doped silicate framework during operation. Despite the improvement in performance imparted by metal oxide doping, the permeance of the membranes still needs to be improved to be attractive for power plant scale $\mathrm{CO}_{2}$ capture.

\section{5 - Optimization of Thin Membrane Deposition}

This section covers the experimental work focusing the synthesis and characterization of mesoporous silica membranes on porous anodic alumina supports by sol-gel dip-coating. The objective of the work was to investigate whether good quality mesoporous silica layers can be deposited on commercially available inexpensive ceramic supports such as Anodisk ${ }^{\mathrm{TM}}$, by simple sol-gel dip-coating procedures wellestablished in our laboratory. The mesoporous silica layers will serve as support of the microporous aminosilicate membrane that will perform the $\mathrm{CO}_{2} /$ air separation. It is anticipated that success in depositing such mesoporous silica sublayers on ceramic supports will reduce significantly the cost of tubular ceramic support (e.g. Membralox ${ }^{\mathrm{TM}}$ ) from about $\$ 5.2 / \mathrm{cm}^{2}$ for supports with a fine-pore $(5 \mathrm{~nm}) \gamma-\mathrm{Al}_{2} \mathrm{O}_{3}$ top-layer needed currently, down to $\$ 2.9 / \mathrm{cm}^{2}$ for supports with a coarse-pore $(100-200 \mathrm{~nm}) \alpha-\mathrm{Al}_{2} \mathrm{O}_{3}$ or $\mathrm{ZrO}_{2}$ top-layer, or even down to $\$ 0.58 / \mathrm{cm}^{2}$ for disk supports such as Anodisk ${ }^{\mathrm{TM}}$. 
Alternatively, membrane can be deposited on high-quality, low-cost, high surface area/volume hollow fiber ceramic support.

\section{1 Experimental Methods}

\section{Membrane Synthesis}

The support employed for mesoporous membrane deposition was commercially available Anodisk $^{\mathrm{TM}}$ with thickness of $\sim 50 \mu \mathrm{m}$ and diameter of $21 \mathrm{~mm}$, supplied by Whatman (England). This support has straight cylindrical pores of diameter $200 \mathrm{~nm}$ running along its thickness, and it is optionally available with a $2-\mu \mathrm{m}$-thick top layer of smaller pores of size 20 or $100 \mathrm{~nm}$. Due to its very small thickness, the support is very fragile, and for this reason it is usually provided with a polymeric ring attached on its circumference to facilitate handling.

The sol used for mesoporous membrane deposition was prepared by mixing TEOS, Ethanol (EtOH), $\mathrm{H}_{2} \mathrm{O}, \mathrm{HCl}$ and pluronic $\mathrm{F} 127$ block copolymer surfactant (BASF) at a molar ratio of 1 TEOS : $20 \mathrm{EtOH}: 5.3 \mathrm{H}_{2} \mathrm{O}: 0.007 \mathrm{HCl}$, while the content of surfactant in the sol was varied from 4.2 to $7.2 \% \mathrm{wt}$. of total. This sol was typically aged for $9-11 \mathrm{~h}$ at $22^{\circ} \mathrm{C}$ without agitation before dip-coating. Subsequent deposition of a microporous gas separation silica membrane was performed by spin-coating, using polymeric silica sols made as described in detail in [15].

Deposition of mesoporous silica layers on the anodisk support was carried out by dipping the support in a surfactant/silica sol of proper composition, withdrawing at a constant speed of $75 \mathrm{~mm} / \mathrm{min}$, drying for 5-10 min, and then calcining for $3 \mathrm{~h}$ at $500^{\circ} \mathrm{C}$ in air to remove the surfactant from the mesopores (see Figure 5.1). Since the calcination step resulted in decomposition of the polymeric handling ring around the disk as well, subsequent microporous membrane deposition was performed by spin-coating.

\section{Membrane Characterization}

The gas transport properties of the anodisk-supported meso- and microporous silica membranes were determined by permporosimetry technique and regular binary gas permeation (see Figure 5.2). In both cases, the membranes were sealed with rubber Orings in a custom stainless steel holder using a porous $\alpha-\mathrm{Al}_{2} \mathrm{O}_{3}$ disk (dia. $22 \mathrm{~mm}$, thickness $2 \mathrm{~mm}$, pore size $200 \mathrm{~nm}$ ) as support of the fragile anodisk. In the permporosimetry configuration, the permeation rate of a non-condensible gas (here $\mathrm{N}_{2}$ ) is measured as a function of increasing partial pressure of a condensible vapor (here ethanol), in order to obtain information about the pore size and pore connectivity of the membrane. In the binary gas permeation, the separation property of a microporous silica membrane deposited on the mesoporous silica layer was measured employing dry feeds of $2 \%$ vol. $\mathrm{CO}_{2}$-balance $\mathrm{N}_{2}$ or $10 \%$ vol. $\mathrm{CO}_{2}$-balance $\mathrm{CH}_{4}$. The composition of the permeate stream in all cases was determined with the aid of a Gas Chromatograph equipped with thermal conductivity detector (Hewlett Packard, model 5890 series II).

SEM observations of the anodisk and mesoporous silica membrane surface were performed in a Hitachi S-5200 field emission Scanning Electron Microscope. TEM was 
performed on a JEOL 2010 Transmission Electron Microscope. Grazing incidence smallangle X-ray scattering (GISAXS) studies were performed in the Advanced Photon Source facility in Argonne National Lab, Argonne, IL.

\section{2 Results and Discussion}

\section{Anodisk support}

Figure 5.3 shows: (a) SEM top view of the surface of a bare $100 \mathrm{~nm}$ anodisk support; (b) SEM top view of the surface of the support after deposition of a F127templated mesoporous silica membrane; and (c) TEM cross-section showing the presence of the mesoporous silica film inside the $100 \mathrm{~nm}$ anodisk pores. GISAXS studies show diffuse rings arising from the cubic- ordered, randomly oriented spherical mesopores of the film (Figure 5.4a), while the lattice parameter (pore-to-pore-center distance) was of the order of $d=14.4 \mathrm{~nm}$ (Figure 5.4b). It is pointed out here that under the conditions employed for dip-coating, the mesoporous membrane was extending only up to the pore mouth, but was not covering the external surface of the anodisk support (see Fig. 5.3b,c). However, if the deposition process is repeated twice, the mesoporous membrane will definitely cover the entire surface of the anodisk support. However, this was not done here due to the difficulty of handling the anodisk after the first calcination step, but definitely this will not be a problem with tubular Membralox ${ }^{\mathrm{TM}}$ ceramic supports (wall thickness $1.5 \mathrm{~mm}$ ) that we plan to use in the future.

Figure 5.5 shows the permporosimetry results for the bare $100 \mathrm{~nm}$ anodisk support, as well as for three F127-templated mesoporous silica membranes prepared with $4.2,5.8$ or $7.3 \%$ wt. loading of surfactant. In the case of the bare anodisk, the $\mathrm{N}_{2}$ permeance does not decrease significantly even after relative saturation of ethanol vapor as high as $90 \%$ is reached (in both feed and permeate sides of the membrane), which indicates that the large pores of the support cannot be blocked by condensing ethanol vapor. For the $4.2 \%$ wt. F127-templated silica membrane, we observe a rapid decrease in $\mathrm{N}_{2}$ permeance even at low relative saturation, which indicates that the mesopores of this membrane are not connected completely and gas transport occurs through the microporous silica wall. For the $7.2 \%$ wt. F127-templated silica membrane, we observe initially a slow decrease in $\mathrm{N}_{2}$ permeance with increasing relative saturation, followed by a rapid loss in permeance at high relative saturation, a result that suggests that the mesopores of this membrane are fully connected. Finally, an intermediate behavior is observed for the 5.8\% wt. F127-templated silica membrane, where transport is governed by both the microporous silica wall as well as a portion of interconnected mesopores. These results further imply that the most suitable mesoporous sublayers are those prepared from silica sols of high loading of surfactant, since these layers would suffer the smallest loss in permeance when humidified $\mathrm{CO}_{2} /$ air feeds are to be separated with the overlying microporous aminosilicate membranes.

Figure 5.6 shows the molecular sieving behavior of a microporous silica membrane spin-coated on a mesoporous $7.2 \% \mathrm{wt}$. F127-templated silica sub-layer, which was initially dip-coated once on a $100 \mathrm{~nm}$ anodisk support. As seen from the figure, the microporous membrane is of reasonable quality, exhibiting high $\mathrm{CO}_{2}$ permeance and binary separation factors $\alpha\left(\mathrm{CO}_{2}: \mathrm{N}_{2}\right)=43$ and $\alpha\left(\mathrm{CO}_{2}: \mathrm{CH}_{4}\right)=116$. On the other hand, 
when the microporous membrane was spin-coated directly on a bare 20 -nm anodisk, no permselectivity for $\mathrm{CO}_{2}$ over $\mathrm{N}_{2}$ or $\mathrm{CH}_{4}$ was observed. This suggests that the mesoporous F127-templated silica layer is necessary to fill the large pores of the support before a continuous microporous gas separation membrane can be deposited. Finally, it would be possible to deposit even better quality microporous membranes on supports coated at least twice with the mesoporous sub-layer, as opposed to only single-coated supports reported here.

\section{Ceramic hollow-fiber support}

The surface of ceramic hollow fiber support (4mm OD x $3 \mathrm{~mm}$ ID) from our potential vendor was characterized by atomic force microscopy (AFM). AFM microanalysis shows rough support surface causes crack on membrane (Figure 5.7). To mitigate the problem, the support surface ( $\alpha$-alumina) was coated with a layer of $\gamma$ alumina layer prior to the deposition of sub-layer and selective layers. The $\mathrm{CO}_{2} / \mathrm{N}_{2}$ ideal selectivity increased from below Knudsen to microporous selectivity indicating an improvement on overlying membrane deposition. Figure 5.8 shows the configuration of single fiber, fiber bundle, and a close-look of membrane cross section.

The results indicate that by using simple sol-gel dip-coating procedures it is possible to deposit mesoporous silica sub-layers on coarse-pore $(\geq 100 \mathrm{~nm})$ inexpensive ceramic supports that will serve as support of a final $\mathrm{CO}_{2}$-permselective aminosilicate gas separation membrane. The surfactant employed for mesoporous sub-layer deposition, F127 block-copolymer commercially available from BASF, was selected because it allows the preparation of silica sols with good consistency necessary to deposit continuous mesoporous films on macroporous ceramic supports, while the resulting mesopore size $(5-7 \mathrm{~nm})$ and silica wall thickness $(\sim 5-7 \mathrm{~nm})$ is high enough to ensure low gas/vapor transport resistance and good mechanical properties of the mesoporous sublayer. This work also indicates that it is possible to deposit the mesoporous silica sublayers on commercial tubular supports of pore size 100-200 nm. The effect of number of coatings on the quality of the final microporous gas separation membrane should be study in details as judged by its $\mathrm{CO}_{2}$-selectivity over $\mathrm{N}_{2}$ or $\mathrm{CH}_{4}$.

\section{6 - Preliminary economic analysis/ system integration}

We conducted an economic analysis of the membrane-based $\mathrm{CO}_{2}$ capture for post combustion applications. The goal of the analysis is to provide a ballpark cost estimate on the concept of using the membrane system for $\mathrm{CO}_{2}$ capture and to provide a sensitivity study on the performance and cost of the proposed membranes.

\subsection{Approach}

The DOE carbon capture and sequestration systems analysis guidelines [34] were used as references for calculation, and additional information required for the calculation was obtained from the literature [35,36,37]. Note that the DOE carbon sequestration program goal for post-combustion systems is capturing $90 \%$ of the $\mathrm{CO}_{2}$ emitted with only a $20 \%$ increase in the cost of electricity (COE). Our analysis is based on the removal of $\mathrm{CO}_{2}$ from pulverized coal (PC) power plants using Illinois \#6 bituminous coal as fuel. 
We have developed an in-house spreadsheet model to conduct the calculation for $90 \%$ $\mathrm{CO}_{2}$ removal efficiency. In this calculation, the additional $\mathrm{CO}_{2}$ emission from auxiliary load is considered and vacuum instead of compression is used as driving force for membrane-based $\mathrm{CO}_{2}$ separation.

\subsection{Results \& Discussion}

\section{Economic analysis of the membrane-based $\mathrm{CO}_{2}$ capture}

Figure 6.1 shows the selectivity requirements based on first principle calculation for the membrane module. Since the $\mathrm{CO}_{2}$ concentration varies from $10 \%$ to $15 \%$ in the flue gas, the required $\mathrm{CO}_{2}: \mathrm{N}_{2}$ selectivity to achieve $90 \%(\mathrm{v} / \mathrm{v}) \mathrm{CO}_{2}$ concentration in the permeate varies from 80 to 50 for $90 \% \mathrm{CO}_{2}$ capture efficiency. Currently, our best performed membrane at $55^{\circ} \mathrm{C}\left(131^{\circ} \mathrm{F}\right.$, which is the temperature that flue gas is exiting the FGD) with dry $10 \%$ vol. $\mathrm{CO}_{2}$ feed has $\mathrm{CO}_{2}: \mathrm{N}_{2}$ selectivity of 40 , which corresponds to $80 \% \mathrm{CO}_{2}$ concentration in the permeate. Note that high concentration of $\mathrm{CO}_{2}$ in the permeate could reduce the cost of compressing the captured $\mathrm{CO}_{2}$ in the downstream for pipeline transportation while the magnitude of $\mathrm{CO}_{2}$ permeance of the proposed membrane affects the $\mathrm{COE}$ of the $\mathrm{PC}$ power plant with a membrane-based $\mathrm{CO}_{2}$ capturing system. When the $\mathrm{CO}_{2}$ permeance of the membrane is increased, the required surface area of the membrane is decreased, thus reducing the volume of the membrane module and associated capital, operation \& maintenance (O\&M), and energy cost. At $55^{\circ} \mathrm{C}$, our best performed membrane has high $\mathrm{CO}_{2}$ permeance of $3.0 \mathrm{~cm}^{3}(\mathrm{STP}) \mathrm{cm}^{-2} \mathrm{~min}^{-1} \mathrm{~atm}^{-1}$ (= $657 \mathrm{GPU}, 1 \mathrm{GPU}=10^{-6} \mathrm{~cm}^{3}$ (STP) $\mathrm{cm}^{-2} \mathrm{~s}^{-1} \mathrm{cmHg}^{-1}$ ) under dry $10 \%$ vol. $\mathrm{CO}_{2}$ feed conditions.

We compared three cases using the Excel template provided by NETL (Note that some typos and formula errors in the template have been corrected):

Case 1: Coal-fired Supercritical Steam Plant with MEA $\mathrm{CO}_{2}$ Removal System (EPRI Case 7A) [35,36]

Case 2: Coal-fired Supercritical Steam Plant (EPRI Case 7C) for reference plant

Case 3: Coal-fired Supercritical Steam Plant with membrane-based $\mathrm{CO}_{2}$ Removal System. (this study)

Similar to the cost structure for MEA facility analysis in the EPRI report [35,36], in the calculation, the capital cost, O\&M cost and energy requirements for the concept membrane-based $\mathrm{CO}_{2}$ separation system are the adding expenses to the cost of electricity $(\mathrm{COE})$ of the reference PC power plant without $\mathrm{CO}_{2}$ capture capability. An example of this calculation is shown in Table 6.1. In Case 1, the $\mathrm{CO}_{2}$ was concentrated into a product stream by MEA absorption and compressed to supercritical condition for transportation while in case 3 , the cost of $\mathrm{CO}_{2}$ removal is based on concentrating $\mathrm{CO}_{2}$ into a product stream by a membrane-based $\mathrm{CO}_{2}$ removal system and compressed to supercritical condition for transportation. The vacuum generated by condensing low-pressure steam was used to drive the membrane gas separation. Since the MEA recirculation pumping energy can be avoided, the net power output with the membrane system can be higher than that with the MEA system. Moreover, the capital cost of the membrane system can 
be lowered compared to the MEA system by avoiding the expensive absorber and stripper and auxiliaries and by the lower land requirements of the membrane system due to smaller size. In the consumables, for membrane system, the cost of MEA could be avoided, but the cost of the membrane was added to the cost of the consumables. The O\&M cost with the membrane system can be less than that with the MEA system, due to less O\&M activities for the membrane system. Note that the membrane system has less environmental impact than the MEA system due to less chemicals used for $\mathrm{CO}_{2}$ capture, although we did not take into account this factor in the cost saving. The summary for the comparison is shown in Figure 6.2. It shows the sensitivity of the cost in $\$$ per tonne $\mathrm{CO}_{2}$ avoided (vertical axis) on the cost of membrane $\left(\$ / \mathrm{ft}^{2}\right.$, horizontal axis) and membrane $\mathrm{CO}_{2}$ permeance $\left(\mathrm{P}=3.0,4.0\right.$ or $\left.5.0 \mathrm{~cm}^{3}(\mathrm{STP}) \mathrm{cm}^{-2} \mathrm{~min}^{-1} \mathrm{~atm}^{-1}\right)$. The performance of the membrane-based $\mathrm{CO}_{2}$ removal system is compared to MEA-based $\mathrm{CO}_{2}$ removal system (in orange line).

\section{Performance and Energy Requirements for Membrane Applications on $\mathrm{CO}_{2}$ Capture}

We also evaluate membrane performance and energy requirements for a practical membrane process to handle the post-combustion $\mathrm{CO}_{2}$ capture. Our original program goal was to achieve $\mathrm{CO}_{2} / \mathrm{N}_{2}$ selectivity 100 and $\mathrm{CO}_{2}$ permeance $1 \times 10^{-3} \mathrm{~cm}^{3} / \mathrm{cm}^{2}-\mathrm{s}-\mathrm{cmHg}$ (or $4.6 \mathrm{~cm}^{3} / \mathrm{cm}^{2}$-min-atm or $\left.7500 \mathrm{~m}^{3} / \mathrm{m}^{2}-\mathrm{s}-\mathrm{Pa}\right)$. The goal was in-line with minimal membrane performance requirements set by DOE system expert. So far, our best membrane for $\mathrm{CO}_{2}$ separation has ideal selectivity of 100 and $\mathrm{CO}_{2}$ permeance of $2.2 \times 10^{-4}$ $\mathrm{cm}^{3} / \mathrm{cm}^{2}$-s-cmHg (or $1 \mathrm{~cm}^{3} / \mathrm{cm}^{2}$-min-atm), which is the best membrane reported in the literature for $\mathrm{CO}_{2} / \mathrm{N}_{2}$ separation. However, accounting for performance loss due to scale up, the permeance needs to be increased at least by factor of five while the selectivity stays the same under the flue gas conditions in order to achieve the program goal. Our new membrane preparation approach using PA-ALD has potential to increase both permeance and selectivity simultaneously by reducing membrane thickness ten-fold from current 100-200 nm thick to 10-20 nm thick and eliminating defects with atomic-level precision of deposition. Detailed PA-ALD approach is discussed in Section 7.

The task of post-combustion $\mathrm{CO}_{2}$ capture exhibits great technical challenges due to high volume of gas to be treated and a low driving force of $\mathrm{CO}_{2}\left(\mathrm{CO}_{2}\right.$ concentration $10-15 \mathrm{wt} \%$ ) for either absorption or membrane-based separation, in addition to other potential complications such as corrosive trace $\mathrm{SO}_{2}$ in the flue stream. $\mathrm{CO}_{2}$ absorption by liquid amine is a mature technology but it is too costly to operate absorption columns for a large-scale $\mathrm{CO}_{2}$ separation process. For membrane, the cost of energy for providing sufficient driving force needs to be considered. Two ways to provide sufficient driving force for membrane-based gas separation, one is compressing flue gas at the retentate side, the other is applying vacuum at the permeate side. The cost of energy is apparently too high for compressing flue gas at the retentate side due to energy lost in compressing majority inert gas $\mathrm{N}_{2}(\sim 90 \%)$, which does not contribute to $\mathrm{CO}_{2}$ permeation. Applying vacuum at the permeate side in our original proposal is a more economical approach if the membrane has high $\mathrm{CO}_{2}$ selectivity. In addition, vacuum generated from low-grade steam in the power plant could be used as vacuum source. Theoretical calculation based on a perfect $\mathrm{CO}_{2}$ selective membrane and vacuum provided fully from vacuum pumps shows that $10-13 \%$ increase in total energy output may be needed for $\mathrm{CO}_{2}$ separation and recompression for transportation. The calculation is shown as follow: 
For exhaust flue gas, if total pressure is 20 psia, partial pressure $\mathrm{CO}_{2}\left(\mathrm{PCO}_{2}\right)$ will be 2.0 psia due to $10 \% \mathrm{CO}_{2}$ in flue gas. Vacuum is assumed to be maintained at permeate at 0.2 psia roughly. For a typical $500 \mathrm{MW}$ bituminous coal-fired power plant, the required $\mathrm{CO}_{2}$ capture rate is from $221 \mathrm{metric}$ tons $/ \mathrm{hr}$ to $283 \mathrm{metric}$ tons $/ \mathrm{hr}$ depending on types of coal used, in order to achieve $90 \%$ capture goal. We calculate the energy requirement based on the fundamental thermodynamic equation: $\mathrm{eW}=\mathrm{nRT} \ln \left(\mathrm{P}_{1} / \mathrm{P}_{2}\right)$, where $\mathrm{e}=$ efficiency of the compressor/vacuum pump, $\mathrm{n}=$ flow rate of captured $\mathrm{CO}_{2}$, $\mathrm{T}=$ temperature, and $\mathrm{R}=$ gas constant. Assuming compressor/vacuum pump efficiency is $90 \%$ and flue gas temperature is $60^{\circ} \mathrm{C}(333 \mathrm{~K})$, the required vacuum energy for $\mathrm{CO}_{2}$ permeation through the membrane is 9.9-12.6 MWe and the required energy for compressing $\mathrm{CO}_{2}$ from 0.2 psia to 2200 psia for pipeline transportation is $39.8-51.1$ MWe; therefore the total ideal energy requirement for capture and re-compression will be between $50-64$ MWe or $10-13 \%$ total power output. Note that vacuum obtained from condensation of low-grade steam could be used as driving force to reduce the energy penalty. Recent publication shows energy requirement for current amine-based capture system is approximately $15-30 \%$ total power output [38]. Based on this information, membrane system for post-combustion capture shows energy more efficient compared to conventional system. Furthermore, for a pre-combustion $\mathrm{CO}_{2}$ capture wherein $\mathrm{CO}_{2}$ is more concentrated (50 volume \%) and at higher pressure, membrane approach is even more economical (estimated 25-32 MWe).

\section{Summary}

The basic conclusion from these results is that with the combination of high membrane $\mathrm{CO}_{2}$ permeance and low membrane cost, the membrane approach could show lower overall cost for $\mathrm{CO}_{2}$ capture compared to the state-of-the-art MEA sorption technology approach. The refinement of the cost model is necessary for more detailed analysis.

\section{7 - Refinement of Membrane Deposition}

\subsection{Experimental Methods}

\section{Plasma-assisted Atomic Layer Deposition (PA-ALD)}

The University of New Mexico has developed an unique plasma-assisted atomic layer deposition (PA-ALD) approach to construct ultra-thin dense silica films on porous supports. Atomic layer deposition (ALD) is a self-limiting layer-by-layer thin film deposition technique composed normally of successive steps of adsorption and hydrolysis/activation of metal halide or metal alkoxide precursors. To deposit a ultra-thin dense silica membrane layer, first, ALD will be performed on a self-assembled nanoporous support where the inside pore is prevented from deposition by passivation. Second ALD is restricted to the extreme surface by plasma activation - plasma Debye length and the radical mean free path is chosen to exceed greatly the pore diameter, thus deposition does not occur within the interior pores. Third, at a temperature of $90 \sim 120{ }^{\circ} \mathrm{C}$, silica precursor vapor is injected into the reactor, allowing the organosilane to react with the $-\mathrm{OH}$ groups on the sample surface. A subsequent Ar purging leads to the formation of a chemisorbed monolayer (or submonolayer) of the percursor molecules. Radio 
frequency (RF) power is then delivered to the coil, creating a plasma. The associated radicals convert surface-adsorbed silica precursor into one atomic layer of solid silica depsotion with a reactive silanols surface chemistry and may promote further conversion to siloxane. Following this, the deposition chamber is purged again to remove the residual gaseous products, completing one cycle; each cycle requires 5 seconds. 20 to 45 cycles should be sufficient to deposit a ultra-thin dense silica layer with thickness 2 to 5 $\mathrm{nm}$.

The conventional ALD process comprises cycles of surface adsorption of precursors and their subsequent reaction to form the deposited layer. Eliminating either one of the steps within the pores will prevent deposition in the pores. Correspondingly, two approaches can be used to avoid the internal deposition:

1) One approach [23] is to prevent the precursor adsorption on the internal pores. In this case, the internal pore surfaces are passivated with inert ligands, $-\mathrm{CH}_{3}$, followed by remote-plasma irradiation to activate the very top surface of the porous substrate by converting $-\mathrm{CH}_{3}$ surface chemistry into the ALD-active -OH surface chemistry. Here plasma is used to pre-treat the nanoporous support BEFORE ALD process, and we call this "plasma-define ALD".

2) The second approach [39] is to prevent the energy source needed for ALD reaction from entering the internal pores, so that ALD deposition is also confined at the very top of the porous substrate. In this aspect, we have designed the ALD process such that the precursors are non-reactive, unless "triggered" by an energy activation step. The activation energy is provided by plasma under conditions where the plasma activates the ALD reaction only at the top surface.

When using HMDS $\left.\left(\mathrm{CH}_{3}\right)_{3} \mathrm{SiNHSi}\left(\mathrm{CH}_{3}\right)_{3}\right)$ as the precursor for the second approach, then, both of the mechanism in the above mentioned will be involved, facilitating the deposition of a ultrathin membrane to the very top of a porous substrate.

$P A-A L D$ versus other competing thin film deposition techniques

PA-ALD has the following distinct advantages over conventional thin film deposition techniques:

Precise sub- nm level thickness control. For conventional thin film depositions such as regular CVD or PVD, the film thicknesses are usually controlled by using a corresponding deposition time. To obtain several-nm-thick thin films, very short deposition times has to be used, which is hard to operate and hard to ensure the run-torun thickness repeatability. PA-ALD deposits thin film layer by layer. For this reason, a thin film with precise thickness control can be obtained simply by using a specific number of deposition cycles, making it easy to achieve membranes with required nanometer thickness.

Inherently uniform thickness over a large area that eliminates pinhole formation at reduced thickness. For conventional thin film deposition techniques, the deposition rates can be influenced by a number of factors, hence the thickness uniformity will be impaired by the variation of any of these parameters over the whole sample area. For a film with thickness non-uniformity exceeding several nanometers, when the average film thickness is reduced to a few nanometers, pinholes will show up at the thinner area, making these films impractical to make several-nm-thick membranes. But for PA-ALD, it is a self-limiting deposition process where the deposition rate is limited 
by the thickness of the surface chemisorption layer. The film thickness is exactly same for all the locations over the whole sample area. This highly uniformity in film thickness makes it possible to achieve nm- thick pinhole free membranes.

Conformal to complex surface morphology including corrugated surfaces. The PA-ALD's chemisorption monolayer is a conformal layer, making it feasible to increase the membrane area using a porous support with corrugated surface [23, 39-41].

Zero penetration into porous support. Properly chosen precursors and plasma ensures thin film deposition to occur only at the very top of a nanoporous substrate, minimizing the effective film thickness for maximum gas flux.

High-quality film. The layer-by-layer deposition mode of PA-ALD is advantageous for achieving high-quality films with less impurities and excellent structural and compositional homogeneousity.

\subsection{Results and Discussion}

\section{Deposition of sub-10 nm thick microporous membrane}

In the past, all materials deposited by ALD were limited to dense non-porous materials. For many membrane applications, it is important that the material posses homogeneous angstrom-sized pores for industrial important separations. Using bridged Silsesquioxane precursor we have resolved this problem [40,41].

We start with a nanoporous silica film (Figure 7.1), consisting of an ordered cubic arrangement of monosized pores, formed by evaporation-induced self-assembly on an underlying anodized alumina support having $20-\mathrm{nm}$ pores aligned normal to the support surface [40]. Following calcination and UV/ozone exposure, the nanoporous film has fully hydroxylated 3.2-nm pores as measured by a surface acoustic wave based technique. To avoid ALD on any interior porosity, which would detrimentally increase the membrane thickness, we expose this hierarchical membrane support structure to hexamethydisilazane and then to trimethychlorosilane vapor at $180{ }^{\circ} \mathrm{C}$ for 5 minutes. This exposure converts the surface and internal hydroxyl groups to trimethylsiloxane groups, which remain inert to hydrolysis reactions and therefore passivate the surface against ALD during subsequent steps. To activate the immediate surface of the nanoporous film to ALD, the sample is exposed to a remote $\mathrm{Ar}+\mathrm{O}_{2}$ plasma for 2 seconds. As reported previously by us, the plasma was designed so that its Debye length (several $\mathrm{mm}$ ) and radical mean free path (several $\mathrm{mm}$ ) are much larger than the pore size. In this condition the plasma radicals cannot penetrate the internal porosity, and only trimethylsiloxane groups residing on the immediate surface of the nanoporous film are converted to silanols $\equiv$ Si-OH. These surface silanols are active to halide and alkoxide ALD precursors, $\mathrm{M}(\mathrm{X})_{\mathrm{n}}$ and $\mathrm{M}(\mathrm{OR})_{\mathrm{n}}$, respectively, undergoing condensation reactions to form $\equiv \mathrm{Si}-\mathrm{O}-\mathrm{M} \equiv$ plus HX and HOR by-products. Therefore ALD takes place on the surface of the substrate, while internal, hydrophobic $-\mathrm{Si}\left(\mathrm{CH}_{3}\right)_{3}$ groups remain unhydrolyzed and do not undergo condensation reactions with ALD precursors.

In the case of passivated internal porosity, successive steps of adsorption and hydrolysis of $\mathrm{M}(\mathrm{X}) \mathrm{n}$ and $\mathrm{M}(\mathrm{OR}) \mathrm{n}$ precursors first reduce the size of surface nanopores and then, when the film thickness exceeds the original pore radius, progressively seal the surface. If molecular-sized pore templates, so-called porogens, could be introduced within a dense, ultrathin sealing layer, their removal would create a corresponding 
ultrathin microporous membrane with controlled pore size and shape. Introduction of organic templates using organosilanes $\mathrm{R}_{\mathrm{x}} \mathrm{SiX}_{4-\mathrm{x}}$ is rather straightforward and has been demonstrated previously. However in this case the condensation reactions position the organic ligands R on the external surface, where they passivate it toward further ALD. Additionally, the coverage of $\mathrm{R}$ groups must be sufficiently low so as to avoid association of multiple R groups, which when removed, would creater larger and more polydisperse pores than individual $\mathrm{R}$ groups. To resolve these problems, we used an organically bridged silsequoxane $(\mathrm{RO})_{3} \mathrm{Si}^{-} \mathrm{R}^{\prime}-\mathrm{Si}(\mathrm{OR})_{3}$ as an ALD precursor. In this case the R' unit, which serves as the pore template, is incorporated uniformly within the developing siloxane framework, avoiding passivation of the surface and reducing template aggregation.

Here as an example, we describe ALD of BTEE (bis(triethoxysilyl)ethane, $\left.\left(\mathrm{C}_{2} \mathrm{H}_{5} \mathrm{O}\right)_{3}-\mathrm{Si}-\mathrm{C}_{2} \mathrm{H}_{4}-\mathrm{Si}-\left(\mathrm{OC}_{2} \mathrm{H}_{5}\right)_{3}\right)$. Following remote plasma exposure to activate the nanoporous substrate, ALD was performed in a home-built reactor according to the following steps: 1) evacuate ALD chamber to a base vacuum of $10^{-6}$ Torr; 2) inject BTEE vapor, causing BTEE molecules to condense with surface $\equiv \mathrm{Si}-\mathrm{OH}$ groups; 3) purge chamber with Ar to remove all non-condensed BTEE and condensation by-products; 4) inject water vapor to hydrolyze the ethoxysilane groups of surface chemisorbed BTEE; 5) purge chamber with Ar to remove residual water vapor and ethanol by-products; 6) repeat steps 2-5 to obtain desired thickness.

Figure 7.1a shows a representative cross-sectional TEM image of the nanoporous supported ALD film prepared by 300 cycles of ALD (each cycle comprising steps 2-5 above) followed by UV/ozone exposure to remove the organic $\mathrm{C} 2$ template. The film is ultra-thin ( $\sim 5-\mathrm{nm}$ thick) and smooth and spans the $\sim 3-\mathrm{nm}$ diameter pores of the underlying support. The somewhat lower electron contrast with respect to silica derives from its sub-nm microporosity (see following discussion) not resolvable in this image. Comparison of the higher magnification images Figure 7.1b (support prior to ALD) and Figure 7.1c (support after ALD) shows that the film is confined to the immediate surface of the support with no evidence of penetration into the nanoporous sublayer. Figure 7.1d shows the electron energy loss spectrum (EELS) of the as-deposited ALD film. Prior to EELS, the sample was cleaned in a plasma oxidizer to remove any carbon contamination on the sample surface as well as epoxy used for cross-sectional sample preparation. The energy loss edges at $104 \mathrm{eV}, 286 \mathrm{eV}$, and $540 \mathrm{eV}$ are attributed to $\mathrm{Si}, \mathrm{C}$, and $\mathrm{O}$, repsectively. The absence of a shoulder edge at $\sim 282 \mathrm{eV}$ indicates that the carbon is mainly $\sigma$-bonded as expected from the bridging ethylene group in the BTEE precursor.14

To demonstrate the efficacy of this approach to form selective membranes, the organic template was removed by 30s of UV/ozone exposure, and the permeance of the film to the series of gases $\mathrm{He}, \mathrm{N}_{2}$, and $\mathrm{SF}_{6}$ was measured at room temperature using standard techniques [23, 39-41]. Figure 7.2 shows the gas permeances and selectivities of the samples after differing numbers of ALD cycles. The original porous support had a $\mathrm{He}$ permeance of $171 \mathrm{cc} / \mathrm{bar}-\mathrm{cm} 2$-min and $\mathrm{He} / \mathrm{N}_{2}$ selectivity and $\mathrm{He} / \mathrm{SF}_{6}$ selectivity of 2.08 and 4.28 , consistent with Knudsen diffusion. With increasing cycle numbers the permeance decreased and, after 100 cycles, the selectivity increased logarithmically. These results are consistent with the requirement to form a defect-free, pore-spanning sealing layer of several nanometer thickness prior to template removal. Due to the thinness of the membrane, after 200 ALD cycles, the He permeance was a very 
remarkable $5.3 \mathrm{cc} / \mathrm{bar}-\mathrm{cm} 2-\mathrm{min}$, and the $\mathrm{He} / \mathrm{N}_{2}$ and $\mathrm{He} / \mathrm{SF}_{6}$ selectivities exceeded $10^{3}$ and $10^{4}$, respectively.

These data indicated that sub-10 nm microporous ALD membane has a narrowly distributed pore size and the pore size can be precisely controlled by using precursors with proper organic ligant as "porogen", manifesting a promising approach for fabricating membranes with both large permeance and selectivities.

Preparation of sub-10 nm microporous silica membrane for $\mathrm{CO}_{2} / \mathrm{N}_{2}$ separation

Microporous membranes prepared by above-mentioned ALD procedures were tested for $\mathrm{CO}_{2} / \mathrm{N}_{2}$ separation. For the membranes prepared with 200 ALD cycles, both $\mathrm{N}_{2}$ permeance and $\mathrm{CO}_{2}$ permeance are $<0.01 \mathrm{MPU}$, which is too low for practical use. For membranes prepared with 100 ALD cycles, the $\mathrm{N}_{2}$ permeance reached 1.5 MPU, indicating that the membrane was not thick enough to eliminate pin-holes. Therefore, membranes prepared with 150 cycles were used.

Design of experiments was used to optimize the experimental conditions including UV treatment duration, processing temperature, precursor exposure time, support quality/handling, plasma activation time and calcination temperature. Table 7.1 and 7.2 summarizes the statistic results thus obtained. It was found that:

1) UV treatment has the highest impact (effect factor $=-1.19$ for permeance and 1.02 for selectivity) on the membrane permeability and selectivity. Longer UV treatment gives better selectivity but reduces $\mathrm{CO}_{2}$ permeability;

2) ALD temperature has a little impact on the results. Higher temperature gives a little better selectivity but reduces $\mathrm{CO}_{2}$ permeability; ALD temperature and UV treatment have a little interplay with each other, probably due to the fact that both of them can somehow contribute to the density of the membrane;

3) ALD precursor/exposure time doesn't have substantial impact on the membrane property, and the impact of ALD carrier gas flow rate on the membrane property is negligible either; The interaction between ALD temperature and the ALD precursor exposure time or the gas flow rate are all negligible.

4) The anodic alumina membrane (AO) support and the manner of handling sample and operating the experiments have a large effect coefficient; therefore a large impact on the membrane quality, indicating that the AO support and the manner for sample handling and experiment operation is a factor that we need to pay attention to.

5) Plasma activation time also has a large impact on the membrane quality, which is another factor that we should optimize to achieve better results.

6) The calcinations temperature doesn't have substantial impact on the membrane permeability but has certain influence on the membrane selectivity.

Fabrication conditions have been optimized according to the statistical result from "Design of experiment", such as using 10 seconds plasma re-activation time and 30 minutes UV post-treatment time. All membranes have the $\mathrm{CO}_{2} / \mathrm{N}_{2}$ selectivities $>5.0$ and the $\mathrm{CO}_{2}$ permeances are all in the range of 0.25-0.35 MPU. However, these are still not sufficient for practical applications in $\mathrm{CO}_{2}$ capture.

Hydrothermal stability of membranes 
To investigate hydrothermal stability of the membrane, three microporous silica samples were treated by water vapor at $95{ }^{\circ} \mathrm{C}$ and $640 \mathrm{mmHg}$ vapor pressure, for 30 seconds then another three and half minutes. The $\mathrm{CO}_{2}$ permeance and the $\mathrm{CO}_{2} / \mathrm{N}_{2}$ selectivity of the membranes thus treated are shown in Figure 7.3. The permeance of the membranes decreased after the hydrothermal treatment. The $\mathrm{CO}_{2} / \mathrm{N}_{2}$ selectivity shows some improvement after short-time hydrothermal treatment but decrease after 4-minutes hydrothermal treatment, indicating a change of membrane property by the hydrothermal treatment.

To improve hydrothermal stability of the membrane, the silica membrane was doped with titanium. Titanium ethoxide was used initially as the precursor for $\mathrm{Ti}$ and mixed with bridged silsesquioxane at volumetric ratios of 1:4 and 1:19. The as-deposited membrane seemed to be dense. No gas permeation could be detected for all the samples, probably due to the fact that Ti- ethoxide has a much higher reactivity than bridged silsesquioxane, which leads to a much faster deposition rate of Ti- precursor than that of the silane precursor. Therefore the as-deposited membrane didn't contain much organic groups that are important for the formation of micro-porosities.

To resolve this issue, less reactive titanium butoxide was used for Ti-doping. ALD was carried out using the $20 \%$ and $5 \%$ mixtures at $180{ }^{\circ} \mathrm{C}$, with exposure/purge time of 1 minute. The total number of ALD cycles for two samples was 150 and 300, respectively. For the samples prepared with $20 \%$ Ti- butoxide, its $\mathrm{CO}_{2}$ permeation rate still tends to be undetectable by standard bubble flow meters. But when Ti-butoxide concentration was reduced to $5 \%$, the sample becomes permeable for $\mathrm{CO}_{2}$ gas. Figure 7.4a,b shows the change in $\mathrm{CO}_{2}$ permeance and $\mathrm{CO}_{2} / \mathrm{N}_{2}$ selectivity for this sample before and after hydrothermal treatments. Both the 150 cycle and 300 cycle samples do not show appreciable change in $\mathrm{CO}_{2} / \mathrm{N}_{2}$ selectivity. The $\mathrm{CO}_{2}$ permeance decreases after initial 4-min hydrothermal treatment but then tends to stabilize, indicating that these Tidoped membranes have better hydrothermal stabilities.

\section{Surface doping with Ag-and Ni- and slight enlargement of pore size}

Since kinetic molecular diameters of $\mathrm{CO}_{2}$ and $\mathrm{N}_{2}$ are so close, based only by size exclusion to achieve great $\mathrm{CO}_{2} / \mathrm{N}_{2}$ separation will be of great challenge. Therefore, the chemistry of the pores must be tuned to facilitate the separation. On the other hand, the pore size of our microporous membrane is close to the $\mathrm{CO}_{2}$ molecular diameter. To achieve greater $\mathrm{CO}_{2}$ permeance, one approach is to slightly increase the pore size of our microporous membrane. Subsequently, we can modify the pore surface chemistry to achieve improved $\mathrm{CO}_{2}$ selectivity.

It was hypothesized surface-bonded amine group could facilitate $\mathrm{CO}_{2}$ transport via surface diffusion. However, amine groups cannot be directly bonded to the pore surface of the microporous ceramic membranes, for example, in a form of $-\mathrm{Si}-\mathrm{NH}_{4}$. Instead, they have to be bonded to the inorganic ceramic surface via bridging organic groups, for example, in the form of $-\mathrm{CH}_{2}-\mathrm{CH}_{2}-\mathrm{NH}_{3}$ but the loose structure of $-\mathrm{CH}_{2}-\mathrm{CH}_{2}$ may lead to the pathway for non-selective $\mathrm{N}_{2}$ permeation. Here, we explore an alternative approach - introducing metallic chemistry to the micropores.

As mentioned in our previous report [41], the angstrom-sized microporosity was generated by removing the bridging organic groups in the membrane deposits and these organic groups functioned as "porogen". The size of these organic groups determined the 
size of the mocropores. Our previous precursor was BTEE $\left((\mathrm{EtO})_{3} \mathrm{Si}_{-} \mathrm{CH}_{2} \mathrm{CH}_{2}-\mathrm{Si}(\mathrm{OEt})_{3}\right)$, where the bridging organic group of $-\mathrm{CH}_{2} \mathrm{CH}_{2}$ - was the porogen group. Here we use two other precursors, with similar structure but a different bridging group. One is $\left((\mathrm{EtO})_{3} \mathrm{Si}\right.$ $\left.\mathrm{CH}_{2}-\mathrm{NH}-\mathrm{CH}_{2}-\mathrm{Si}(\mathrm{OEt})_{3}\right)$, where the porogen is $-\mathrm{CH}_{2}-\mathrm{NH}-\mathrm{CH}_{2-}$; the other one is $\left((\mathrm{EtO})_{3} \mathrm{Si}-\mathrm{C}_{6} \mathrm{H}_{4} \mathrm{C}_{6} \mathrm{H}_{4}-\mathrm{Si}(\mathrm{OEt})_{3}\right)$, where the porogen is the double $\mathrm{C}_{6}$ ring of $-\mathrm{C}_{6} \mathrm{H}_{4} \mathrm{C}_{6} \mathrm{H}_{4}-$. Both porogens are larger than that in BTEE.

Ni- was introduced to the micropores using nickel nitrate. Ti-doped membrane was soaked in $0.5 \mathrm{M} \mathrm{Ni}\left(\mathrm{NO}_{3}\right)_{2}$ solution for two hours and dried in air on filter paper. The membrane was subsequently heat-treated in vacuum oven at $50{ }^{\circ} \mathrm{C}$ for another 30 minutes, followed by soaking in $0.01 \mathrm{M} \mathrm{Na}_{2} \mathrm{CO}_{3}$ solution. The membrane was then rinsed with DI water thoroughly and treated in vacuum oven again at $50{ }^{\circ} \mathrm{C}$ for 30 minutes. The above process was repeated for 4 times to achieve sufficient Ni loading.

Table 7.3 shows the permeation results of the membranes prepared using the above two precursors, after a 300 ALD cycles, and 30 minutes UV treatment, and compared it to the previous sample prepared using BTEE. For the sample using precursor $(\mathrm{EtO})_{3} \mathrm{Si}-\mathrm{C}_{6} \mathrm{H}_{4} \mathrm{C}_{6} \mathrm{H}_{4}-\mathrm{Si}(\mathrm{OEt})_{3}$, the membrane's permeance was extremely high $(>20$ $\mathrm{sccm} /$ bar $)$ but the $\mathrm{CO}_{2} / \mathrm{N}_{2}$ selectivity was very poor $(<3.0)$, which was essentially the performance of porous support. We discovered later that the vapor pressure for this precursor was too low for vapor-phase thin-film deposition.

For the sample using precursor $(\mathrm{EtO})_{3} \mathrm{Si}-\mathrm{CH}_{2}-\mathrm{NH}-\mathrm{CH}_{2}-\mathrm{Si}(\mathrm{OEt})_{3}$, the $\mathrm{CO}_{2}$ permeance was $0.18 \mathrm{sccm} /$ bar before $\mathrm{Ni}$ - modification, higher than that of $\mathrm{BTEE}$ membrane, and its original $\mathrm{CO}_{2} / \mathrm{N}_{2}$ selectivity was 4.3 . After $\mathrm{Ni}$ - modification, the membrane's permeance was slightly reduced to from 0.18 to $0.11 \mathrm{sccm} / \mathrm{bar}$, and the $\mathrm{CO}_{2} / \mathrm{N}_{2}$ selectivity was improved to 21 . In Table 7.3, the results suggest that $\mathrm{CO}_{2}$ permeance increases using precursors with a larger porogen.

\section{Effect of elevated temperatures}

The impact of temperature on the membranes performance has been investigated. Figure 7.5 shows the $\mathrm{CO}_{2}$ permeace vs. the temperature (the dotted line). At room temperature, the membrane's $\mathrm{CO}_{2}$ permeance was about $0.11 \mathrm{MPU}$. The $\mathrm{CO}_{2}$ permeance increased while temperature increased but reduced at $250{ }^{\circ} \mathrm{C}$. Increasing temperature will accelerate gas transport process, either through Knudsen diffusion or surface diffusion. We believe that the dominating mechanism for $\mathrm{CO}_{2}$ transport through our Ni-doped microporous ALD membrane is surface diffusion facilitated by $\mathrm{CO}_{2}$ adsorption /desorption process on $\mathrm{Ni}$ - species. The surface exchange rate also increases while temperature increases, resulting in the increase in $\mathrm{CO}_{2}$ permeance. However, this surface exchange rate is limited by the amount of $\mathrm{Ni}$-species that are available at the pore surface, and we believe that the decreased $\mathrm{CO}_{2}$ permeance at $250{ }^{\circ} \mathrm{C}$ can be attributed to the surface re-arrangement of the available Ni- atoms at higher temperatures.

For the membrane treated with $\mathrm{Ni}$, the $\mathrm{Ni}$ - species should stay on the pore surface at the beginning, but as temperature increases, since $\mathrm{NiO}$ - is a dissolvable component in $\mathrm{SiO}_{2}$ network at elevated temperatures, they will slowly diffuse into the $\mathrm{SiO}_{2}$ network and no longer be available on the pore surface to contribute to the $\mathrm{CO}_{2}$ surface diffusion. This probably is the reason that the $\mathrm{CO}_{2}$ permeance reduces at $250{ }^{\circ} \mathrm{C}$.

The solid line in Figure 7.5 shows the $\mathrm{CO}_{2} / \mathrm{N}_{2}$ selectivity vs. the temperature. The selectivity increases as temperature increases but reduces at around $250{ }^{\circ} \mathrm{C}$. Again, this is 
because that the surface diffusion of $\mathrm{CO}_{2}$ becomes significantly faster at higher temperature, while the transport of $\mathrm{N}_{2}$ through the micropores is mainly by Knudsen diffusion, which doesn't increase as fast as the surface diffusion process. Therefore, as temperature increase, the transport of both $\mathrm{N}_{2}$ and $\mathrm{CO}_{2}$ increase, but the transport of $\mathrm{CO}_{2}$ increases faster than $\mathrm{N}_{2}$ does. However, at $250{ }^{\circ} \mathrm{C}$, the amount of surface Ni- species was less due to its dissolution into the silica network, therefore the transport of $\mathrm{CO}_{2}$ slows down and the $\mathrm{CO}_{2} / \mathrm{N}_{2}$ selectivity decreases drastically.

To compare the properties of the samples went through various measurement temperatures, their permeances were re-measured at room temperature and the results are shown in Figure 7.6. It is clear here that after the membranes went through high temperatures, their room-temperature performance were decreased. The higher the temperature, the more its performance decreases. This confirms our assumption that the amount of available Ni-species on the pore surface was reduced due to their dissolution into the $\mathrm{SiO}_{2}$ network.

\section{Ag-doped and dual-Ni-doped membranes}

To stabilize membrane performance at elevated temperatures, two approaches were used: 1) Ag-, instead of $\mathrm{Ni}$-, was introduced to the pores of our microporous membrane; 2) Ni- was doped again after the Ni-doped membrane was treated at $250{ }^{\circ} \mathrm{C}$. Good membrane performance and high thermal stability were achieved in both approaches.

For Ag doped membrane, microporous silica ALD membrane was prepared using $(\mathrm{EtO})_{3} \mathrm{Si}-\mathrm{CH}_{2}-\mathrm{NH}-\mathrm{CH}_{2}-\mathrm{Si}(\mathrm{OEt})_{3}$ as the precursor. The membrane was soaked in $0.5 \mathrm{M}$ $\mathrm{Ag}\left(\mathrm{NO}_{3}\right)$ solution for $2 \mathrm{hrs}$ and dried in air on filter paper followed by heat treatment in vacuum oven at $50{ }^{\circ} \mathrm{C}$ for another 30 minutes. Finally, the membrane was UV-treated for 30 minutes.

Figure 7.7a shows the $\mathrm{CO}_{2}$ permeance of the Ag-doped membrane measured at various temperatures. The Ag-doped membrane was compared to the Ni-doped membrane (Figure 7.7b). Like the Ni-doped membrane, the Ag-doped membrane shows much better $\mathrm{CO}_{2} / \mathrm{N}_{2}$ selectivity than the undoped membrane. Compared with the Nidoped microporous membrane, the Ag-doped membrane has a slightly lower $\mathrm{CO}_{2}$ permeance at lower temperatures, e.g. $<150{ }^{\circ} \mathrm{C}$. But, at temperatures higher than $150{ }^{\circ} \mathrm{C}$, the Ag-doped membrane has a better performance than Ni-doped membrane. In addition, its $\mathrm{CO}_{2}$ permeance keeps increasing as temperature increases and there is no "dropping" in performance at $250{ }^{\circ} \mathrm{C}$ as observed in the Ni-doped membrane (Figure 7.7b), indicating that the Ag-doped membrane has a better thermal stability than the Ni-doped membrane.

Both $\mathrm{Ni}$ - and $\mathrm{Ag}$ - have strong affinity to $\mathrm{CO}_{2}$ which is believed to be the mechanism for increased $\mathrm{CO}_{2}$ transport in our $\mathrm{Ni}$ - or Ag- surface-doped microporous ALD membrane. The binary or ternary systems comprising $\mathrm{SiO}_{2}$ and $\mathrm{NiO}$ have been studied in some literatures and the solubility of $\mathrm{NiO}$ in $\mathrm{SiO}_{2}$ has been indicated in these literatures [43]. In contrast, $\mathrm{AgO}$ has much smaller solubility in a silica. This is probably the reason that the surface Ag- species on the microporous ALD silica has a better thermal stability than the Ni- species.

On the other hand, dual-Ni-doped was prepared by the following procedure: Nidoped membrane was first prepared by approach as described before using $(\mathrm{EtO})_{3} \mathrm{Si}_{-} \mathrm{CH}_{2}-$ 
$\mathrm{NH}-\mathrm{CH}_{2}-\mathrm{Si}(\mathrm{OEt})_{3}$ as the precursor. The membrane was treated at $250{ }^{\circ} \mathrm{C}$ for $2 \mathrm{hrs}$ and subsequently was doped again with $\mathrm{Ni}$ - by the same process. Figure 7.7c shows the $\mathrm{CO}_{2}$ permeace and $\mathrm{CO}_{2} / \mathrm{N}_{2}$ selectivity of the dual-Ni-doped membrane measured at various temperatures. Compared to single-doped $\mathrm{Ni}$ - membrane, its overall $\mathrm{CO}_{2}$ permeance was reduced, probably due to the shrinkage of pore size during the second Ni-doping step. However, its $\mathrm{CO}_{2} / \mathrm{N}_{2}$ selectivity is better at elevated temperatures. In addition, there was an increase instead of decrease in performance at $250{ }^{\circ} \mathrm{C}$, suggesting that the thermal stability of Ni- doped microporous silica membrane has been improved by dual-doping process. As for the possible mechanism of this phenomenon, we believe that after the first Ni- doping and a subsequent $250{ }^{\circ} \mathrm{C}$ treatment, the membrane already contains some $\mathrm{Ni}$ - inside its silica network. The dissolution of surface $\mathrm{Ni}$ - species prepared by the second Ni-doping step was retarded. As a result, the surface Ni- species processed by the second doping process was more stable and the membrane performance was improved.

Among the three samples shown in Figure 7.7, Ag-doped microporous membrane has the best $\mathrm{CO}_{2}$ permeance and the dual-Ni-doped sample has the best $\mathrm{CO}_{2} / \mathrm{N}_{2}$ selectivity at $150-250{ }^{\circ} \mathrm{C}$. Both samples have stabilized performance at $250{ }^{\circ} \mathrm{C}$.

\section{The effect of water vapor on membrane performance}

The humidified feed (50\% R.H.) comprising $10 \% \mathrm{CO}_{2}$ in $\mathrm{N}_{2}$ at ambient pressure (1 atm) was used to simulate the flue gas. Both the Ag-doped and the dual-Ni-doped membranes were treated by this simulated flue gas (SFG) in a pyrex tube at $80{ }^{\circ} \mathrm{C}$ for 72 hours.

Figure 7.8a shows the performance of dual-Ni-doped membrane before and after the SFG treatment and Figure 7.8b shows the performance of Ag-doped membrane. The dotted lines represent data for original membrane, and the solid lines represent data for sample after SFG treatment. For both membranes, after SFG treatment, their $\mathrm{CO}_{2}$ permeance was reduced by about $25 \%$. Their $\mathrm{CO}_{2} / \mathrm{N}_{2}$ selectivities showed slightly increase for low temperature measurements $\left(25-100{ }^{\circ} \mathrm{C}\right)$ and decrease for higher temperature measurement $\left(150-250{ }^{\circ} \mathrm{C}\right)$. In general, the membrane's performance was slightly reduced after SFG treatment but the change was acceptable, demonstrating that these membranes have a good humidity resistance.

\section{The effect of $\mathrm{SO}_{2}$ on membrane performance}

The effect of $\mathrm{SO}_{2}$ was measured with the previous SFG containing $10 \mathrm{ppm} \mathrm{SO}_{2}$. Both the Ag-doped and the dual-Ni-doped membranes were treated with the humidified $\mathrm{SO}_{2}$-containing SFG at $80{ }^{\circ} \mathrm{C}$ for $60 \mathrm{hrs}$.

Figure 7.9a shows the performance of dual-Ni-doped membrane before and after the SFG treatment and Figure 7.9b shows the performance of Ag-doped membrane. The dotted lines represent data for original membrane, and the solid lines represent data for samples after $\mathrm{SO}_{2}$-SFG treatment. For dual-Ni-doped membranes, after $\mathrm{SO}_{2}$ containing SFG treatment, the $\mathrm{CO}_{2}$ permeance was reduced by about $45 \%$, and the $\mathrm{CO}_{2} / \mathrm{N}_{2}$ selectivity was reduced by about $25 \%$. For Ag-doped membrane after $\mathrm{SO}_{2}-\mathrm{SFG}$ treatment, both of its $\mathrm{CO}_{2} / \mathrm{N}_{2}$ selectivity and $\mathrm{CO}_{2}$ permeance were reduced drastically. In addition, both permeance and selectivity didn't increase much as testing temperature increased, indicating that Ag- species on pore surface was not functioning as the $\mathrm{CO}_{2}$ 
carrier any more. In general, the dual-Ni-doped membrane has moderate $\mathrm{SO}_{2}$ resistance but the Ag- doped membrane seems to have a poor $\mathrm{SO}_{2}$ resistance.

\section{Summary}

In summary, both Ag-doped and dual-Ni-doped microporous silica membranes have good $\mathrm{CO}_{2}$ permeance and $\mathrm{CO}_{2} / \mathrm{N}_{2}$ selectivity at moderately elevated temperatures, as well as good thermal stability and humidity resistance. The sulfur-resistance for Agdoped membrane was apparently not sufficient but the sulfur-resistance for dual-Nidoped membrane was considerably better.

So far our experimental data have demonstrated an effective strategy of fabricating high-performance membrane for $\mathrm{CO}_{2} / \mathrm{N}_{2}$ separation: fabricating ultra-thin microporous membrane via ALD process and then modifying the pore surface with small metallic ions that are thermally stable on silica surface and has strong $\mathrm{CO}_{2}$ affinities to enhance $\mathrm{CO}_{2}$ transport. The advantages of this ALD approach can be summarized as: 1) ALD is a self-limiting deposition process that can economically deposit a thin film over a large area with superb film thickness homogeneity and high efficiency of precursor usage, better than conventional CVD or PVD; 2) the precise layer-by-layer deposition mode of ALD process allows us to easily fabricate nm-thick pin-hole free membranes, and this "ultra-thin" nature makes it possible to achieve large $\mathrm{CO}_{2}$ flux through the membrane; 3 ) the angstrom-sized microporosity templated by organic groups in this ALD process are narrowly distributed and the pore size can be controlled by using specific organic groups, e.g. $-\mathrm{C}_{2} \mathrm{H}_{2}-\mathrm{NH}-\mathrm{C}_{2} \mathrm{H}_{2}-$. This narrowly distributed and controllable pore size is essential for achieving high separation ratios; 4) the pore surface chemistry can be easily tuned with metallic ions to enhance its selective transport, e.g. Ni- or Ag- addition to the pore surface to enhance the $\mathrm{CO}_{2}$ transport.

Nevertheless, more works can be done in future to further develop this technology to improve sulfur-resistivity and overall performance of the membrane (e.g. permeance and selectivity). With these in mind, other additives beside $\mathrm{Ni}$ - should be studied, doping during ALD process can be improved, and the range of ALD materials can be broadened including such as non-silica materials.

\section{8 - Conclusion}

Electricity generation using fossil fuel is responsible for a large fraction of carbon dioxide $\left(\mathrm{CO}_{2}\right)$ emissions worldwide. Increased concentration of carbon dioxide in the atmosphere results in global warming. One remedy is to capture the $\mathrm{CO}_{2}$ from flue gas and subsequently sequestrate it. The task of post-combustion $\mathrm{CO}_{2}$ capture exhibits great technical challenges due to high volume of gases to be treated and a low driving force of $\mathrm{CO}_{2}\left(\mathrm{CO}_{2}\right.$ concentration 10-15 wt \%) for either absorption or membrane-based separation, in addition to other potential complications such as corrosive trace $\mathrm{SO}_{2}$ in the flue stream. $\mathrm{CO}_{2}$ absorption by liquid amine is a mature technology but it is too costly to operate absorption columns for a large-scale $\mathrm{CO}_{2}$ separation process. For membrane, the cost of energy for providing sufficient driving force needs to be considered. There are two ways to provide sufficient driving force for membrane-based gas separation: one is compressing flue gas at the retentate side, the other is applying vacuum at the permeate side. The cost of energy is apparently too high for compressing flue gas at the retentate 
side due to energy lost in compressing majority inert gas $\mathrm{N}_{2}(\sim 90 \%)$, which does not contribute to $\mathrm{CO}_{2}$ permeation. Applying vacuum at the permeate side in our original proposal is a more economical approach if the membrane has high $\mathrm{CO}_{2}$ selectivity. In addition, vacuum generated from low-grade steam in the power plant could be used as vacuum source. Theoretical calculation based on a perfect $\mathrm{CO}_{2}$ selective membrane and vacuum provided fully from vacuum pumps shows that $10-13 \%$ increase in total energy output may be needed for $\mathrm{CO}_{2}$ separation and recompression for transportation. This shows great advantage compared to current amine-based capture system which is approximately $15-30 \%$ total power output.

The required membrane performance for the application is estimated $\mathrm{CO}_{2} / \mathrm{N}_{2}$ selectivity 100 and $\mathrm{CO}_{2}$ permeance $1 \times 10^{-3} \mathrm{~cm}^{3} / \mathrm{cm}^{2}-\mathrm{s}-\mathrm{cmHg}\left(\right.$ or $4.6 \mathrm{~cm}^{3} / \mathrm{cm}^{2}$-min-atm or $7500 \mathrm{~m}^{3} / \mathrm{m}^{2}-\mathrm{s}-\mathrm{Pa}$ ). The candidate membrane also needs to have good durability against corrosive trace components in common flue gas, such as $\mathrm{SO}_{2}$. So far, none of commercial available membranes can meet this stringent target. The goal of this project is to develop a new class of membrane that can meet the requirements. We commence with the development of three types of porous inorganic membranes: pure, amine-derivatized and nickel-doped sol-gel silica membranes deposited on commercial ceramic supports. An extensive synthetic and permeation test study was carried out in order to optimize membrane $\mathrm{CO}_{2}$ permeance, $\mathrm{CO}_{2}: \mathrm{N}_{2}$ separation factor and resistance against densification. Pure silica membranes prepared under optimized conditions exhibited an attractive combination of $\mathrm{CO}_{2}$ permeance of 2.0 MPU $\left(1 \mathrm{MPU}=1 \mathrm{~cm}^{3}(\mathrm{STP}) \cdot \mathrm{cm}^{-2} \cdot \mathrm{min}^{-1} \cdot \mathrm{atm}^{-1}\right)$ and $\mathrm{CO}_{2}: \mathrm{N}_{2}$ separation factor of 80 with a dry 10:90 (v/v) $\mathrm{CO}_{2}: \mathrm{N}_{2}$ feed at $25^{\circ} \mathrm{C}$. However, these membranes exhibited flux decline phenomena under prolonged exposure to humidified feeds, especially in the presence of trace $\mathrm{SO}_{2}$ gas in the feed. Doping the membranes with nickel (II) nitrate salt was effective in retarding densification, as manifested by combined higher permeance and higher separation factor of the doped membrane compared to the pure (undoped) silica membrane after 168 hours exposure to simulated flue gas conditions. Despite better performance compared to commercial membranes, the new membranes still fall short of project target. In order to improve both permeance and selectivity, we introduce a thin-film deposition technique referred to plasma-assisted atomic layer deposition (PA-ALD). PA-ALD has potential to increase both permeance and selectivity simultaneously by reducing membrane thickness and eliminating defects with atomic-level precision of deposition. This monolayer-bymonolayer deposition technique was indeed capable of depositing an ultra thin $2.5-5 \mathrm{~nm}$ defect-free layer on top of a mesoporous/microporous support, more than an order of magnitude reduction from the previous 100-200 nm thickness. Various strategies were employed to enhance membrane performance, such as utilizing larger porogens to enlarge pore size for higher permeance, incorporation of titanium to stabilize hydrothermal performance, doping of small metal particles with $\mathrm{CO}_{2}$ affinity to enhance $\mathrm{CO}_{2}$ selectivity. An extensive parametric study was also performed to optimize various process factors. Both Ag-doped and dual-Ni-doped microporous silica membranes deposited by the PA-ALD method had good $\mathrm{CO}_{2} / \mathrm{N}_{2}$ selectivities (40-60) at moderately elevated temperatures $\left(200-250^{\circ} \mathrm{C}\right)$, as well as good thermal stability and humidity resistance. Sulfur-resistance for Ag-doped membrane was apparently not sufficient but the dual-Ni-doped membrane had moderate sulfur-resistance. With significant reduction in membrane thickness and subsequent performance enhancing strategies, PA-ALD did 
not make significant improvement as expected. The best reported $\mathrm{CO}_{2}$ permeance was approaching $2 \mathrm{MPU}$ at $250^{\circ} \mathrm{C}$. The $\mathrm{CO}_{2}$ permeance shows temperature-activated transport and both permeance and selectivity increase with temperature. Despite progress made by implementing the PA-ALD membrane processing technique, the membranes still fall short of the project goal.

\section{Recommendations}

PA-ALD was introduced to improve permeance by drastically reducing membrane thickness. Reducing thickness, it did, from $100-200 \mathrm{~nm}$ to $2.5-5 \mathrm{~nm}$, more than an order of magnitude reduction. However, permeance did not increase by the same order of magnitude. In fact, permeance remained relatively the same. Even though PAALD method used the same chemistry as pure silica membrane produced by dip coating, the fact that PA-ALD operates in vapor phase changes the resulting structure, possibly significantly reducing porosity due to differential vapor pressure of various components. Effort to choose slow reacting component proved to be a step in the right direction. Future work in this area to significantly increase porosity in the ultra thin membrane deposited by PA-ALD will be critical to the success of high permeance porous membrane.

In this study, various metals were used to improve membrane performance, e.g. $\mathrm{Ni}$ and $\mathrm{Ti}$ for membrane hydrothermal stability, Ag for enhancing selectivity and they proved to be beneficial. Continuous improvement in the area of metal doping will be an asset to membrane development.

Time and again membrane performance was significantly impacted by the quality of the underlying membrane support, sometimes to the benefit (e.g. smooth Anodisk) but most likely to the detriment such as cracks and pinholes. As the requirements of membrane performance becomes higher, thus demanding thinner membrane for higher permeance, the requirements for higher quality becomes more urgent. Any improvement in membrane support will directly benefit overall membrane development.

Through this study, it became obvious that it is difficult to control pore size with the presence of water vapor. When the separation mechanism is by size exclusion, it is unreliable to attain exact control size as water vapor is adsorbed onto the pore surface. The amount of water adsorbed, thus the thickness of the water layer depends on the water vapor pressure. The application of size exclusion membrane is most suitable for situations with low or no water present or for elevated temperature where again, with little to no water present.

Continuous improvement in the area of metal doping, PA-ALD processing, and quality of the underlying membrane support could potentially attain overall improvement of membrane performance to meet the requirements for industrial applications. 


\section{9 - Reference}

1. R. Baker, Future directions of membrane gas separation technology, Ind. Eng. Chem. Res. 41 (2002) 1393.

2. B.D. Freeman, Basis of permeability/selectivity tradeoff relations in polymeric gas separation membranes, Macromolecules 32 (1999) 375.

3. W.J. Koros, R. Mahajan, Pushing the limits on possibilities for large scale gas separations: Which strategies? J. Membr. Sci. 175 (2000) 181.

4. R. Bredesen, K. Jordal, O. Bolland, High-temperature membranes in power generation with $\mathrm{CO}_{2}$ capture, Chem. Eng. Proc. 43 (2004) 1129.

5. R. Bounaceur, N. Lape, D. Roizard, C. Vallieres, E. Favre, Membrane processes for post-combustion carbon dioxide capture: A parametric study, Energy 31 (2006) 2220 .

6. E. Favre, Carbon dioxide recovery from post-combustion processes: Can gas permeation membranes compete with absorption? J. Membr. Sci. 294 (2007) 50.

7. C.E. Powell, G.G. Qiao, Polymeric $\mathrm{CO}_{2} / \mathrm{N}_{2}$ gas separation membranes for the capture of carbon dioxide from power plant flue gases, J. Membr. Sci. 279 (2006) 1.

8. P.K. Gantzel, U. Merten, Gas separations with high flux cellulose acetate membranes, Ind. Eng. Chem. Proc. Des. Dev. 9 (1970) 331.

9. Y.S. Lin, I. Kumakiri, B.N. Nair, H. Alsyouri, Microporous inorganic membranes, Separ. Purif. Methods, 31 (2002) 229.

10. K. Kusakabe, T. Kuroda, S. Morooka, Separation of carbon dioxide from nitrogen using ion-exchanged faujasite-type zeolite membranes formed on porous support tubes, J. Membr. Sci. 148 (1998) 13.

11. H.B. Park, Y.K. Kim, J.M. Lee, S.Y. Lee, Y.M. Lee, Relationship between chemical structure of aromatic polyimides and gas permeation properties of their carbon molecular sieve membranes, J. Membr. Sci. 229 (2004) 117.

12. M. Noack, P. Kölsch, R. Schäfer, P. Toussaint, Jürgen Caro, Molecular sieve membranes for industrial applications: Problems, Progress, Solutions, Chem. Eng. Technol. 25 (2002) 221.

13. H. Verweij, Y.S. Lin, J. Dong, Microporous silica and zeolite membranes for hydrogen purification, MRS Bull. 31 (2006) 756.

14. Y. Gu, S.T. Oyama, High molecular permeance in a poreless ceramic membrane, Adv. Mater. 19 (2007) 1636.

15. C.Y. Tsai, S.Y. Tam, Y. Lu, C.J. Brinker, Dual-layer asymmetric microporous silica membranes, J. Membr. Sci. 169 (2000) 255.

16. Y. Lu, G. Cao, R.P. Kale, S. Prabakar, G.P. López, C.J. Brinker, Microporous silica prepared by organic templating: Relationship between the molecular template and pore structure, Chem. Mater. 11 (1999) 1223.

17. G. Xomeritakis, S. Naik, C.M. Braunbarth, C.J. Cornelius, R. Pardey, C.J. Brinker, Organic-templated silica membranes I. Gas and vapor transport properties, J. Membr. Sci. 215 (2003) 225.

18. J.H. Moon, H. Ahn, S.H. Hyun, C.H. Lee, Separation characteristics of tetrapropylammonium bromide templating silica/alumina composite membrane in $\mathrm{CO}_{2} / \mathrm{N}_{2}$, $\mathrm{CO}_{2} / \mathrm{H}_{2}$ and $\mathrm{CH}_{4} / \mathrm{H}_{2}$ systems, Korean J. Chem. Eng. 21 (2004) 477. 
19. J.H. Moon, Y.J. Park, M.B. Kim, S.H. Hyun, C.H. Lee, Permeation and separation of a carbon dioxide/nitrogen mixture in a methyltriethoxysilane templation silica/ $\alpha$ alumina composite membrane, J. Membr. Sci. 250 (2005) 195.

20. G. Xomeritakis, C.Y. Tsai, C.J. Brinker, Microporous sol-gel derived aminosilicate membrane for enhanced carbon dioxide separation, Separ. Purif. Technol. 42 (2005) 249.

21. B.A. McCool, W.J. DeSisto, Amino-functionalized silica membranes for enhanced carbon dioxide permeation, Adv. Funct. Mater. 15 (2005) 1635.

22. T.A. Peters, J. Fontalvo, M.A.G. Vorstman, N.E. Benes, R.A. van Dam, Z.A.E.P. Vroon, E.L.J. van Soest-Vercammen, J.T.F. Keurentjes, Hollow fibre microporous silica membranes for gas separation and pervaporation. Synthesis, performance and stability, J. Membr. Sci. 248 (2005) 73.

23. G. Xomeritakis, N.G. Liu, Z. Chen, Y.B. Jiang, R. Köhn, P.E. Johnson, C.Y. Tsai, P.B. Shah, S. Khalil, S. Singh, C.J. Brinker, Anodic alumina supported dual-layer microporous silica membranes, J. Membr. Sci. 287 (2007) 157.

24. R.M. de Vos, H. Verweij, Improved performance of silica membranes for gas separation, J. Membr. Sci. 143 (1998) 37.

25. C.J. Brinker, R. Sehgal, S.L. Hietala, R. Deshpande, D.M. Smith, D. Loy, C.S. Ashley, Sol-gel strategies for controlled porosity inorganic materials, J. Membr. Sci. 94 (1994) 85.

26. H. Fan, C. Hartshorn, T. Buchheit, D. Tallant, R. Assink, R. Simpson, D.J. Kissel, D.J. Lacks, S. Torquato, C.J. Brinker, Modulus-density scaling behaviour and framework architecture of nanoporous self-assembled silicas, Nature Mater. 6 (2007), 418.

27. M. Kanezashi, M. Asaeda, Stability of $\mathrm{H}_{2}$-permselective silica membranes in steam at high temperature, J. Chem. Eng. Japan 38 (2005) 908.

28. M. Kanezashi, T. Fujita, M. Asaeda, Nickel-doped silica membranes for separation of helium from organic gas mixtures, Separ. Sci. Technol. 40 (2005) 225.

29. M. Kanezashi, M. Asaeda, Hydrogen permeation characteristics and stability of Nidoped silica membranes in steam at high temperature, J. Membr. Sci. 271 (2006) 86.

30. Y.S. Lin, C.H. Chang, R. Gopalan, Improvement of thermal stability of porous nano structured ceramic membranes, Ind. Eng. Chem. Res. 33 (1994) 860.

31. G.P. Fotou, Y.S. Lin, S.E. Pratsinis, Hydrothermal stability of pure and modified microporous silica membranes, J. Mater. Sci. 30 (1995) 2803.

32. Y.B. Jiang, N. Liu, H. Gerung, J.L. Cecchi, C.J. Brinker, Nanometer-thick conformal pore sealing of self-assembled mesoporous silica by plasma-assisted atomic layer deposition, J. Am. Chem. Soc. 128 (2006) 11018.

33. Y.B. Jiang, G. Xomeritakis, Z. Chen, D. Dunphy, D.J. Kissel, J.L. Cecchi, C.J. Brinker, Sub-10 nm thick microporous membranes made by plasma-defined atomic layer deposition of a bridged silsesquioxane precursor, J. Am. Chem. Soc. 129 (2007) 15446.

34. Carbon Capture and Sequestration Systems Analysis Guidelines, US Department of Energy, Office of Fossil Energy, National Energy Technology Laboratory, April 2005.

35. Evaluation of Innovative Fossil Fuel Power Plants with $\mathrm{CO}_{2}$ Removal, EPRI, 2000. 
36. Updated Cost and Performance Estimates for Fossil Fuel Power Plants with $\mathrm{CO}_{2}$ Removal, interim report, EPRI, 2002.

37. David J., Economic Evaluation of Leading Technology Options for Sequestration of Carbon Dioxide, Thesis, MIT, 2000.

38. Rubin et al. Energy Policy, 35 (2007) 4444-4454

39. Y.-B. Jiang, J.L. Cecchi, and C.J. Brinker, Method of making dense, conformal, ultrathin cap layers for nanoporous low-k ILD by plasma-assisted atomic layer deposition, US patent application no. 20070190777.

40. Y.-B. Jiang, C.J. Brinker and J.L. Cecchi, Ultra-thin Microporous/Hybrid Membranes Made by successive surface activation and reaction (ALD, provisional patent: TA 2007 "SD-10704/S-112596", also UNM-828 PRO.

41. Y.-B. Jiang et al., Sub-10nm Thick Microporous Membranes Made by PlasmaDefined Atomic Layer Deposition of a Bridged Silsesquioxane Precursor, J. Am. Chem. Soc. Comm. 129 (2007) 15446-15447

42. G. K. Xomeritakis, Y-B Jiang, C.-Y. A. Tsai, J. Zhang, C.J. Brinker, "Novel DualFunctional Membrane for $\mathrm{CO}_{2}$ Capture from Fossil Fuel Power Plants", $7^{\text {th }}$ Annual Conference on Carbon Capture \& Sequestration, May 5-8, Pittsburg PA (2008)

43. C. Alejandro; R. Antonio; S. Rangel; R. dan; R. Vargas ; "The solubility and activity determination of $\mathrm{NiO}$ in the $\mathrm{SiO}_{2}-\mathrm{NiO}-\mathrm{FeO}$ system", Journal of noncrystalline solids v 354, no30, pp. 3533-3539, 2008

\section{0 - Appendix Publications resulted from this project}

[1] G. Xomeritakis, C.-Y. Tsai, Y.B. Jiang, C.J. Brinker, "Tubular Ceramic-Supported Sol-Gel Silica-Based Membranes for Flue Gas Carbon Dioxide Capture and Sequestration", J. Memb. Sci., 341 (2009) 30-36

[2] G. K. Xomeritakis, Y-B Jiang, C.-Y. A. Tsai, J. Zhang, C.J. Brinker, "Novel DualFunctional Membrane for $\mathrm{CO}_{2}$ Capture from Fossil Fuel Power Plants", $7^{\text {th }}$ Annual Conference on Carbon Capture \& Sequestration, May 5-8, Pittsburg PA (2008)

[3] G. Xomeritakis, N.G. Liu, Z. Chen, Y.-B. Jiang, R. Kohn, P.E. Johnson, C.-Y. Tsai, P.B. Shah, S. Khalil, S. Singh, C.J. Brinker, "Anodic Alumina Supported Dual-Layer Microporous Silica Membranes”, J. Memb. Sci., 287, (2007) 157-161

[4] G. Xomeritakis, C.-Y. Tsai, C. Jeffrey Brinker, "Microporous Sol-Gel Derived Aminosilicate Membrane for Enhanced Carbon Dioxide Separation", Separation and Purification Technology, 42(3) (2005) 249-257

[5] Y.-B. Jiang et al., Sub-10nm Thick Microporous Membranes Made by PlasmaDefined Atomic Layer Deposition of a Bridged Silsesquioxane Precursor, J. Am. Chem. Soc. Comm. 129 (2007) 15446-15447

\section{Acknowledgements}

We are grateful to Mr. José Figueroa and other members of NETL's staff for useful technical discussions during the course of this project. Sandia is a multiprogram laboratory operated by Sandia Corporation, a Lockheed-Martin Company, for the United States Department of Energy's National Nuclear Security Administration under Contract DE-AC04-94AL85000. 


\section{Graphical Materials List(s)}

Table 3.1 Typical amine-silica and pure silica sol recipes used for membrane deposition in this study.

Table 3.2 $\mathrm{CO}_{2}: \mathrm{N}_{2}$ separation performance at $25^{\circ} \mathrm{C}$ of fresh tubular pure silica membranes prepared by recipes $\mathrm{Si}-1$ and $\mathrm{Si}-2$.

Table 3.3 $\mathrm{CO}_{2}: \mathrm{N}_{2}$ separation performance at $25^{\circ} \mathrm{C}$ of fresh tubular $\mathrm{Ni}$-doped silica membranes prepared by a modified $\mathrm{Si}-2$ recipe.

Table 6.1 An example of cost estimate for a PC power plant with a membrane-based $\mathrm{CO}_{2}$ removal system (Case 3), compared to a $\mathrm{PC}$ power plant without $\mathrm{CO}_{2}$ capture (Case 1) and to a $\mathrm{PC}$ power plant with $\mathrm{MEA} \mathrm{CO}_{2}$ removal system (Case 2).

Table 7.1 Fractional Factorial Fit: $\mathrm{CO}_{2}$ permeance versus ALD temp, ALD exp, UV

Table 7.2 Fractional Factorial Fit: $\mathrm{CO}_{2} / \mathrm{N}_{2}$ selectivity versus ALD temp, ALD exp, UV

Table 7.3 Gas permeance of membranes prepared with precursors with various "porogens"

Fig. 3.1 Mixed gas separation performance at $22^{\circ} \mathrm{C}$ of a tubular aminosilica membrane prepared with recipe aSi-1.

Fig. 3.2 Mixed gas separation performance at $25^{\circ} \mathrm{C}$ of a tubular aminosilica membrane prepared with recipe aSi-2.

Fig. 3.3 Mixed gas separation performance at $22^{\circ} \mathrm{C}$ of a Anodisk-supported aminosilica membrane prepared with recipe aSi-3.

Fig. 3.4 Molecular sieving behavior of membrane M8 in Table 2 prepared according to ref. [20].

Fig. 3.5 Mixed gas separation performance at $25-100^{\circ} \mathrm{C}$ of a tubular silica membrane prepared with recipe $\mathrm{Si}-2$.

Fig. 3.6 Plot of separation factor $\alpha\left(\mathrm{CO}_{2}: \mathrm{N}_{2}\right)$ vs $\mathrm{CO}_{2}$ permeance for increasing feed humidity content, for a tubular silica membrane prepared with recipe $\mathrm{Si}-2$.

Fig. 4.1 Plot of $\mathrm{CO}_{2}$ permeance and separation factor $\alpha\left(\mathrm{CO}_{2}: \mathrm{N}_{2}\right)$ as a function of exposure time to SFG conditions for different (pure and Ni-doped) tubular silica membranes.

Fig. 4.2 Mixed gas separation performance at $62^{\circ} \mathrm{C}$ of a tubular pure silica membrane prepared with recipe $\mathrm{Si}-2$. 
Fig. 4.3 Mixed gas separation performance at $65^{\circ} \mathrm{C}$ of the tubular pure silica membrane shown in Fig. 6.

Fig. 4.4 Mixed gas separation performance at $56^{\circ} \mathrm{C}$ of a tubular Ni-doped silica membrane.

Fig. 5.1 Schematic represenation of the sol-gel dip-coating process for depositing mesoporous silica films on porous anodisk supports.

Fig. 5.2 Experimental set-up for gas permeation and permporosimetry experiments.

Fig. 5.3 (a) SEM top view of the 100-nm anodisk support; (b) SEM top view of the 100$\mathrm{nm}$ anodisk support after deposition of a $4.2 \%$ wt. F127-templated mesoporous silica layer; (c) cross-sectional TEM of (b) showing the mesoporous structure of the silica sublayer.

Fig. 5.4 (a) GISAXS pattern of a 7.2\% wt. F127-templated mesoporous silica film dipcoated on $20 \mathrm{~nm}$ anodisk, showing a diffuse ring arising from the randomly-oriented spherical mesopores with 3D cubic arrangement; (b) intensity integration of the pattern shown in (a), showing a peak at $2 \theta=0.5^{\circ}$, corresponding to a cubic lattice of lattice parameter $\mathrm{d}=14.4 \mathrm{~nm}$.

Fig. 5.5 Permporosimetry results at $22^{\circ} \mathrm{C}$ of the 100 -nm anodisk support and three different mesoporous silica layers templated with 4.2, 5.8 and 7.2\% wt. F127 surfactant in the precursor silica sol.

Fig. 5.6 Gas separation performance at $22^{\circ} \mathrm{C}$ of a microporous silica membrane spincoated on a $7.2 \%$ wt. F127-templated mesoporous silica sub-layer dip-coated on a 100nm anodisk support.

Fig. 5.7 AFM microanalysis shows rough ceramic fiber support surface causes crack on membrane (depth of the valley $1.5 \mu \mathrm{m}$ ).

Fig. 5.8 Ceramic hollow fibers (a) individual fiber, (b) bundle, and (c) cross-section.

Fig. 6.1 Selectivity requirements of the membrane module for $90 \% \mathrm{CO}_{2}$ capture efficiency.

Fig. 6.2 The effects of cost of membrane $\left(\$ / \mathrm{ft}^{2}\right)$ and $\mathrm{CO}_{2}$ permeance $(\mathrm{P}=3.0,4.0$ or 5.0 $\mathrm{cm}^{3}$ (STP) $\mathrm{cm}^{-2} \mathrm{~min}^{-1} \mathrm{~atm}^{-1}$ ) on cost of per tonne $\mathrm{CO}_{2}$ avoided (\$/tonne of $\mathrm{CO}_{2}$ avoided). The performance of the membrane-based $\mathrm{CO}_{2}$ removal system is compared to MEAbased $\mathrm{CO}_{2}$ removal system (in orange line). 
Fig. 7.1 a) cross-sectional TEM image of the hybrid membrane supported on mesoporous silica; b) original mesoporous silica support; c) support coated with ALD membrane; d) EELS spectrum of the membrane.

Fig. 7.2. Gas permeances of ALD membranes to $\mathrm{He}, \mathrm{N}_{2}$ and $\mathrm{SF}_{6}$ with kinetic diameters of $2.2,3.6$ and $5.5 \AA$, respectively.

Fig. 7.3 Effect of hydrothermal treatment on parent microporous silica membranes

Fig. 7.4 Effect of hydrothermal treatment for Ti-doped microporous ALD membranes (a) permeance (b) selectivity

Fig. 7.5 Effect of elevated temperatures for Ni-doped microporous ALD membranes

Fig. 7.6, Room temperature performance of Ni-doped microporous ALD membranes after tested at various temperatures

Fig. 7.7a, b, c, Performance of Ag- and dual-Ni-doped membrane (a) Ag-doped, (b) Nidoped, and (c) dual-Ni-doped.

Fig. 7.8a, b, Membranes performance before and after humidified SFG treatment (a) dual-Ni-doped and (b) Ag-doped

Fig. 7.9a,b Membranes performance before and after $\mathrm{SO}_{2}-\mathrm{SFG}$ treatment (a) dual-Nidoped (b) Ag-doped. 


\section{Appendix I Tables}

Table 3.1 Typical amine-silica and pure silica sol recipes used for membrane deposition in this study.

\begin{tabular}{clc}
\hline Recipe & Molar composition & Reaction condition \\
\hline aSi-1 & $0.2-\mathrm{NH}_{2}: 1 \mathrm{Si}: 22 \mathrm{EtOH}: 5 \mathrm{H}_{2} \mathrm{O}: 0.4 \mathrm{HCl}$ & $\begin{array}{l}15 \text { min agitation at } 25^{\circ} \mathrm{C}, \\
\text { then } 24 \mathrm{hr} \text { aging at } 25-50^{\circ} \mathrm{C}\end{array}$ \\
aSi-2 & $0.2-\mathrm{NH}_{2}: 1 \mathrm{Si}: 22 \mathrm{EtOH}: 3.3 \mathrm{H}_{2} \mathrm{O}: 0.2 \mathrm{HCl}$ & $\begin{array}{l}15 \text { min agitation at } 25^{\circ} \mathrm{C}, \\
\text { then } 24 \mathrm{hr} \text { aging at } 25-50^{\circ} \mathrm{C}\end{array}$ \\
aSi-3 & $0.2-\mathrm{NH}_{2}: 1 \mathrm{Si}: 44 \mathrm{EtOH}: 3.3 \mathrm{H}_{2} \mathrm{O}: 0.067 \mathrm{HCl}$ & $\begin{array}{c}20 \text { min agitation while warming } \\
\text { from }-20 \text { to } 25^{\circ} \mathrm{C}\end{array}$ \\
Si-1 & $1 \mathrm{Si}: 3.8 \mathrm{EtOH}: 6.4 \mathrm{H}_{2} \mathrm{O}: 8.5 \times 10^{-3} \mathrm{HNO}_{3}$ & $\begin{array}{c}180 \text { min stirring at } 60^{\circ} \mathrm{C} \text { under } \\
\text { reflux }\end{array}$ \\
Si-2 & $1 \mathrm{Si}: 22 \mathrm{EtOH}: 6.4 \mathrm{H}_{2} \mathrm{O}: 8.5 \times 10^{-3} \mathrm{HNO}_{3}$ & $\begin{array}{l}15 \text { min agitation at } 25^{\circ} \mathrm{C}, \\
\text { then } 24 \mathrm{hr} \text { aging at } 25-50^{\circ} \mathrm{C}\end{array}$ \\
\hline
\end{tabular}


Table 3.2 $\mathrm{CO}_{2}: \mathrm{N}_{2}$ separation performance at $25^{\circ} \mathrm{C}$ of fresh tubular pure silica membranes prepared by recipes Si-1 and Si-2. The feed was a 10:90 (v/v) $\mathrm{CO}_{2}: \mathrm{N}_{2}$ mixture. Sample M8 was prepared with molar ratio $\mathrm{H}^{+}: \mathrm{Si}=0.085$ in the precursor silica sol.

\begin{tabular}{llcc}
\hline Sample & Sol recipe & $\begin{array}{c}\mathrm{CO}_{2} \text { permeance, MPU } \\
{\left[\mathrm{cm}^{3}(\mathrm{STP}) \cdot \mathrm{cm}^{-2} \cdot \mathrm{min}^{-1} \cdot \mathrm{atm}^{-1}\right]}\end{array}$ & $\begin{array}{c}\text { Separation factor } \\
{\left[\mathrm{CO}_{2}: \mathrm{N}_{2}\right]}\end{array}$ \\
\hline M1 & $\mathrm{Si}-1$ & 2.5 & 50.4 \\
M2 & $\mathrm{Si}-2$ & 2.6 & 52.7 \\
M3 & $\mathrm{Si}-2$ & 1.4 & 48.6 \\
M4 & $\mathrm{Si}-2$ & 2.0 & 78.4 \\
M5 & $\mathrm{Si}-2$ & 1.7 & 57.0 \\
M6 & $\mathrm{Si}-2$ & 2.4 & 44.5 \\
M7 & $\mathrm{Si}-2$ & 2.2 & 59.7 \\
M8 & $\mathrm{Si}-1[24]$ & 11.3 & 4.1 \\
\hline
\end{tabular}


Table 3.3 $\mathrm{CO}_{2}: \mathrm{N}_{2}$ separation performance at $25^{\circ} \mathrm{C}$ of fresh tubular Ni-doped silica membranes prepared by a modified Si-2 recipe. The feed was a 10:90 (v/v) $\mathrm{CO}_{2}: \mathrm{N}_{2}$ mixture.

\begin{tabular}{lccc}
\hline Sample & Ni:Si ratio & $\begin{array}{c}\mathrm{CO}_{2} \text { permeance, } \mathrm{MPU} \\
{\left[\mathrm{cm}^{3}(\mathrm{STP}) \cdot \mathrm{cm}^{-2} \cdot \mathrm{min}^{-1} \cdot \mathrm{atm}^{-1}\right]}\end{array}$ & $\begin{array}{c}\text { Separation factor } \\
{\left[\mathrm{CO}_{2}: \mathrm{N}_{2}\right]}\end{array}$ \\
\hline $\mathrm{N} 1$ & 0.56 & 21.9 \\
$\mathrm{~N} 2$ & 0.1 & 3.15 & 19.2 \\
$\mathrm{~N} 3$ & 0.1 & 4.92 & 16.4 \\
$\mathrm{~N} 4$ & 0.1 & 5.96 & 21.7 \\
$\mathrm{~N} 5$ & 0.2 & 0.58 & 92.0 \\
\hline
\end{tabular}


Table 6.1 An example of cost estimate for a $\mathrm{PC}$ power plant with a membrane-based $\mathrm{CO}_{2}$ removal system (Case 3), compared to a $\mathrm{PC}$ power plant without $\mathrm{CO}_{2}$ capture (Case 1) and to a PC power plant with MEA $\mathrm{CO}_{2}$ removal system (Case 2). In case 3 , the cost of membrane of $20 \$ / \mathrm{ft}^{2}$ and $\mathrm{CO}_{2}$ permeance of $3.0 \mathrm{~cm}^{3}$ (STP) $\mathrm{cm}^{-2} \mathrm{~min}^{-1} \mathrm{~atm}^{-1}$ were used for calculation. The cost of the membrane and $\mathrm{CO}_{2}$ permeance were varied subsequently to determine the cost window (shown in Figure 6.2).

\begin{tabular}{|c|c|c|c|}
\hline Capital Cost Summary & $\begin{array}{c}\text { No } \mathrm{CO}_{2} \text { Capture } \\
\text { (Case 1) } \\
\text { x } \$ 1000\end{array}$ & $\begin{array}{c}\text { With } \mathrm{CO}_{2} \text { Capture } \\
\text { (Case 2)-MEA } \\
x \$ 1000\end{array}$ & $\begin{array}{c}\text { With } \mathrm{CO}_{2} \text { Capture } \\
\text { (Case 3)-MEMB } \\
\text { x } \$ 1000\end{array}$ \\
\hline Coal and Sorbent Handling & $\$ 15,822$ & $\$ 15,822$ & $\$ 15,822$ \\
\hline Coal and Sorbent Preparation and Feed & $\$ 12,409$ & $\$ 12,409$ & $\$ 12,409$ \\
\hline Feedwater Systems & $\$ 24,854$ & $\$ 23,061$ & $\$ 23,061$ \\
\hline PC Boiler and Accessories & $\$ 109,564$ & $\$ 108,954$ & $\$ 108,954$ \\
\hline Flue Gas Cleanup & $\$ 61,486$ & $\$ 59,410$ & $\$ 59,410$ \\
\hline Mercury Removal & $\$ 0$ & $\$ 0$ & $\$ 0$ \\
\hline $\begin{array}{l}\mathrm{CO}_{2} \text { Removal and Compression } \\
\text { Combustion Turbine/Generator and }\end{array}$ & $\$ 0$ & $\$ 111,769$ & $\$ 10,000$ \\
\hline Accessories & $\$ 0$ & $\$ 0$ & $\$ 0$ \\
\hline HRSG \& Stack & $\$ 20,544$ & $\$ 18,014$ & $\$ 18,014$ \\
\hline Steam Turbine Generator and Accessories & $\$ 72,885$ & $\$ 62,245$ & $\$ 62,245$ \\
\hline Cooling Water System & $\$ 19,584$ & $\$ 17,133$ & $\$ 17,133$ \\
\hline Ash/Spent Sorbent Handling System & $\$ 19,252$ & $\$ 19,252$ & $\$ 19,252$ \\
\hline Accessory Electric Plant & $\$ 24,152$ & $\$ 31,341$ & $\$ 31,341$ \\
\hline Instrumentation \& Controls & $\$ 9,341$ & $\$ 8,879$ & $\$ 8,879$ \\
\hline Buildings \& Structures & $\$ 35,699$ & $\$ 33,695$ & $\$ 33,695$ \\
\hline Process Capital & $\$ 425,592$ & $\$ 521,984$ & $\$ 420,215$ \\
\hline Engineering Fees & $\$ 25,536$ & $\$ 31,319$ & $\$ 25,213$ \\
\hline Process Contingency & $\$ 0$ & $\$ 6,024$ & $\$ 539$ \\
\hline Project Contingency & $\$ 65,296$ & $\$ 81,454$ & $\$ 64,449$ \\
\hline Allowable Funds Used During Construction & $\$ 42,842$ & $\$ 52,929$ & $\$ 52,929$ \\
\hline Land Cost & $\$ 512$ & $\$ 544$ & $\$ 515$ \\
\hline Inventory Capital & $\$ 5,530$ & $\$ 6,316$ & $\$ 6,316$ \\
\hline Preproduction Costs & $\$ 15,064$ & $\$ 18,379$ & $\$ 18,379$ \\
\hline Total Capital Requirement (TCR) & $\$ 580,372$ & $\$ 718,950$ & $\$ 588,555$ \\
\hline Levelized Capital Charge Factor (\%) & $14 \%$ & $14 \%$ & $14 \%$ \\
\hline Capacity Factor (\%) & $65 \%$ & $65 \%$ & $65 \%$ \\
\hline Capital c/kWh & 3.09 & 5.37 & 4.37 \\
\hline Production c/kWh & 2.04 & 3.19 & 3.83 \\
\hline Total c/kWh & 5.13 & 8.56 & 8.20 \\
\hline $\mathrm{CO}_{2}$ emitted (kg/kwh) & 0.776 & 0.109 & 0.108 \\
\hline Incremental COE, cents/kWh & & 3.43 & 3.06 \\
\hline Energy Penalty (\%) & & 28.7 & 28.3 \\
\hline $\begin{array}{l}\text { Mitigation Cost, Capture vs. Reference, } \\
\text { (\$/tonne of } \mathrm{CO}_{2} \text { avoided) }\end{array}$ & & 51 & 46 \\
\hline
\end{tabular}


Table 7.1 Fractional Factorial Fit: $\mathrm{CO}_{2}$ permeance versus ALD temp, ALD exp, UV

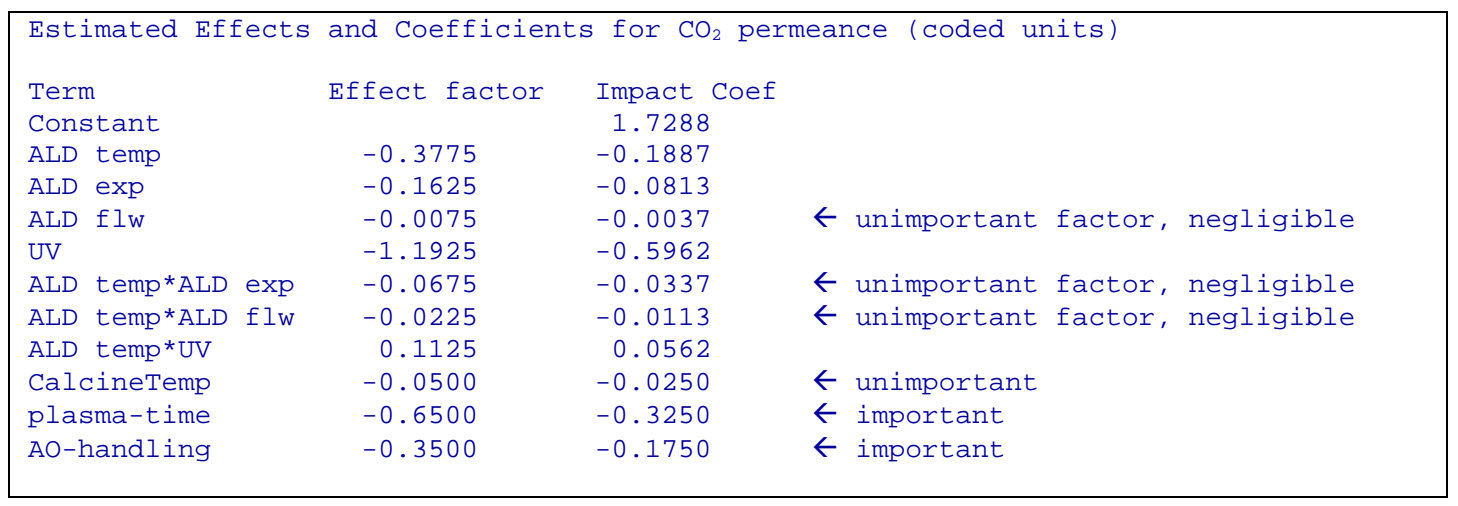

Table 7.2 Fractional Factorial Fit: $\mathrm{CO}_{2} / \mathrm{N}_{2}$ selectivity versus ALD temp, ALD exp, UV

\begin{tabular}{|c|c|c|c|}
\hline Term & Effect & Coef & \\
\hline Constant & & 1.97625 & \\
\hline ALD temp & $\odot .34750$ & 0.17375 & \\
\hline ALD exp & 0.12750 & 0.06375 & \\
\hline $\begin{array}{l}\text { ALD flW } \\
\text { UV }\end{array}$ & $\begin{array}{r}-0.00250 \\
1.02750\end{array}$ & $\begin{array}{r}-0.00125 \\
0.51375\end{array}$ & $\leftarrow$ unimportant factor, negligible \\
\hline ALD temp*ALD exp & $\odot .07250$ & 0.03625 & $\leftarrow$ unimportant factor, negligible \\
\hline ALD temp*ALD flw & -0.00750 & -0.00375 & $\leftarrow$ unimportant factor, negligible \\
\hline ALD temp*UV & $\odot .12250$ & 0.06125 & \\
\hline CalcineTemp & $\odot .4000$ & 0.2000 & $\leftarrow$ less important \\
\hline Plasma-time & 1.0000 & 0.5000 & $\leftarrow$ important \\
\hline AO-handling & 3.0000 & 1.5000 & $\leftarrow$ important \\
\hline
\end{tabular}

Table 7.3 Gas permeance of membranes prepared with precursors with various "porogens"

\begin{tabular}{|c|c|c|c|}
\hline \multicolumn{2}{|c|}{ precursors } & \multirow{2}{*}{$\begin{array}{c}\begin{array}{r}\mathrm{CO}_{2} \text { Permeance } \\
\text { (sccm/bar or } \mathrm{MPU})\end{array} \\
0.10\end{array}$} & \multirow{2}{*}{$\begin{array}{c}\mathrm{CO}_{2} / \mathrm{N}_{2} \\
5.7\end{array}$} \\
\hline$\left((\mathrm{EtO})_{3} \mathrm{Si}-\right.$ & Original & & \\
\hline BTEE & After Ni- modification & 0.04 & 23 \\
\hline \multirow{2}{*}{$\begin{array}{c}(\mathrm{EtO})_{3} \mathrm{Si}-\mathrm{CH}_{2}- \\
\mathrm{NH}-\mathrm{CH}_{2}-\mathrm{Si}(\mathrm{OEt})_{3}\end{array}$} & Before Ni- modification & 0.18 & 4.3 \\
\hline & After Ni- modification & 0.11 & 21 \\
\hline \multirow{2}{*}{$\begin{array}{c}(\mathrm{EtO})_{3} \mathrm{Si}- \\
\mathrm{C}_{6} \mathrm{H}_{4} \mathrm{C}_{6} \mathrm{H}_{4}-\mathrm{Si}(\mathrm{OEt})_{3}\end{array}$} & Before Ni- modification & $\begin{array}{l}24.3 \text { (no membrane } \\
\text { formed by ALD) }\end{array}$ & 2.2 \\
\hline & After Ni- modification & 23.1 & 2.5 \\
\hline
\end{tabular}




\section{Appendix II Figures}

\section{Figure Captions}

3.1 Mixed gas separation performance at $22^{\circ} \mathrm{C}$ of a tubular aminosilica membrane prepared with recipe aSi-1. The feed was a $10: 90(\mathrm{v} / \mathrm{v}) \mathrm{CO}_{2}: \mathrm{N}_{2}$ mixture.

3.2 Mixed gas separation performance at $25^{\circ} \mathrm{C}$ of a tubular aminosilica membrane prepared with recipe aSi-2. The feed was a $10: 90(\mathrm{v} / \mathrm{v}) \mathrm{CO}_{2}: \mathrm{N}_{2}$ mixture.

3.3 Mixed gas separation performance at $22^{\circ} \mathrm{C}$ of a Anodisk-supported aminosilica membrane prepared with recipe aSi-3. The feed was a 50:50 (v/v) $\mathrm{CO}_{2}: \mathrm{N}_{2}$ mixture.

3.4 Molecular sieving behavior of membrane M8 in Table 2 prepared according to ref. [20].

3.5 Mixed gas separation performance at $25-100^{\circ} \mathrm{C}$ of a tubular silica membrane prepared with recipe $\mathrm{Si}-2$. The feed was a 10:10:80 (v/v) $\mathrm{CO}_{2}: \mathrm{N}_{2}: \mathrm{He}$ mixture.

3.6 Plot of separation factor $\alpha\left(\mathrm{CO}_{2}: \mathrm{N}_{2}\right)$ vs $\mathrm{CO}_{2}$ permeance for increasing feed humidity content, for a tubular silica membrane prepared with recipe $\mathrm{Si}-2$. The feed was a 20:80 (v/v) $\mathrm{CO}_{2}: \mathrm{N}_{2}$ mixture.

4.1 Plot of $\mathrm{CO}_{2}$ permeance and separation factor $\alpha\left(\mathrm{CO}_{2}: \mathrm{N}_{2}\right)$ as a function of exposure time to SFG conditions for different (pure and Ni-doped) tubular silica membranes. The separation performance was measured with a 10:90 (v/v) $\mathrm{CO}_{2}: \mathrm{N}_{2}$ feed at $25^{\circ} \mathrm{C}$ before and after the indicated exposure time.

4.2 Mixed gas separation performance at $62^{\circ} \mathrm{C}$ of a tubular pure silica membrane prepared with recipe $\mathrm{Si}-2$. The membrane was exposed for 60 hours in SFG conditions. The feed was a 10:90 (v/v) $\mathrm{CO}_{2}: \mathrm{N}_{2}$ mixture.

4.3 Mixed gas separation performance at $65^{\circ} \mathrm{C}$ of the tubular pure silica membrane shown in Fig. 6. The membrane was exposed for additional 60 hours (total 120 hours) in SFG conditions. The feed was a 10:90 (v/v) $\mathrm{CO}_{2}: \mathrm{N}_{2}$ mixture.

4.4 Mixed gas separation performance at $56^{\circ} \mathrm{C}$ of a tubular Ni-doped silica membrane. The membrane was exposed for 163 hours in SFG conditions. The feed was a 10:90 (v/v) $\mathrm{CO}_{2}: \mathrm{N}_{2}$ mixture.

5.1 Schematic represenation of the sol-gel dip-coating process for depositing mesoporous silica films on porous anodisk supports.

5.2 Experimental set-up for gas permeation and permporosimetry experiments. 
5.3 (a) SEM top view of the 100-nm anodisk support; (b) SEM top view of the 100-nm anodisk support after deposition of a $4.2 \% \mathrm{wt}$. F127-templated mesoporous silica layer; (c) cross-sectional TEM of (b) showing the mesoporous structure of the silica sub-layer.

5.4 (a) GISAXS pattern of a 7.2\% wt. F127-templated mesoporous silica film dip-coated on $20 \mathrm{~nm}$ anodisk, showing a diffuse ring arising from the randomly-oriented spherical mesopores with 3D cubic arrangement; (b) intensity integration of the pattern shown in (a), showing a peak at $2 \theta=0.5^{\circ}$, corresponding to a cubic lattice of lattice parameter $\mathrm{d}=$ $14.4 \mathrm{~nm}$.

5.5 Permporosimetry results at $22^{\circ} \mathrm{C}$ of the 100 -nm anodisk support and three different mesoporous silica layers templated with 4.2, 5.8 and $7.2 \%$ wt. F127 surfactant in the precursor silica sol. Note that approaching a near-zero $\mathrm{N}_{2}$ permeance with increasing relative saturation indicates the absence of macroscopic defects in the mesoporous silica films, which is necessary requirement for subsequent deposition of a good-quality microporous gas separation membrane.

5.6 Gas separation performance at $22^{\circ} \mathrm{C}$ of a microporous silica membrane spin-coated on a $7.2 \%$ wt. F127-templated mesoporous silica sub-layer dip-coated on a $100-\mathrm{nm}$ anodisk support. The feed was a $2 \% \mathrm{CO}_{2}$-balance $\mathrm{N}_{2}$ or a $10 \% \mathrm{CO}_{2}$-balance $\mathrm{CH}_{4}$ binary mixture and the sweep was He. Both feed and sweep flow rates were $100 \mathrm{cc}(\mathrm{STP}) / \mathrm{min}$, while no $\Delta \mathrm{P}$ was applied across the membrane.

5.7 AFM microanalysis shows rough ceramic fiber support surface causes crack on membrane (depth of the valley $1.5 \mu \mathrm{m}$ ).

5.8 Ceramic hollow fibers (a) individual fiber, (b) bundle, and (c) cross-section.

6.1 Selectivity requirements of the membrane module for $90 \% \mathrm{CO}_{2}$ capture efficiency.

6.2 The effects of cost of membrane $\left(\$ / \mathrm{ft}^{2}\right)$ and $\mathrm{CO}_{2}$ permeance $\left(\mathrm{P}=3.0,4.0\right.$ or $5.0 \mathrm{~cm}^{3}$ (STP) $\mathrm{cm}^{-2} \mathrm{~min}^{-1} \mathrm{~atm}^{-1}$ ) on cost of per tonne $\mathrm{CO}_{2}$ avoided (\$/tonne of $\mathrm{CO}_{2}$ avoided). The performance of the membrane-based $\mathrm{CO}_{2}$ removal system is compared to MEA-based $\mathrm{CO}_{2}$ removal system (in orange line).

7.1 a) cross-sectional TEM image of the hybrid membrane supported on mesoporous silica; b) original mesoporous silica support; c) support coated with ALD membrane; d) EELS spectrum of the membrane.

7.2. Gas permeances of ALD membranes to $\mathrm{He}, \mathrm{N}_{2}$ and $\mathrm{SF}_{6}$ with kinetic diameters of 2.2, 3.6 and $5.5 \AA$, respectively.

7.3 a, b, Effect of hydrothermal treatment on parent microporous silica membranes (a) permeance (b) selectivity 
7.4 Effect of hydrothermal treatment for Ti-doped microporous ALD membranes (a) permeance (b) selectivity

7.5 Effect of elevated temperatures for Ni-doped microporous ALD membranes

7.6, Room temperature performance of Ni-doped microporous ALD membranes after tested at various temperatures

7.7a, b, c, Performance of Ag- and dual-Ni-doped membrane (a) Ag-doped, (b) Nidoped, and (c) dual-Ni-doped.

7.8a, b, Membranes performance before and after humidified SFG treatment (a) dual-Nidoped and (b) Ag-doped

7.9a,b Membranes performance before and after $\mathrm{SO}_{2}-\mathrm{SFG}$ treatment (a) dual-Ni-doped (b) Ag-doped. 
Figure 3.1

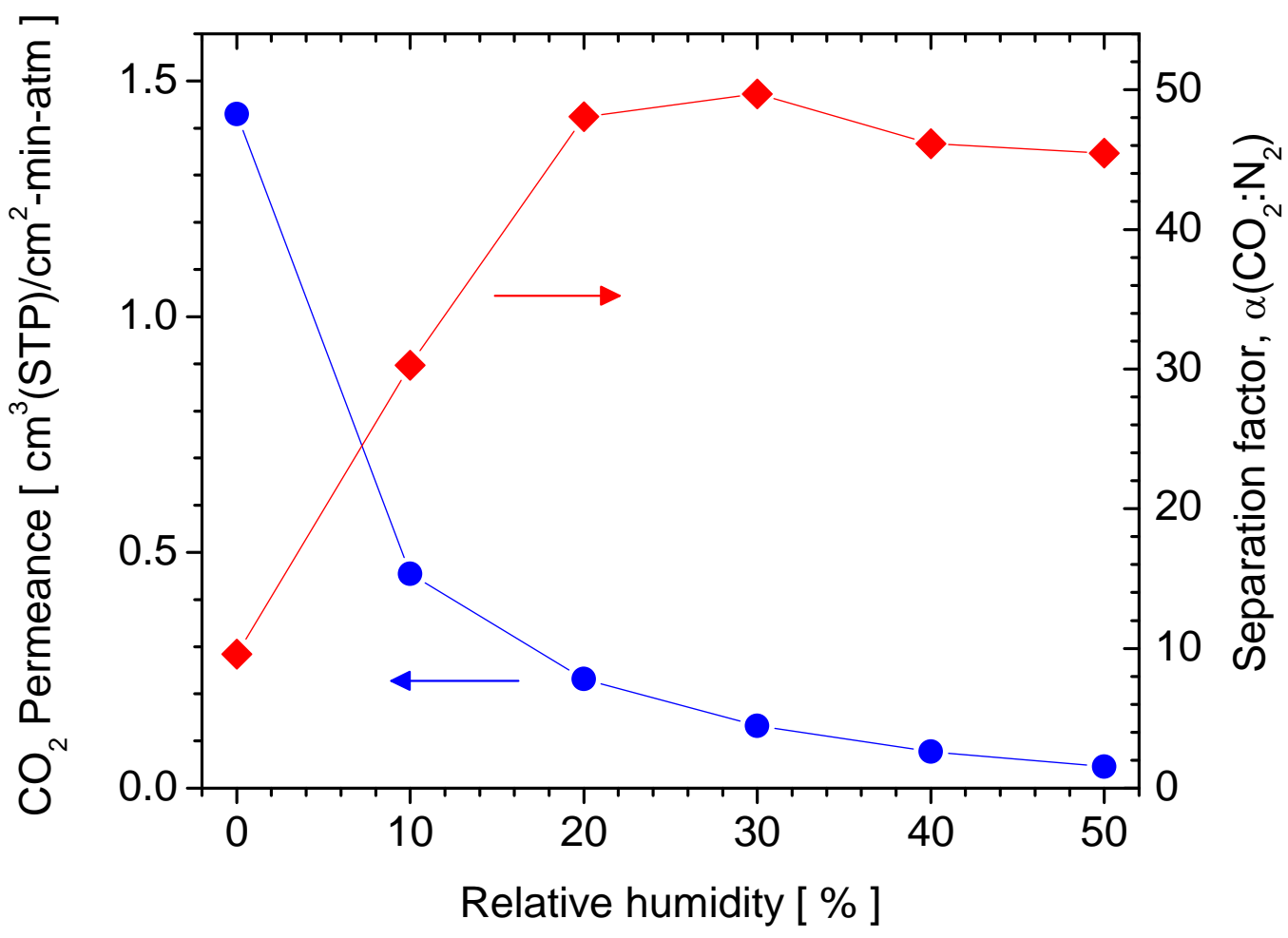


Figure 3.2

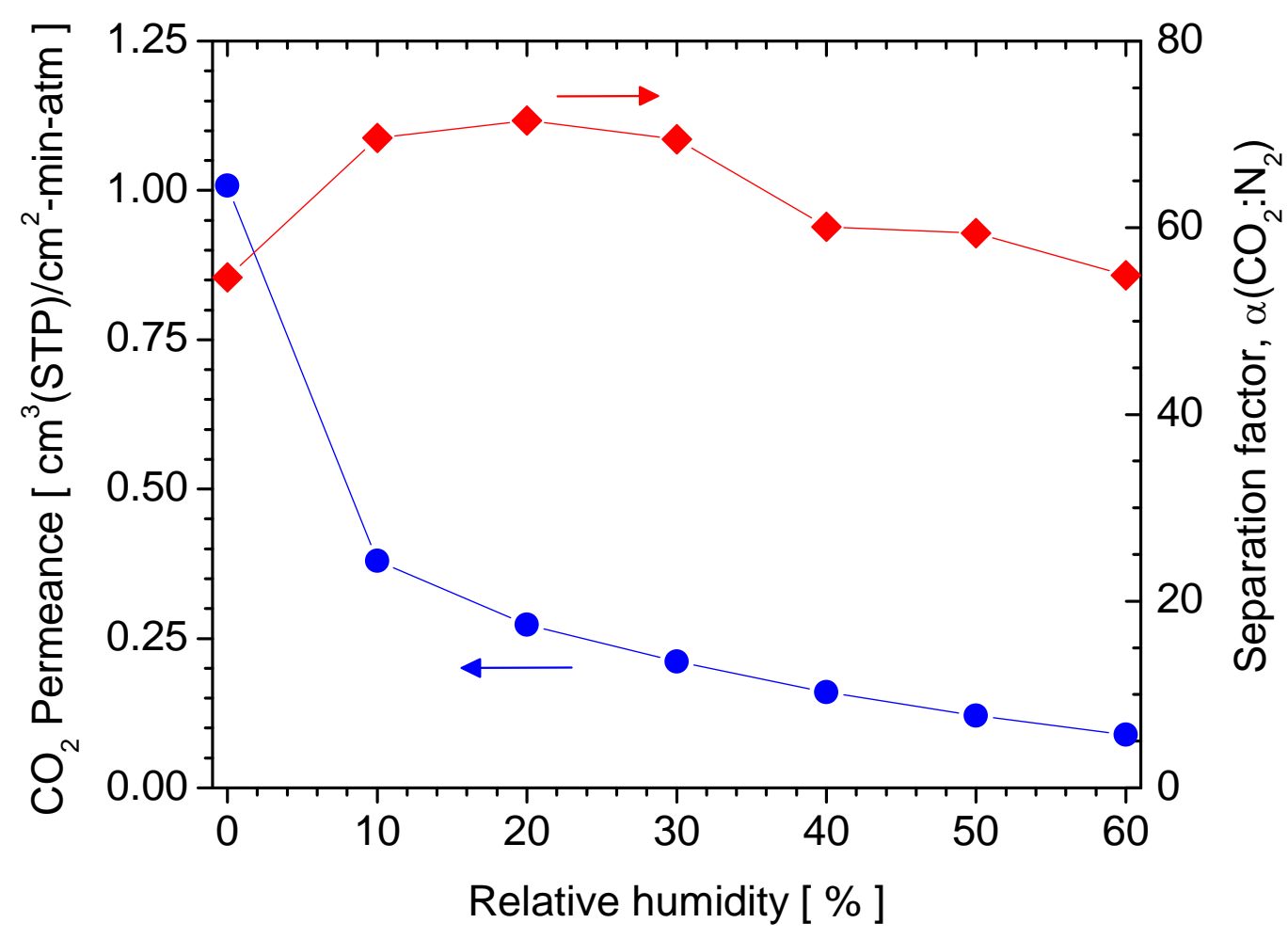


Figure 3.3

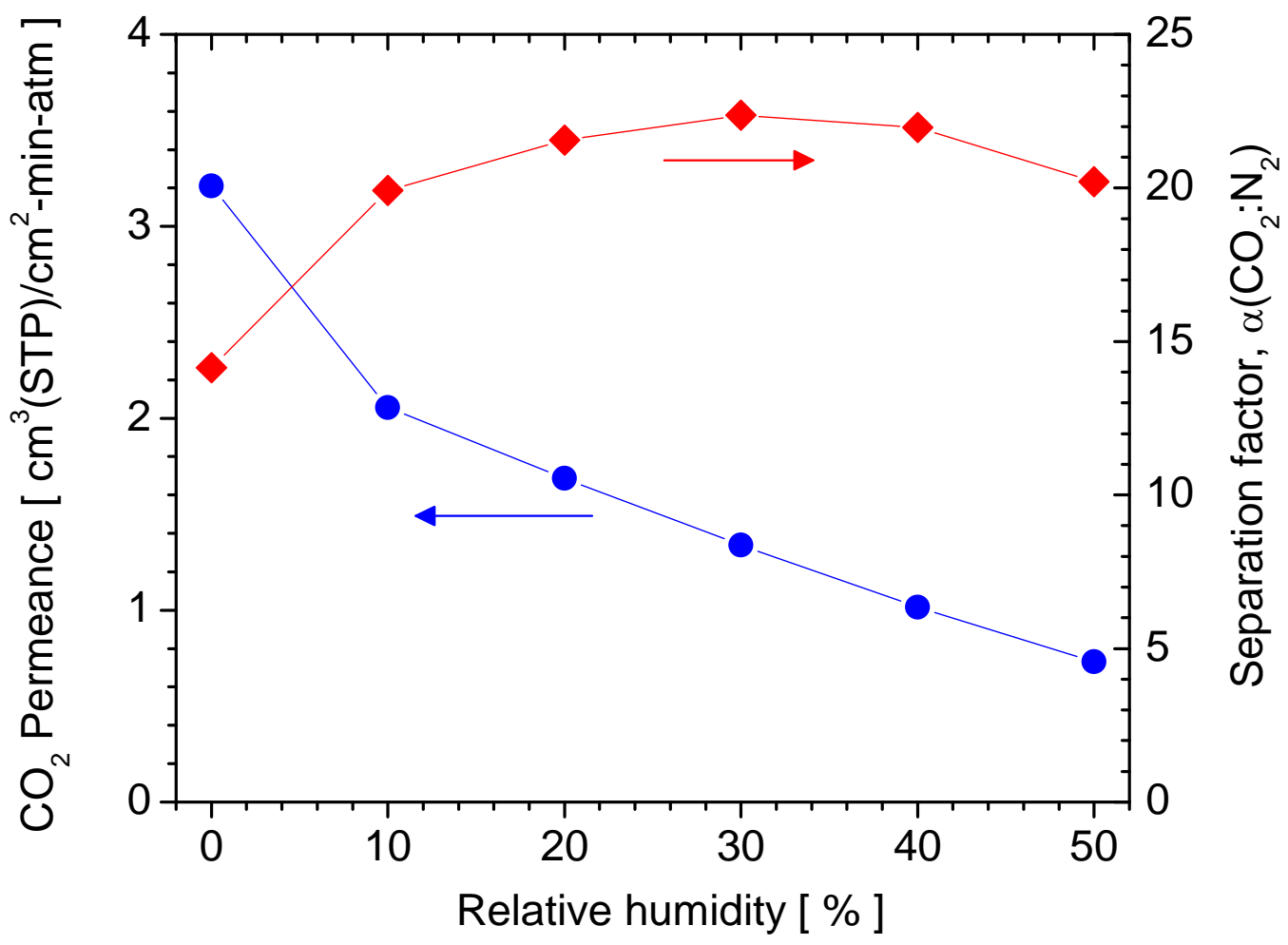

Figure 3.4 


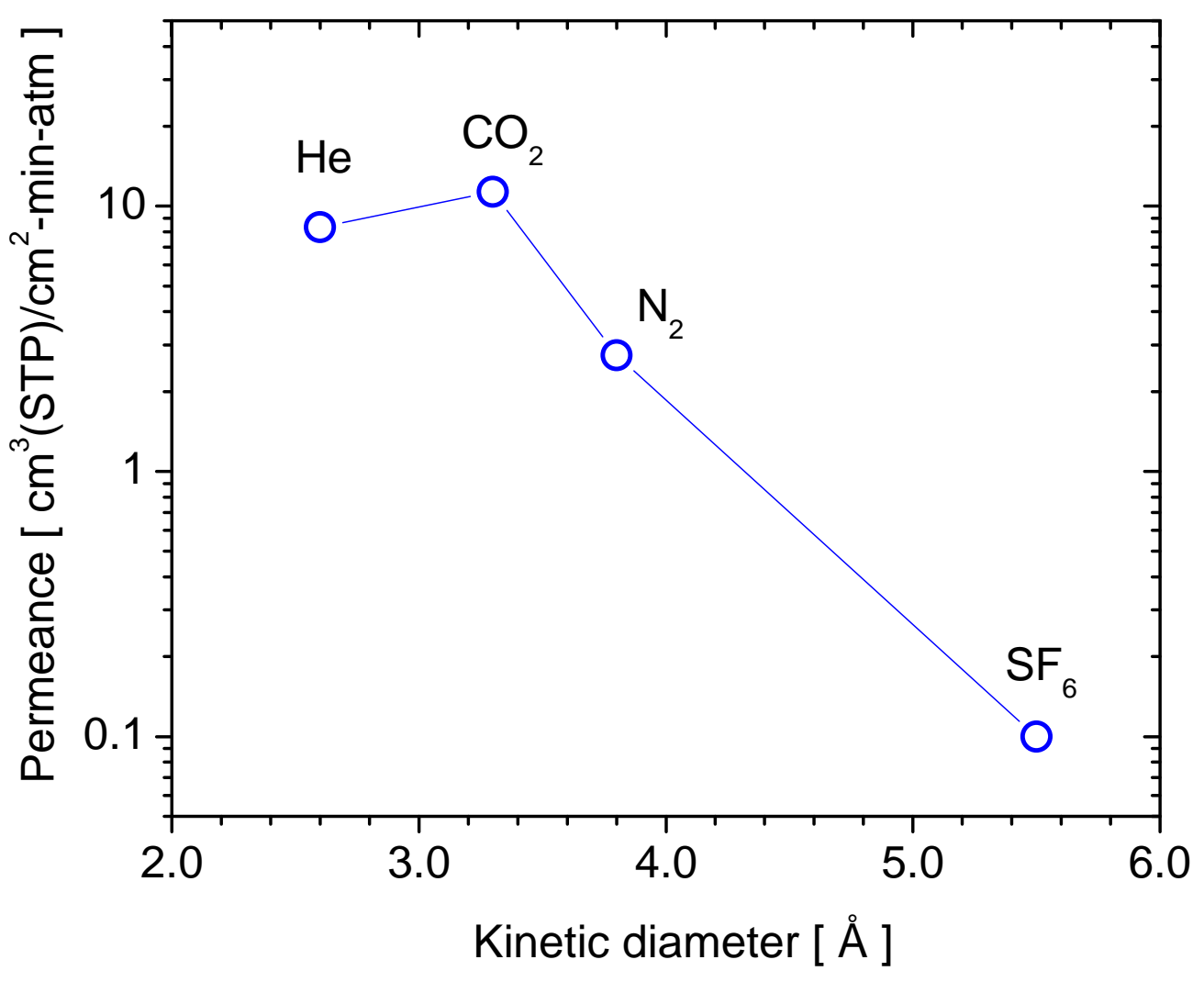


Figure 3.5

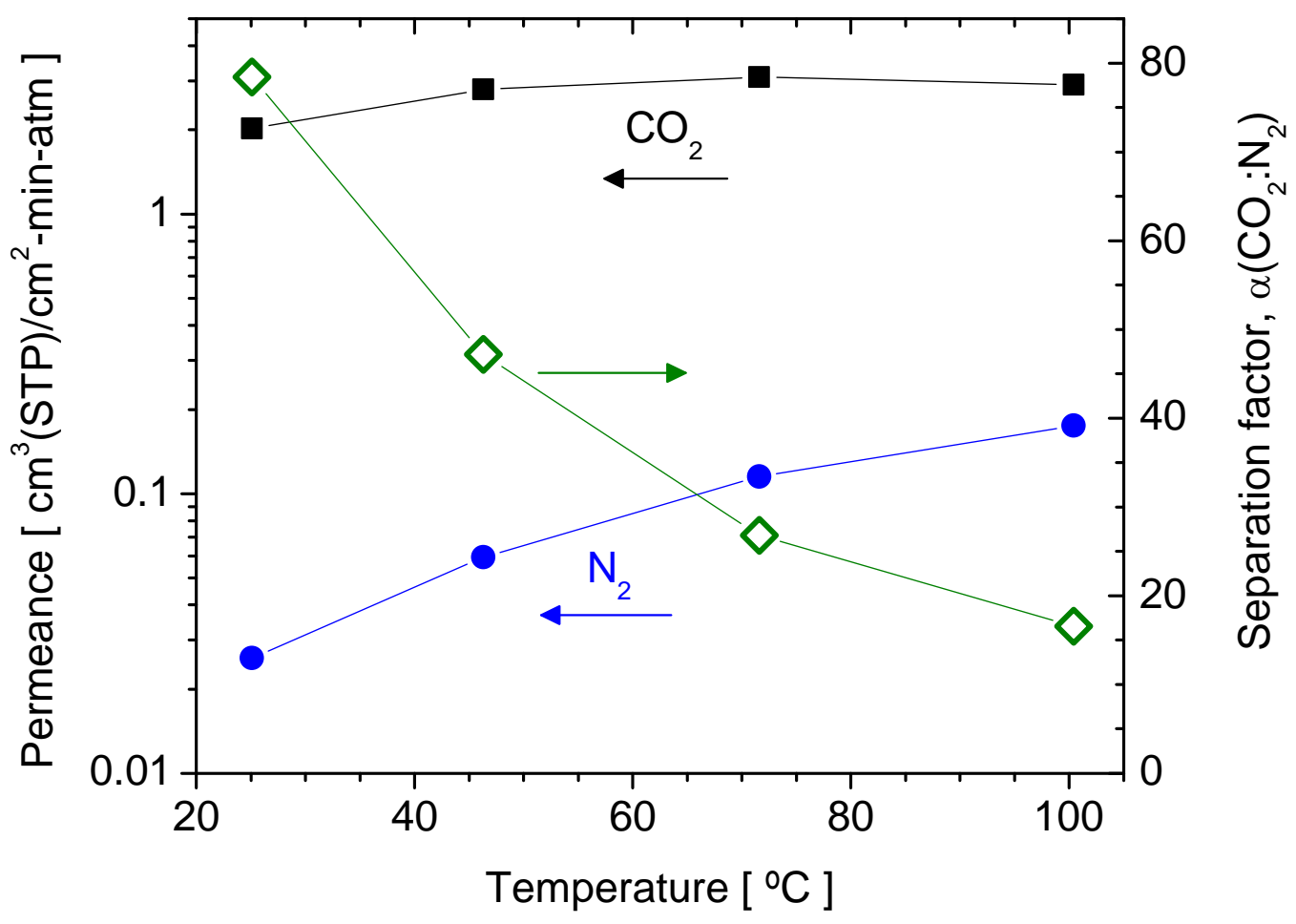


Figure 3.6

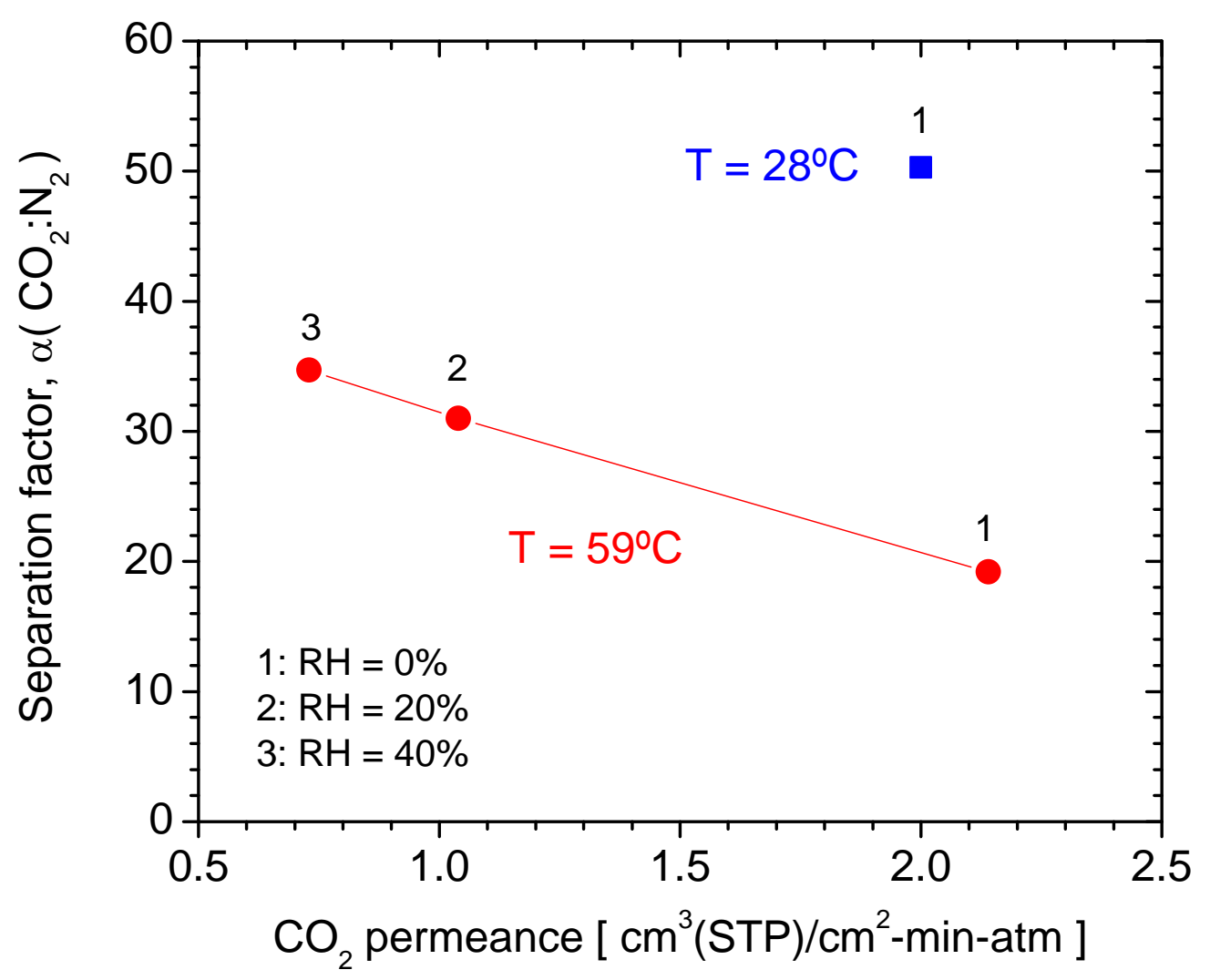


Figure 4.1

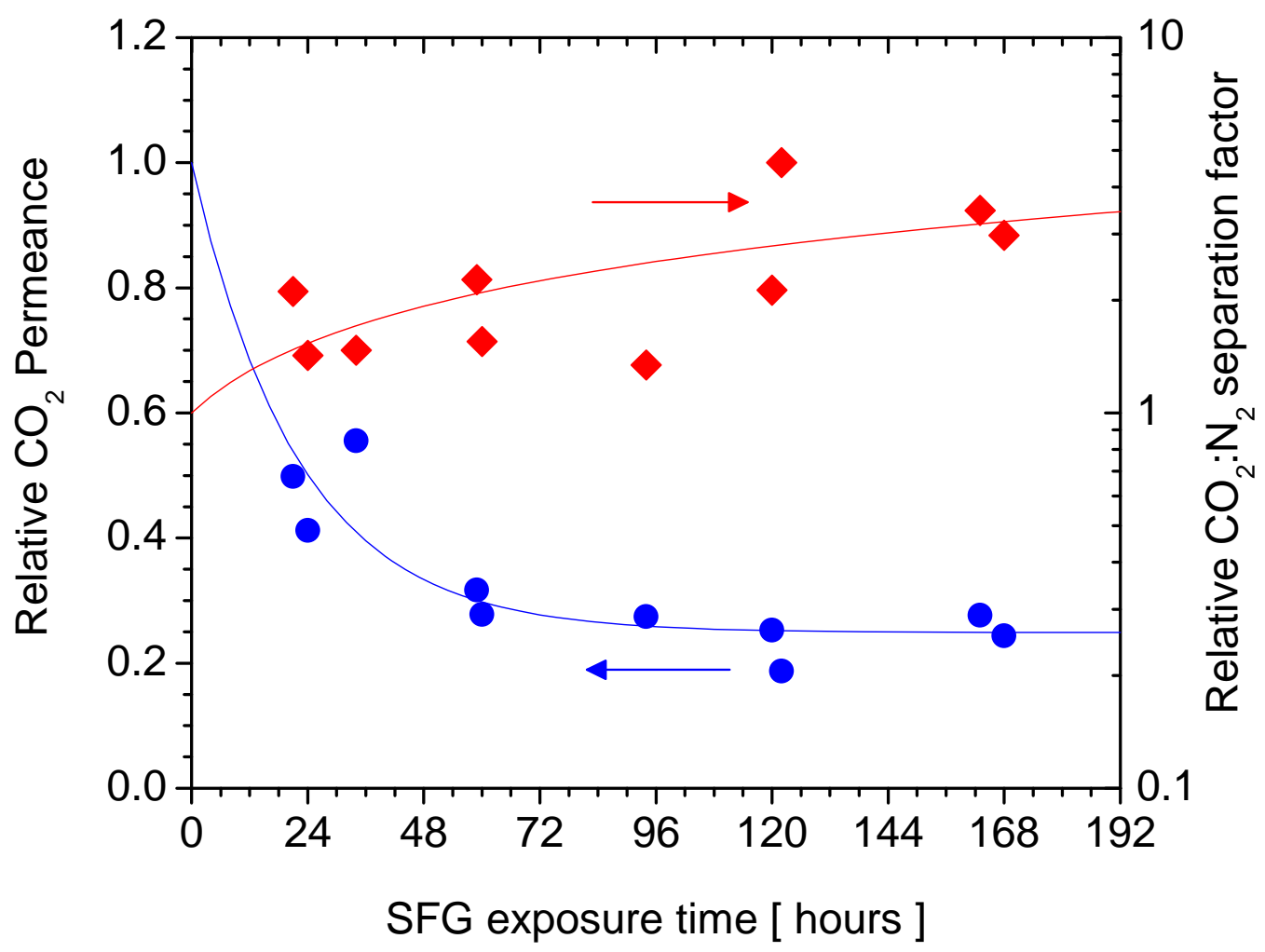


Figure 4.2

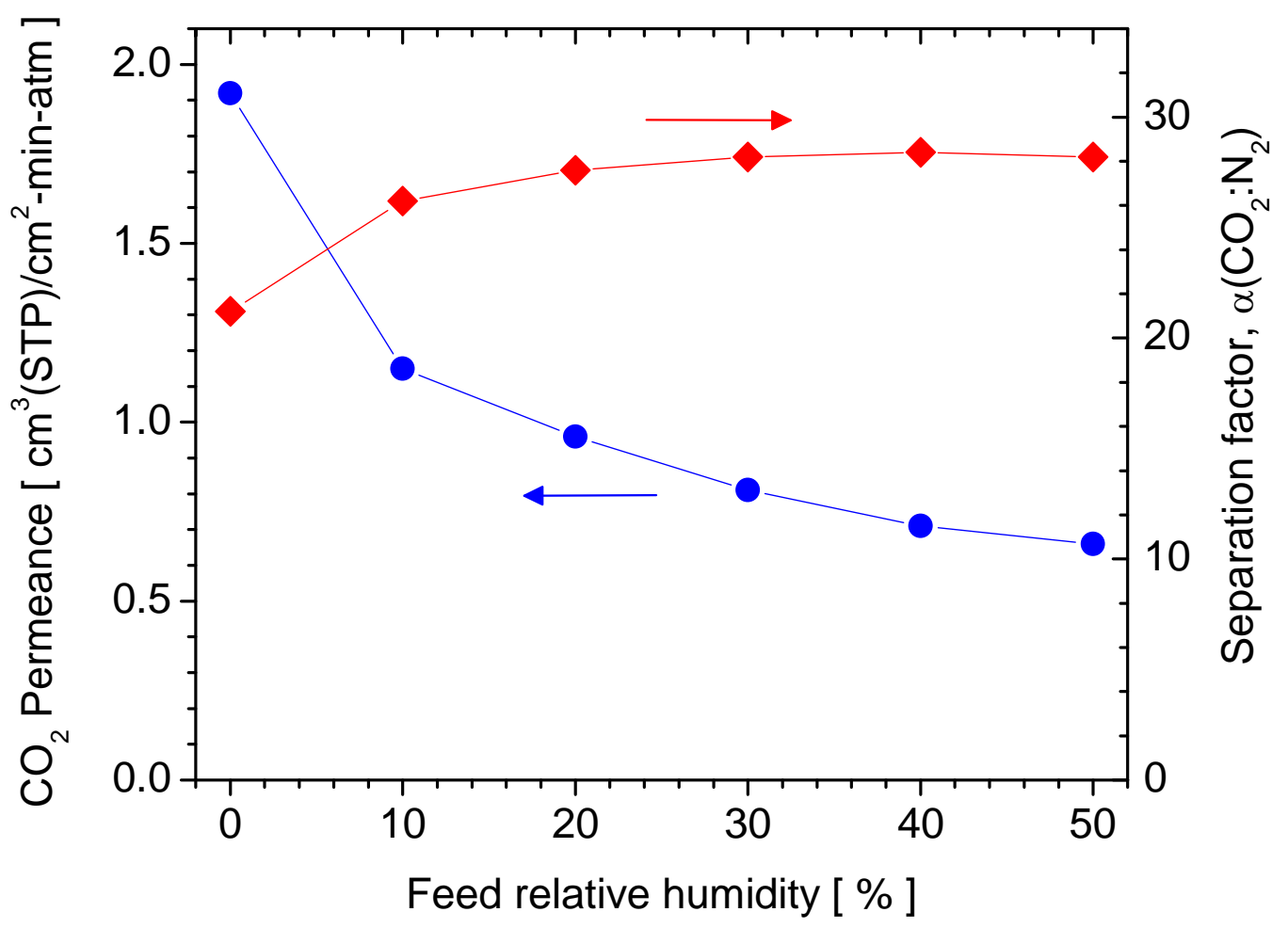


Figure 4.3

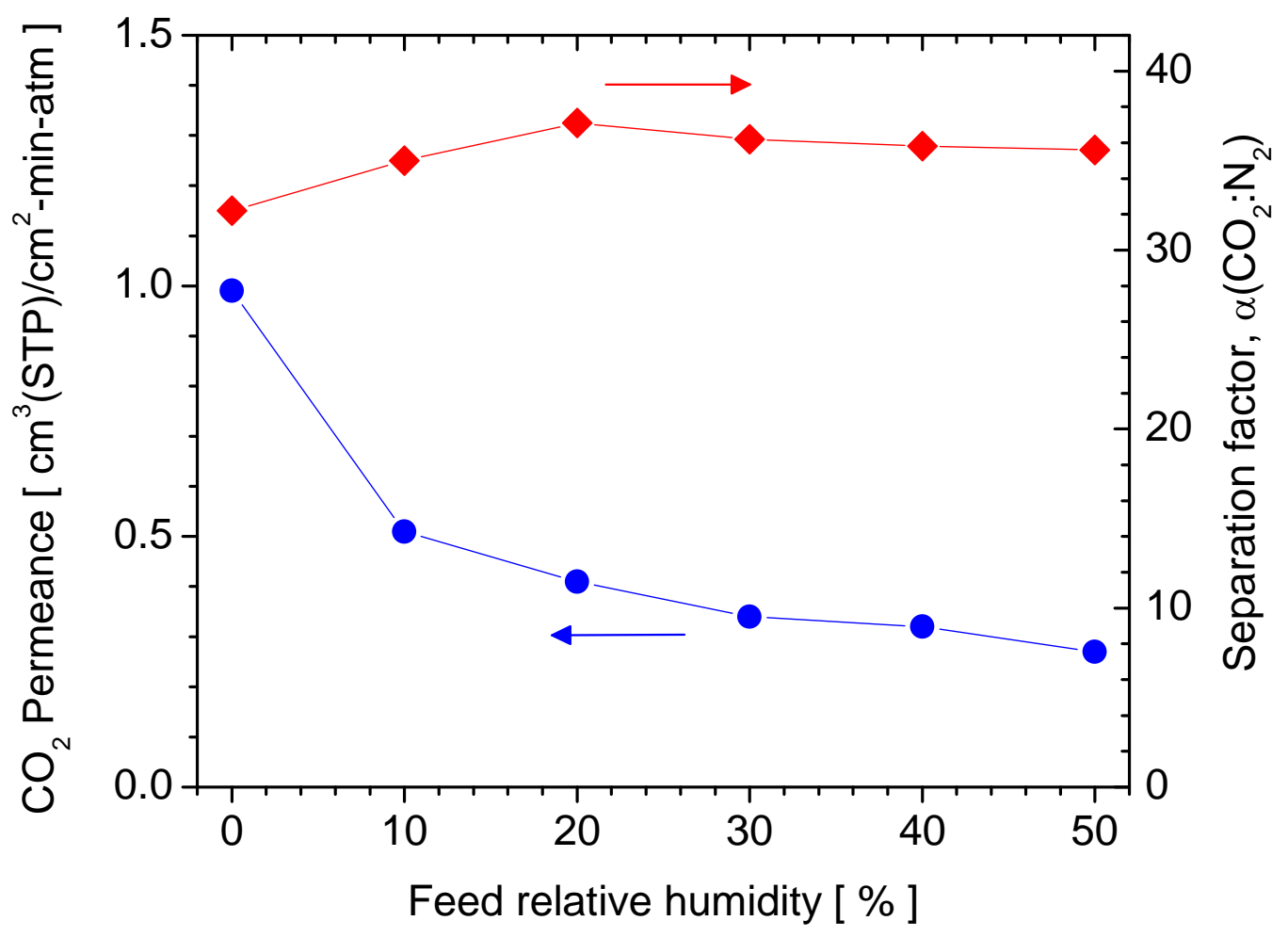


Figure 4.4

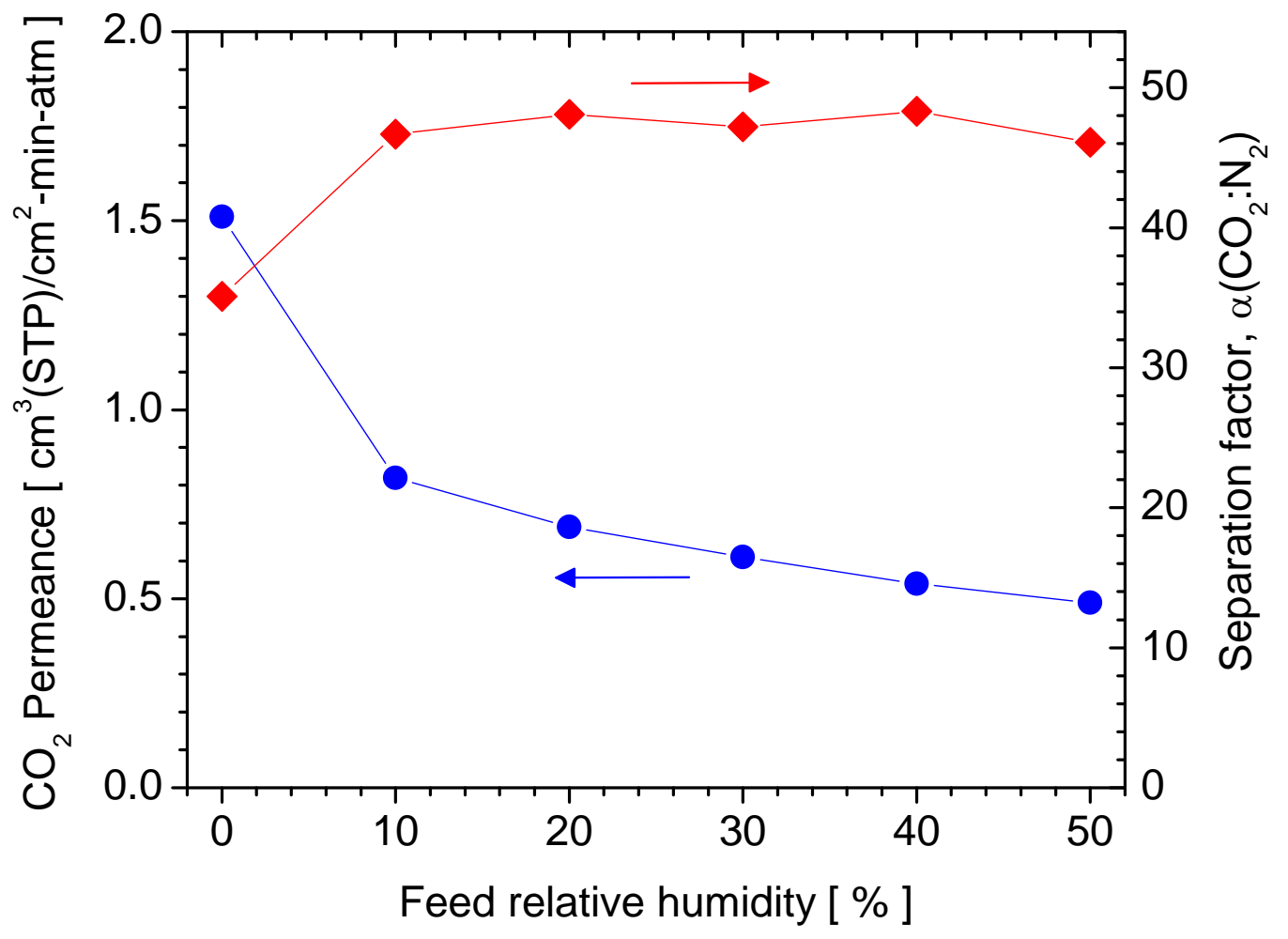


Figure 5.1

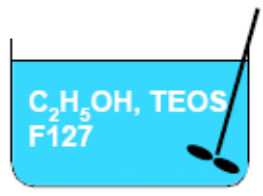

Initially TEOS and F127 are dissolved in ethanol
TEOS : $\mathrm{H}_{2} \mathrm{O}: \mathrm{HCl}:$ EtOH

$\begin{array}{llll}1.0 & 5.3 & 0.007 & 20\end{array}$

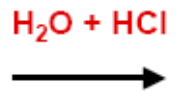

Aging (9-11 h)

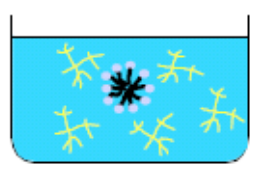

Dipping sol (4-7\% wt. F127)

Drying, calcination
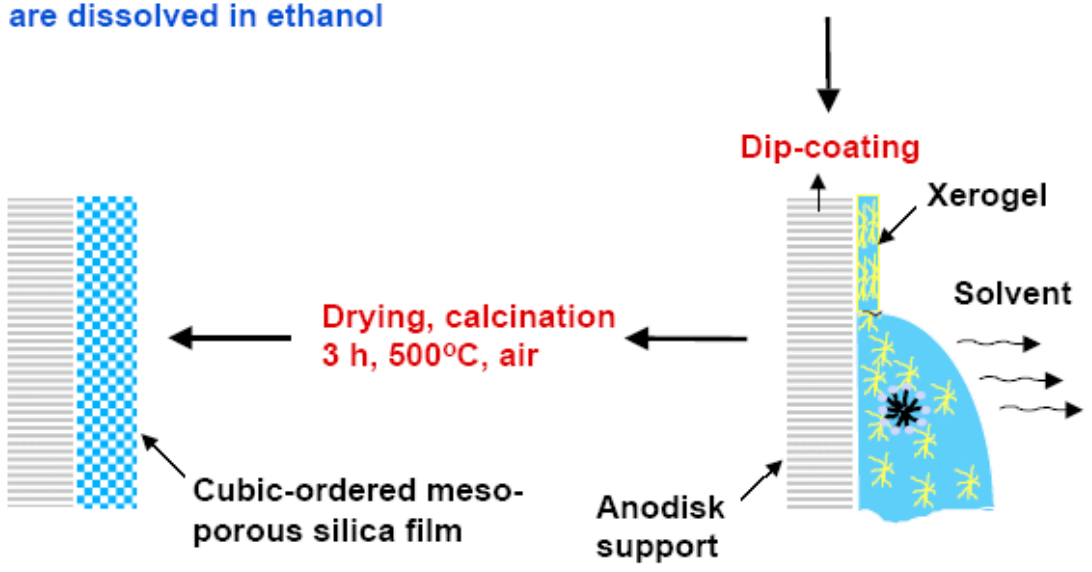
Figure 5.2

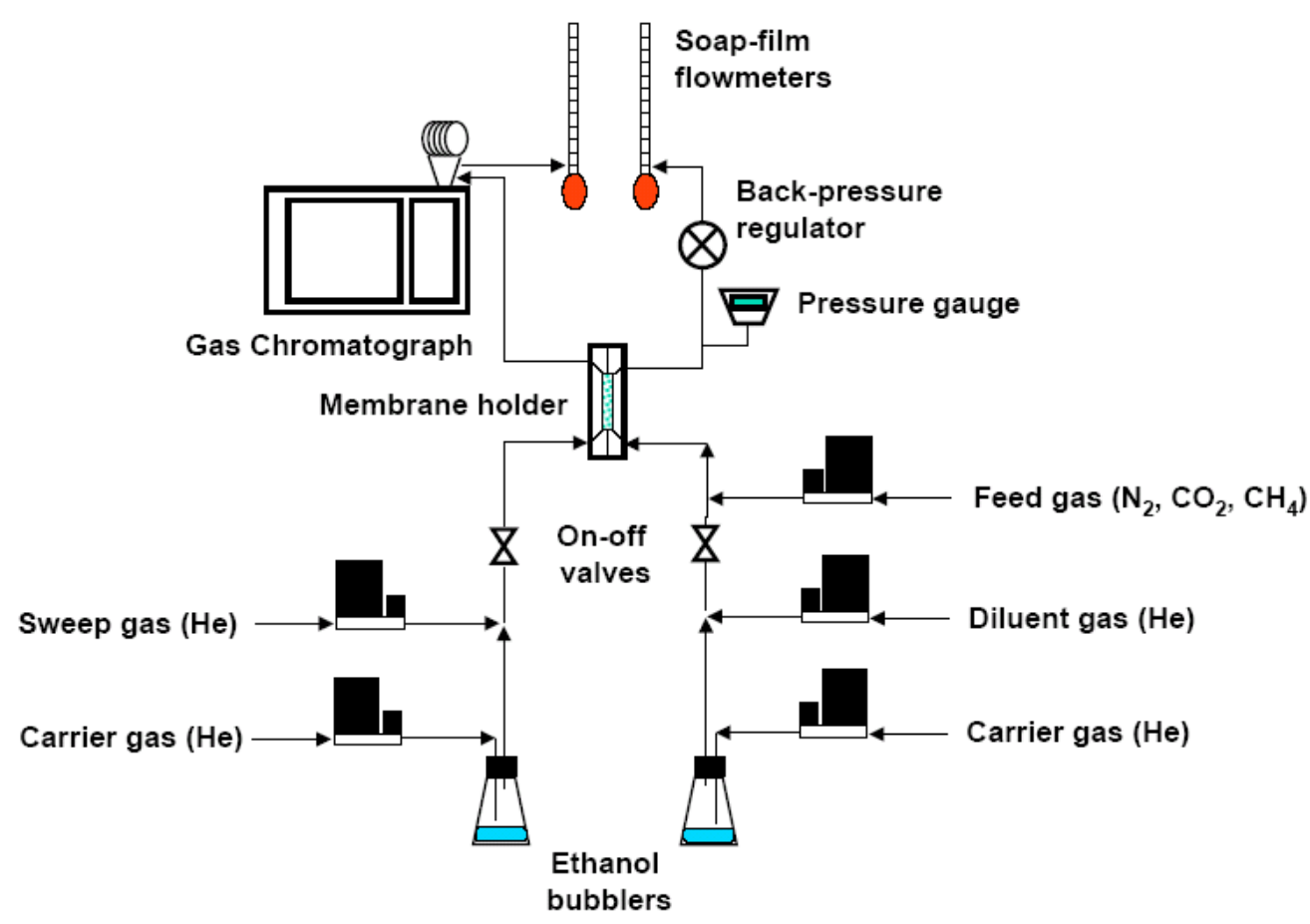


Figure 5.3

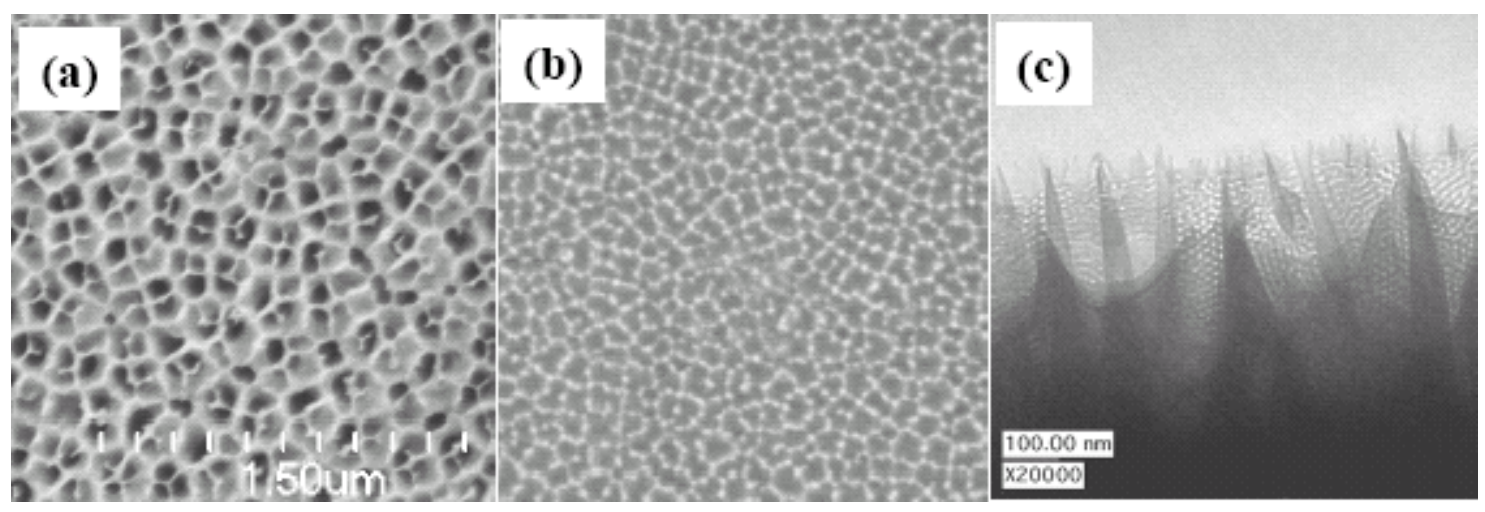


Figure 5.4

(a)

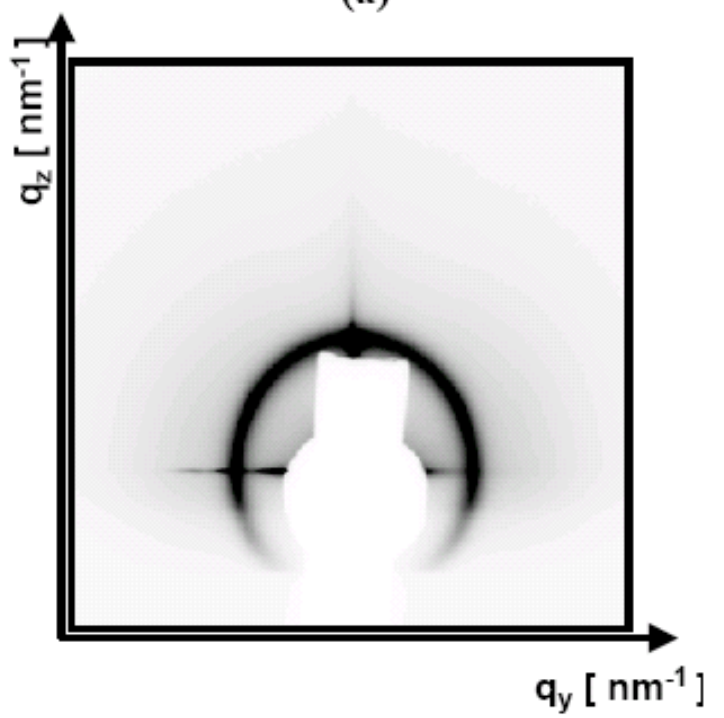

(b)

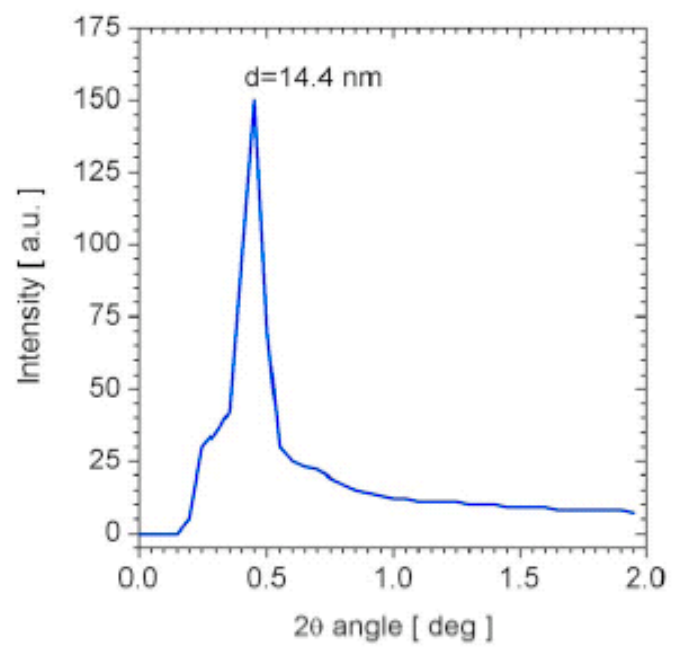


Figure 5.5

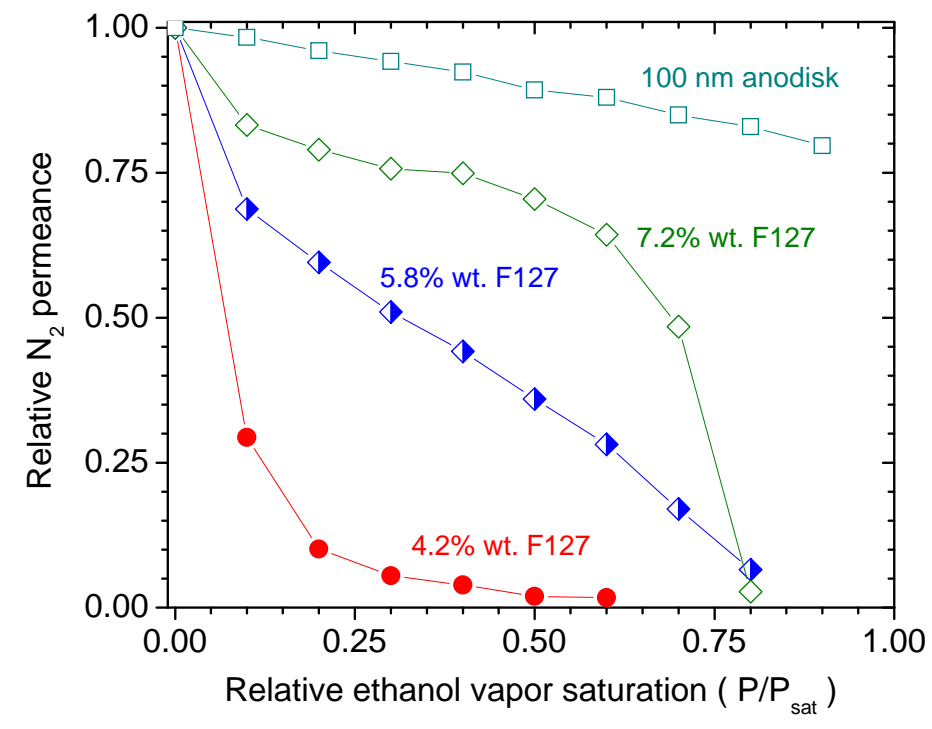


Figure 5.6

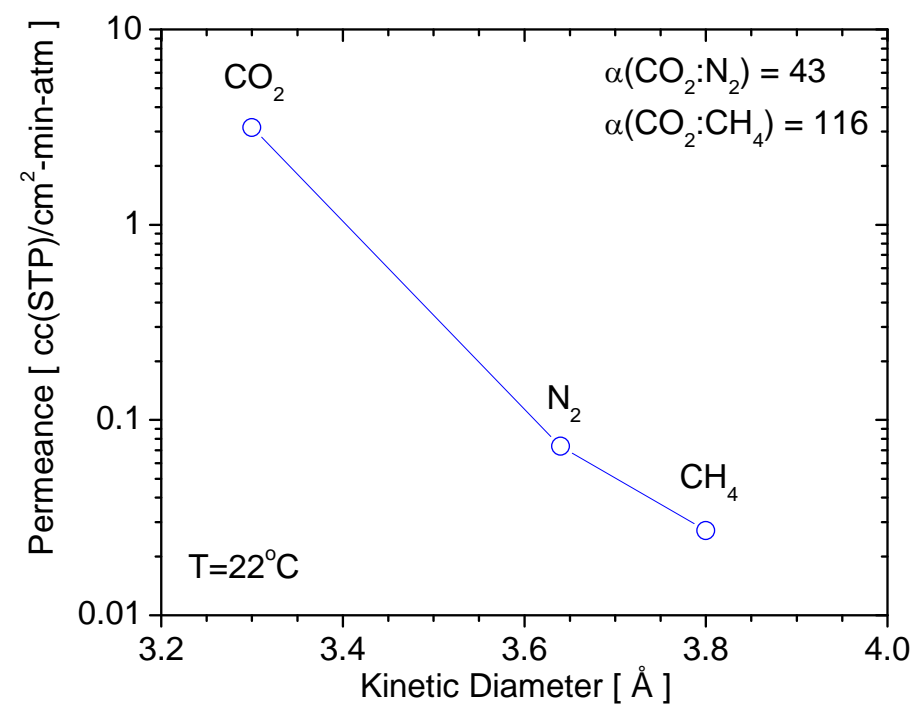




\section{Figure 5.7}
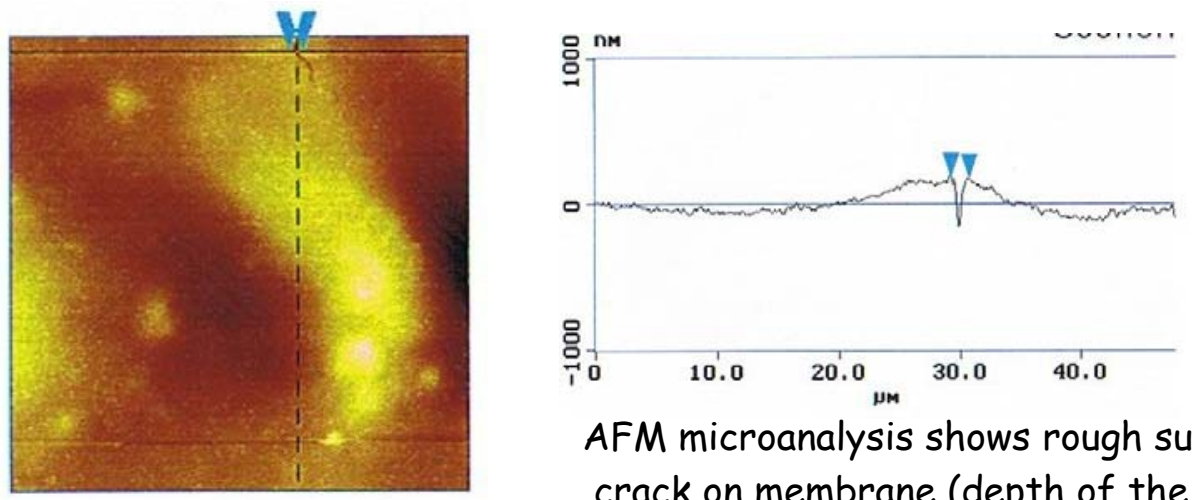

AFM microanalysis shows rough support surface causes crack on membrane (depth of the valley $1.5 \mu \mathrm{m}$ ) 
Figure 5.8

Sinale fiber

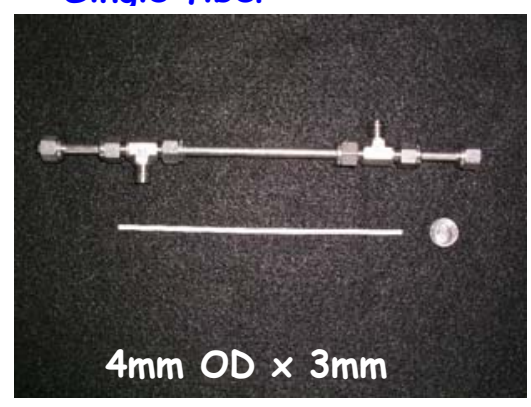

fiber

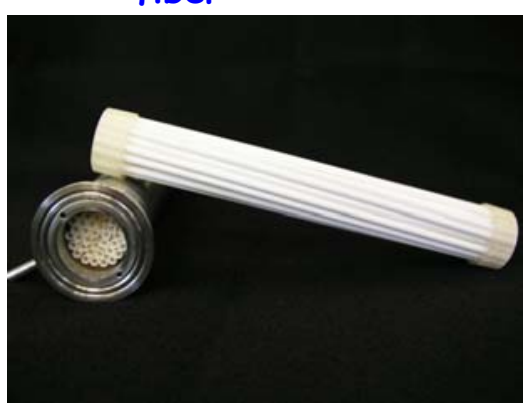

asymmetric inside

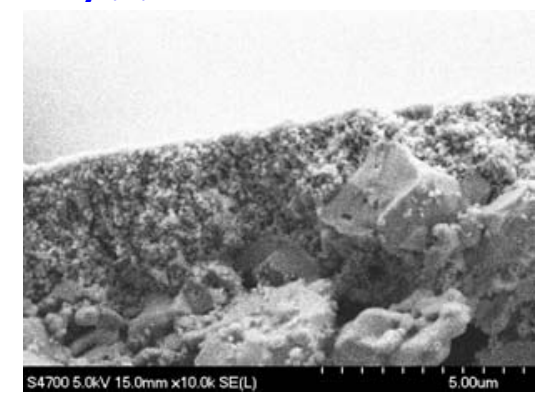


Figure 6.1

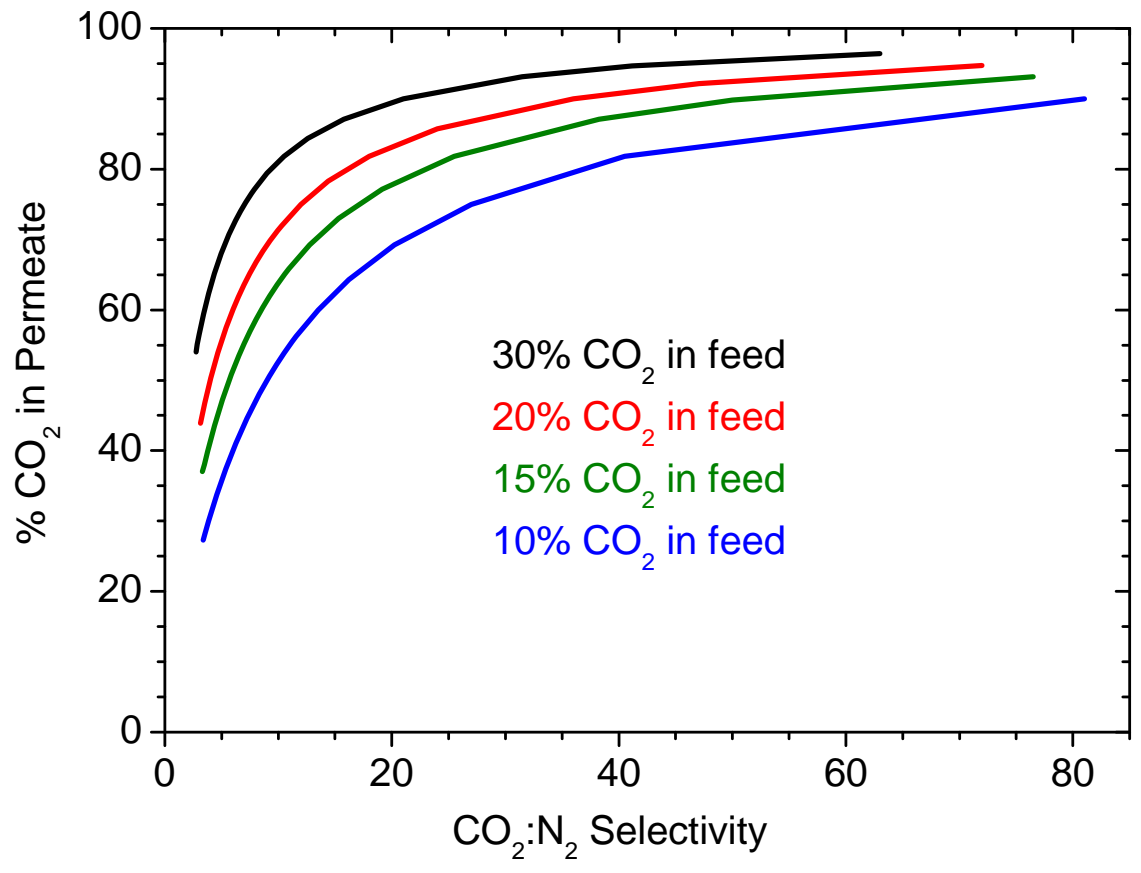


Figure 6.2

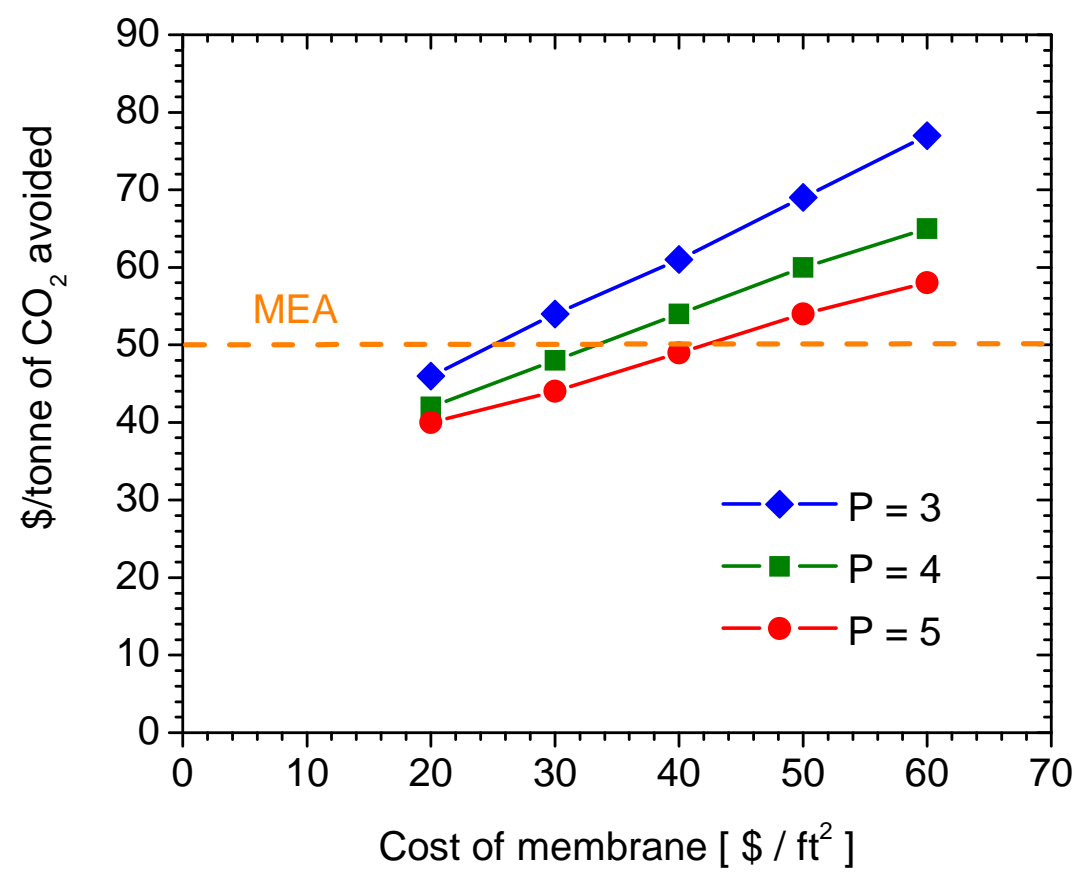




\section{Figure 7.1}

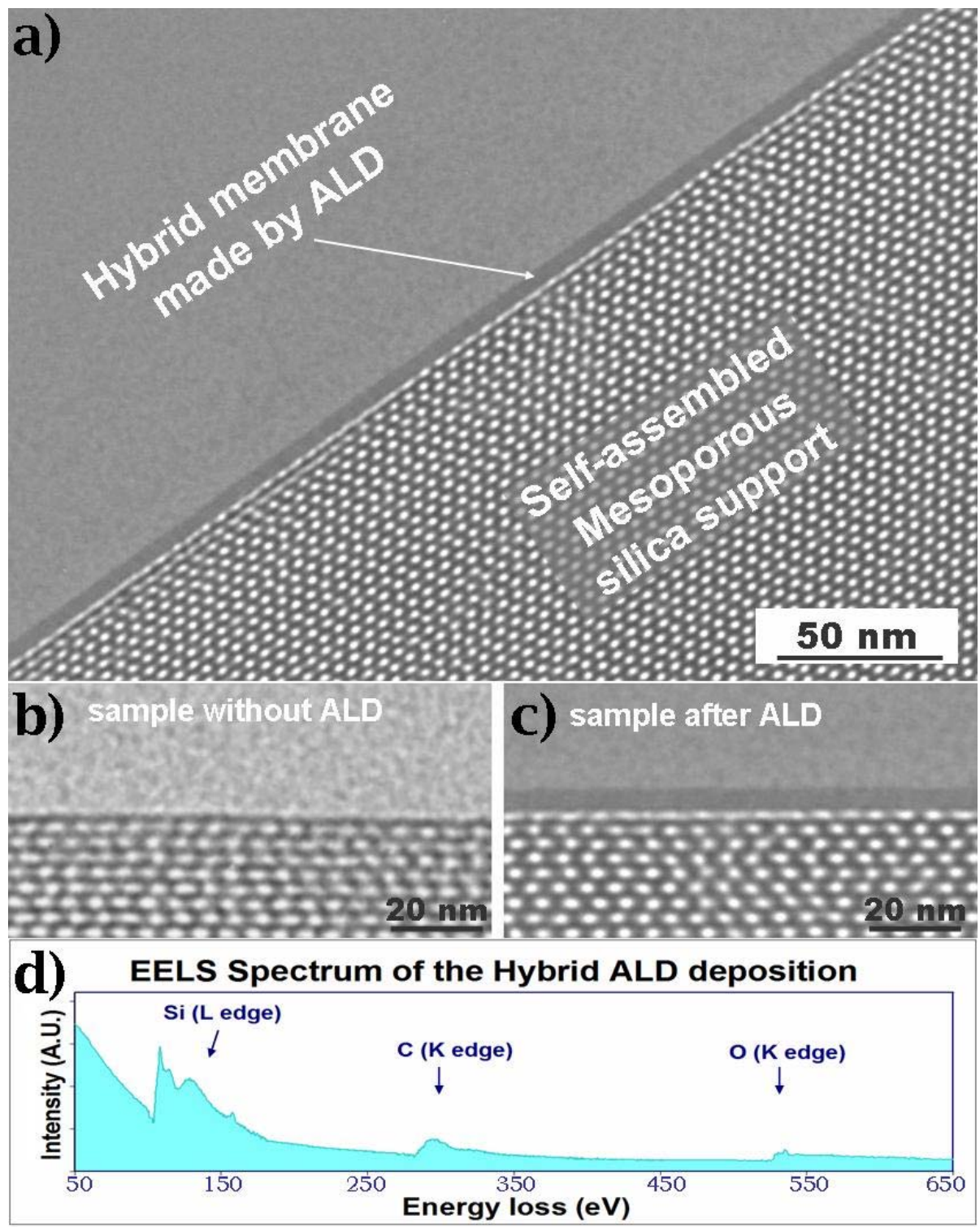

Figure 7.1. a) cross-sectional TEM image of the hybrid membrane supported on mesoporous silica; b) original mesoporous silica support; c) support coated with ALD membrane; d) EELS spectrum of the membrane. 


\section{Figure 7.2}

\section{Gas permeances for membranes made with different ALD cycles}

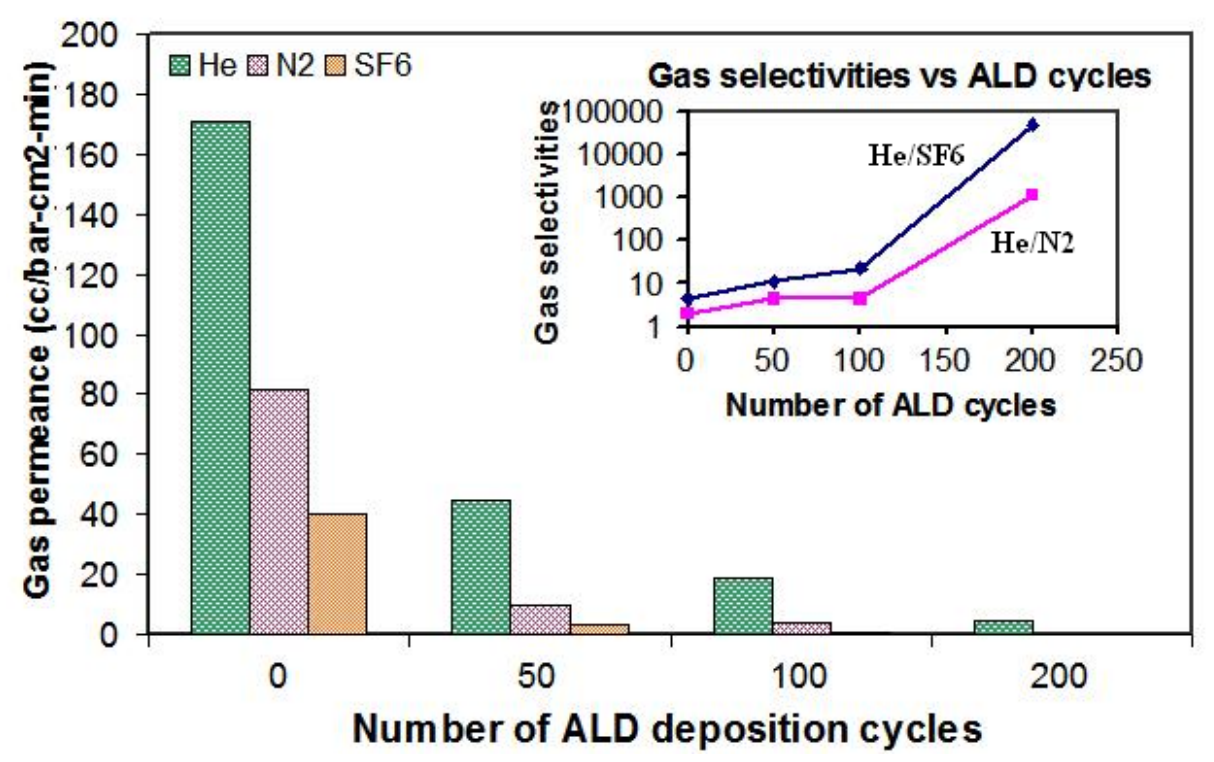

Figure7.2. Gas permeances of ALD membranes to $\mathrm{He}, \mathrm{N}_{2}$ and $\mathrm{SF}_{6}$ with kinetic diameters of 2.2, 3.6 and $5.5 \AA$, respectively. 
Figure 7.3

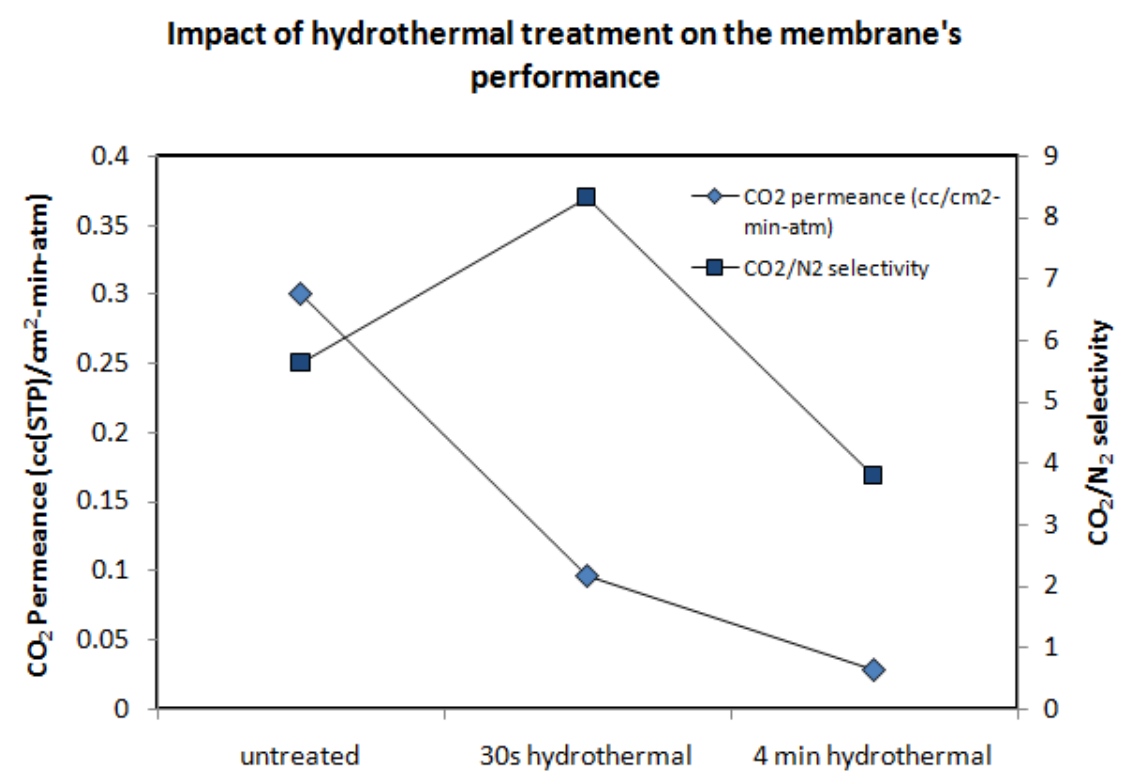

Figure 7.3 Effect of hydrothermal treatment on parent microporous silica membranes 
Figure 7.4
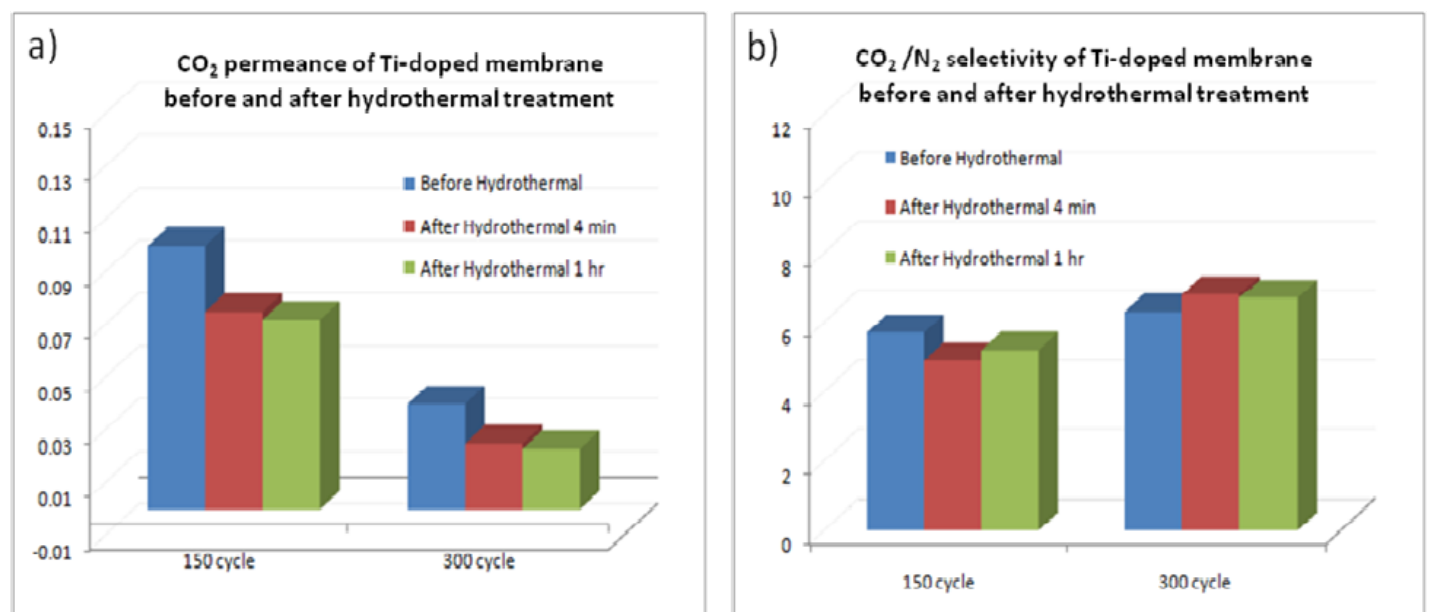

Figure 7.4 Effect of hydrothermal treatment for Ti-doped microporous ALD membranes 


\section{Figure 7.5}

\section{Performance of Ni-doped microporous ALD membrane at different temperatures}

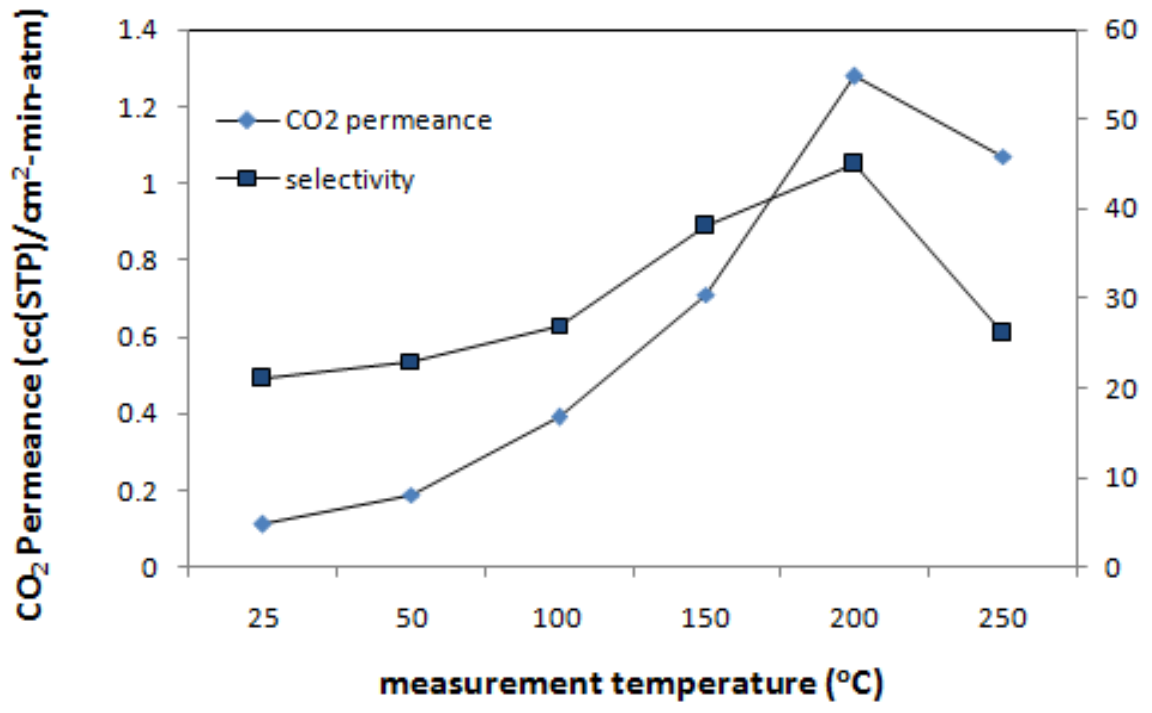

Figure 7.5 Effect of elevated temperatures for Ni-doped microporous ALD membranes 
Figure 7.6

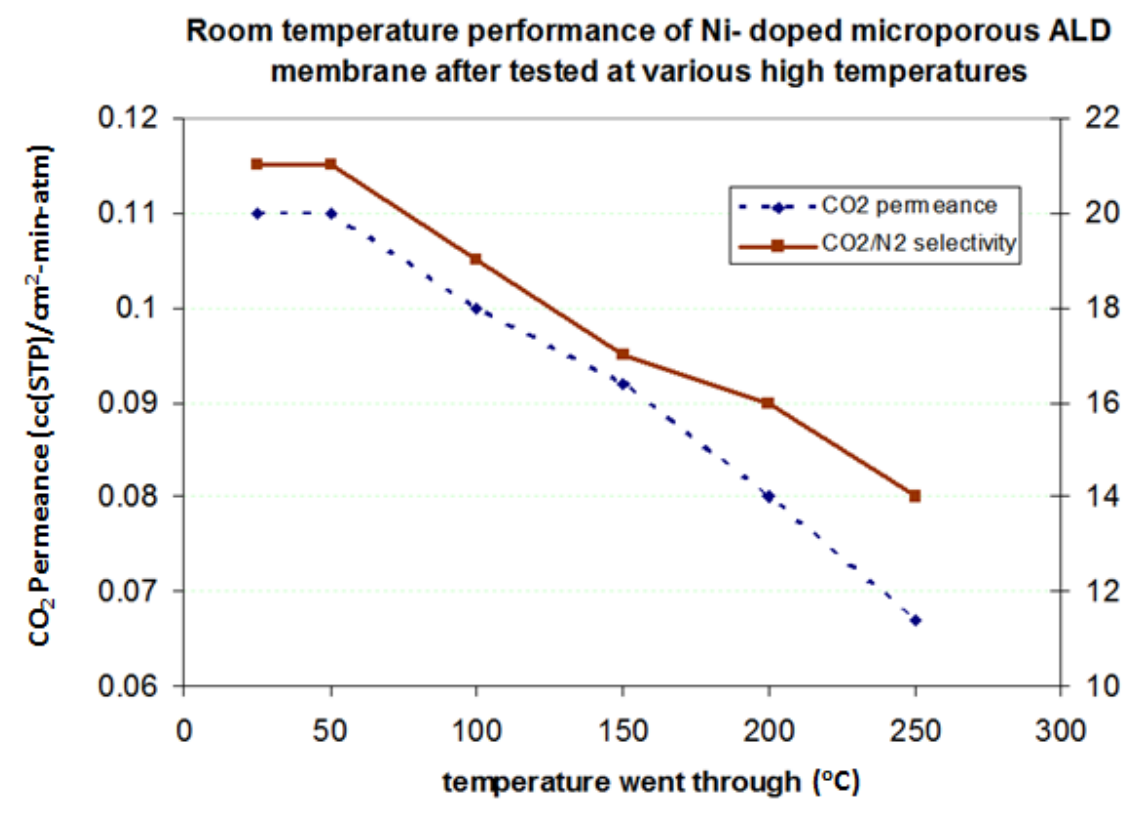

Figure 7.6, Room temperature performance of Ni-doped microporous ALD membranes after tested at various temperatures 
Figure 7.7

a) Perform ance of Ag-doped microporous ALD membrane at different temperatures

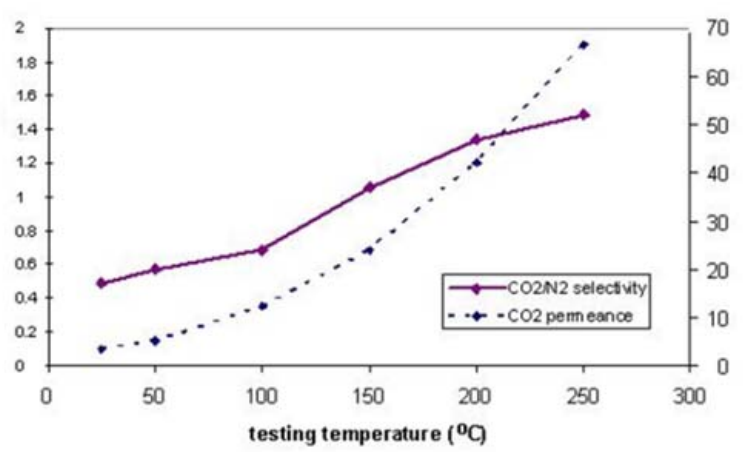

b)

Performance of Ni-doped microporous ALD membrane at different temperatures

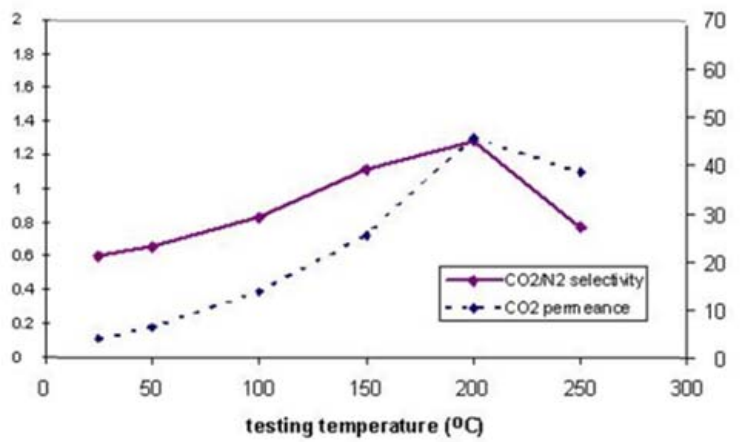

c)

Perform ance of double-Ni-doped microporous ALD membrane at different temperatures

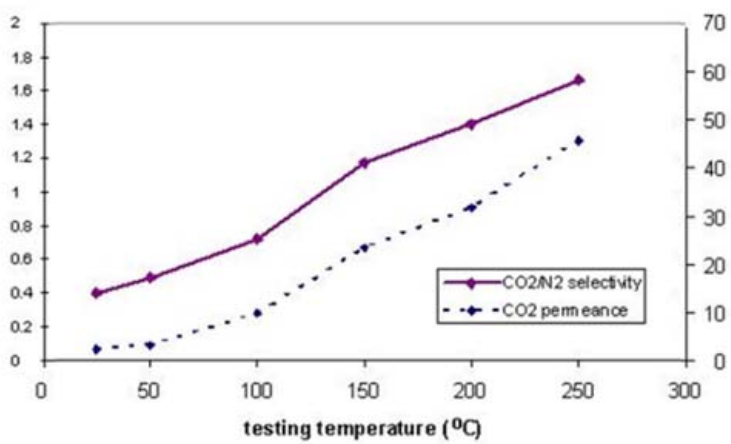

7.7a, b, c, Performance of Ag- and dual-Ni-doped membrane (a) Ag-doped, (b) Ni-doped, and (c) dualNi-doped. 


\section{Figure 7.8}

a)

Dual-Ni-doped microporous ALD membrane before and after

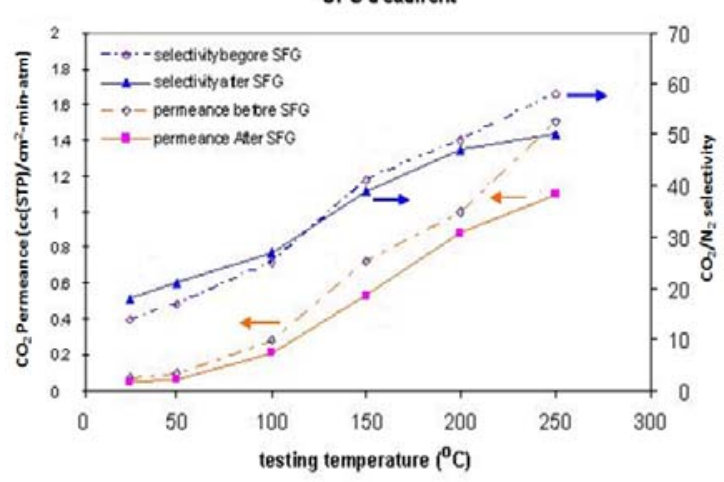

b) Ag-doped microporous ALD membrane before and after SFG

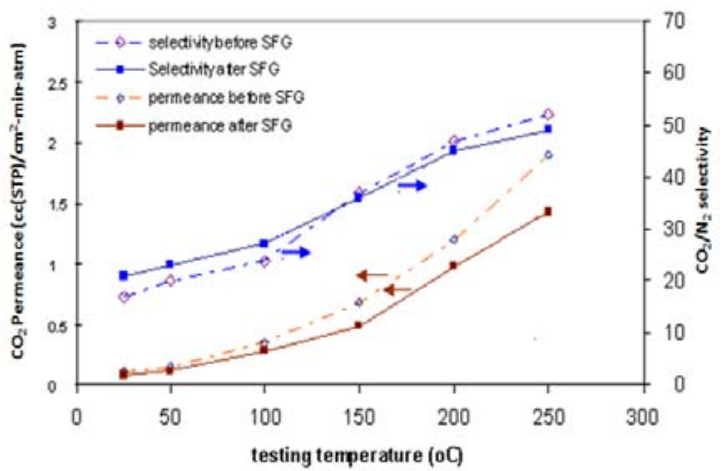

7.8a, b, Membranes performance before and after humidified SFG treatment (a) dual-Nidoped and (b) Ag-doped 
Figure 7.9

a) Dual-Ni-doped microporous ALD membrane before and after SO2-SFG treatment

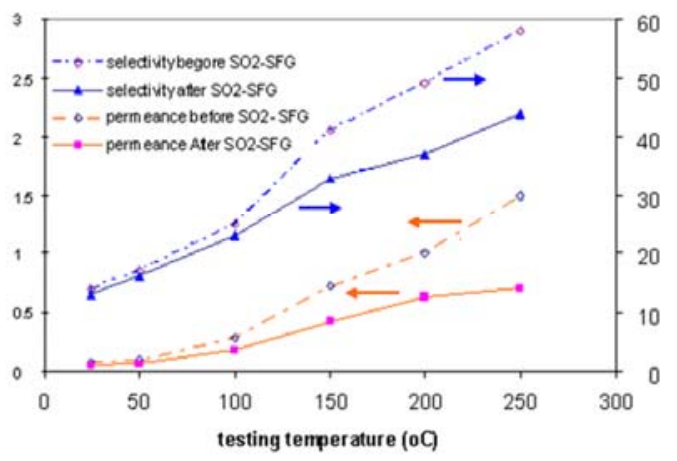

b) Ag-doped microporous ALD membrane before and after SFG

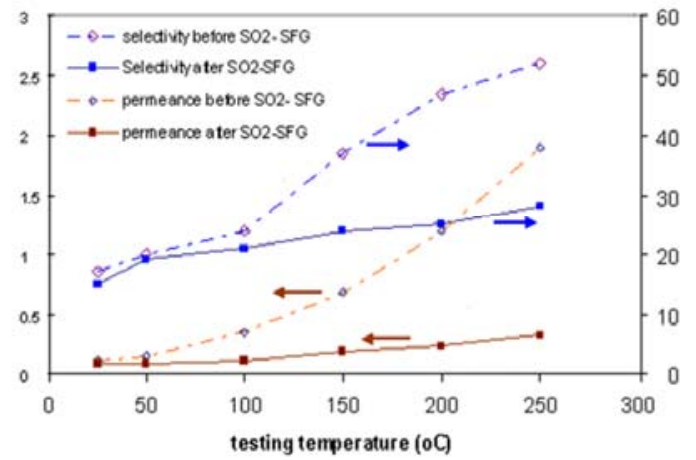

7.9a,b Membranes performance before and after $\mathrm{SO}_{2}$-SFG treatment (a) dual-Ni-doped (b) Ag-doped. 


\section{List of Acronyms and Abbreviations}

\begin{tabular}{|c|c|}
\hline AFM & Atomic force microscopy \\
\hline ALD & Atomic Layer Deposition \\
\hline APTES & 3-aminopropyltriethoxysilane \\
\hline BTEE & (bis(triethoxysilyl)ethane, $\left(\mathrm{C}_{2} \mathrm{H}_{5} \mathrm{O}\right)_{3}-\mathrm{Si}-\mathrm{C}_{2} \mathrm{H}_{4}-\mathrm{Si}-\left(\mathrm{OC}_{2} \mathrm{H}_{5}\right)_{3}$ ) \\
\hline $\mathrm{COE}$ & Cost of Electricity \\
\hline CVD & Chemical Vapor Deposition \\
\hline DOE & US Department of Energy \\
\hline $\mathrm{EtOH}$ & Ethyl alcohol \\
\hline F127 & Pluronic F127 block copolymer surfactant \\
\hline FAU & Faujasite-type zeolite \\
\hline FGD & Flue-gas desulfurization \\
\hline FTIR & Fourier transform inferred spectroscopy \\
\hline GISAXS & Grazing incidence small-angle X-ray scattering \\
\hline GPU & $10^{-6} \mathrm{~cm}^{3}(\mathrm{STP}) \mathrm{cm}^{-2} \mathrm{~s}^{-1} \mathrm{cmHg}^{-1}$ \\
\hline HMDS & $\left.\mathrm{CH}_{3}\right)_{3} \mathrm{SiNHSi}\left(\mathrm{CH}_{3}\right)_{3}$ \\
\hline MEA & Aqueous monoethanolamine \\
\hline MPU & Gas Permeation Unite, $1 \mathrm{MPU}=1.0 \mathrm{~cm}^{3}(\mathrm{STP}) \cdot \mathrm{cm}^{-2} \cdot \mathrm{min}^{-1} \cdot \mathrm{atm}^{-1}$ \\
\hline NETL & National energy technology laboratory \\
\hline $\mathrm{P}$ & Permeance \\
\hline PA-ALD & Plasma-assisted atomic layer deposition \\
\hline $\mathrm{PC}$ & Pulverized Coal \\
\hline PVD & Plasma vapor deposition \\
\hline ppm & parts per million \\
\hline RF & Radio frequency \\
\hline RH & Relative humidity \\
\hline SEM & Scanning Electron Microscope \\
\hline SFG & Simulated Flue Gas Condition \\
\hline STP & Standard temperature and pressure condition $\left({ }^{\circ} \mathrm{C}, 1 \mathrm{~atm}\right)$ \\
\hline $\mathrm{T}$ & Temperature \\
\hline TEM & Transmission Electron Microscope \\
\hline TEOS & Tetraethylorthosilicate \\
\hline TGA & Thermal gravimetric analyzer \\
\hline$\alpha$ & Binary gas selectivity \\
\hline$\Delta \mathrm{P}$ & Pressure differential \\
\hline
\end{tabular}

